\title{
List of Drugs in Development for Neurodegenerative Diseases: Update October 2011
}

\author{
Vanda Pogačić Kramp \\ Novartis Pharma AG, Basel, Switzerland
}

Neurodegenerative diseases are an increasingly important issue in our society. There are, however, still many obstacles on the way to finding methods for the cure. This table is intended to give an overview over neurodegenerative drugs that are currently in research and development, providing the reader with an idea about the complexity of drug discovery in this field. It is intended only as a starting point and my recommendation is to obtain additional information from the internet in order to check for the newest developments.

Note that the drugs that are registered, launched, discontinued, with no development reported, or used for research tools in the previous issues are deleted in this issue.

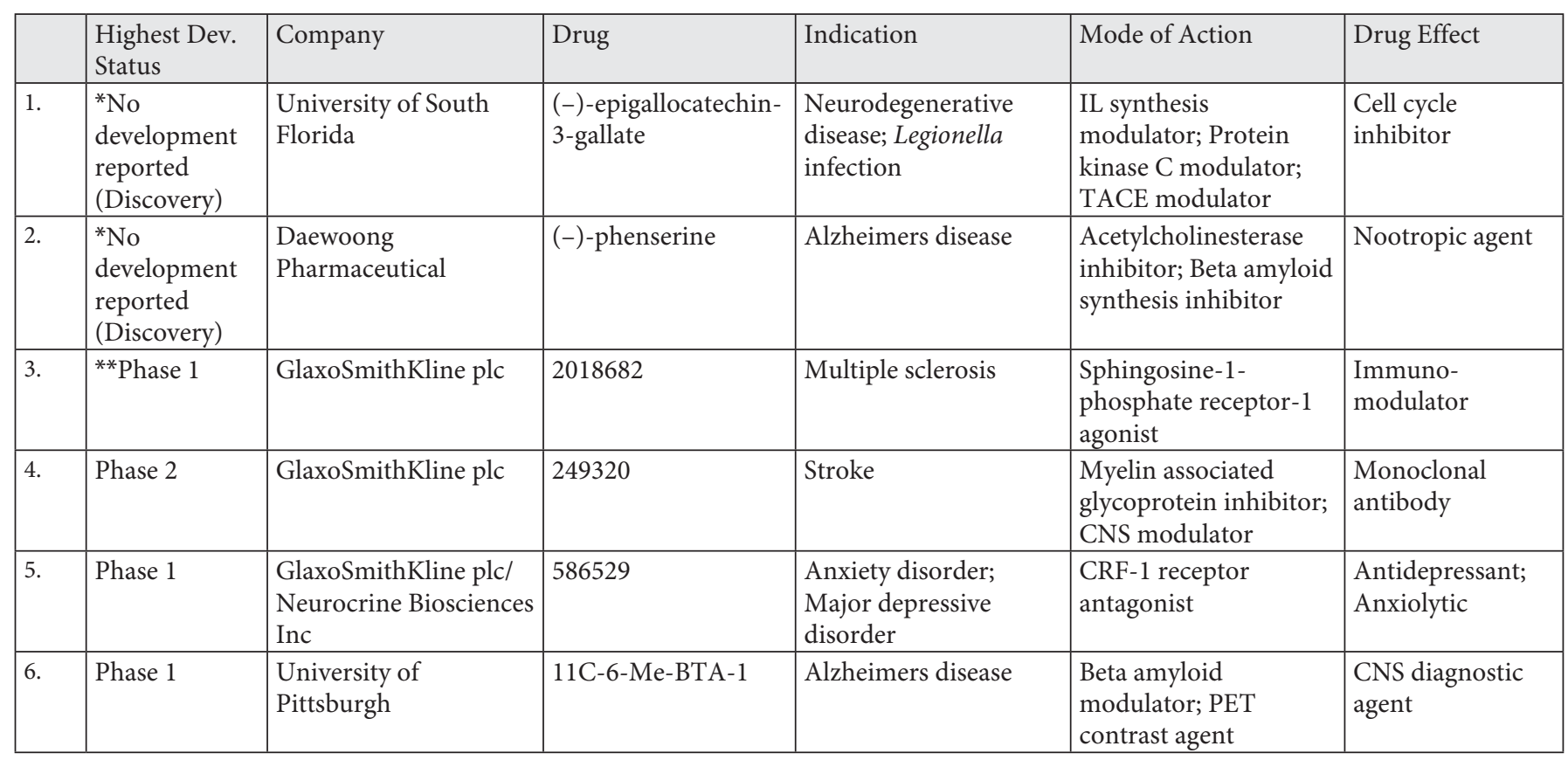

\footnotetext{
* Changes made from the last issue; ${ }^{* *}$ newly added drug.
}

\section{KARGER}

Fax +4161306 1234

E-Mail karger@karger.ch

www.karger.com
(C) 2011 S. Karger AG, Basel

1660-2854/12/0094-0210\$38.00/0

Accessible online at:

www.karger.com/ndd
Dr. Vanda Pogačić Kramp

Novartis Pharma AG

Postfach, 4002 Basel (Switzerland)

E-Mail vanda.pogacic@novartis.com 


\begin{tabular}{|c|c|c|c|c|c|c|}
\hline & $\begin{array}{l}\text { Highest Dev. } \\
\text { Status }\end{array}$ & Company & Drug & Indication & Mode of Action & Drug Effect \\
\hline 7. & Phase 1 & AstraZeneca plc & 11C-AZD-2184 & Alzheimers disease & $\begin{array}{l}\text { Beta amyloid } \\
\text { modulator; PET } \\
\text { contrast agent }\end{array}$ & $\begin{array}{l}\text { CNS diagnostic } \\
\text { agent }\end{array}$ \\
\hline 8. & $\begin{array}{l}{ }^{*} \mathrm{No} \\
\text { development } \\
\text { reported } \\
(\text { Phase } 1) \\
\end{array}$ & AstraZeneca plc & 11C-AZD-2995 & Alzheimers disease & $\begin{array}{l}\text { Beta amyloid } \\
\text { modulator; PET } \\
\text { contrast agent }\end{array}$ & $\begin{array}{l}\text { CNS diagnostic } \\
\text { agent }\end{array}$ \\
\hline 9. & $\begin{array}{l}{ }^{*} \text { No } \\
\text { development } \\
\text { reported } \\
(\text { Phase } 1)\end{array}$ & GlaxoSmithKline plc & 11C-GSK-215083 & $\begin{array}{l}\text { Neurodegenerative } \\
\text { disease }\end{array}$ & $\begin{array}{l}\text { 5-HT } 6 \text { receptor } \\
\text { antagonist }\end{array}$ & $\begin{array}{l}\text { PET contrast } \\
\text { agent; CNS } \\
\text { diagnostic agent }\end{array}$ \\
\hline 10. & Phase 1 & $\begin{array}{l}\text { National Institutes of } \\
\text { Health }\end{array}$ & 11C-PBR-28 & Brain disease & $\begin{array}{l}\text { Benzodiazepine } \\
\text { receptor modulator }\end{array}$ & $\begin{array}{l}\text { PET contrast } \\
\text { agent; } \\
\text { Radiodiagnostic; } \\
\text { CNS diagnostic } \\
\text { agent }\end{array}$ \\
\hline 12. & ${ }^{* *}$ Phase 1 & $\begin{array}{l}\text { Institute for } \\
\text { Neurodegenerative } \\
\text { Disorders }\end{array}$ & 123I-MNI-168 & Alzheimers disease & & $\begin{array}{l}\text { Imaging agent; } \\
\text { SPECT contrast } \\
\text { agent; CNS } \\
\text { diagnostic agent } \\
\end{array}$ \\
\hline 13. & Phase 1 & $\begin{array}{l}\text { Molecular } \\
\text { Neuroimaging Llc }\end{array}$ & 123I-MNI-330 & Alzheimers disease & Imaging agent & $\begin{array}{l}\text { CNS diagnostic } \\
\text { agent }\end{array}$ \\
\hline 14. & **Phase 1 & $\begin{array}{l}\text { Institute for } \\
\text { Neurodegenerative } \\
\text { Disorders }\end{array}$ & 123I-MNI-420 & $\begin{array}{l}\text { Huntingtons chorea; } \\
\text { Parkinsons disease }\end{array}$ & & $\begin{array}{l}\text { Imaging agent; } \\
\text { SPECT contrast } \\
\text { agent; CNS } \\
\text { diagnostic agent } \\
\end{array}$ \\
\hline 16. & $\begin{array}{l}{ }^{*} \text { No } \\
\text { development } \\
\text { reported } \\
\text { (Phase 1) }\end{array}$ & $\begin{array}{l}\text { University of } \\
\text { California Los Angeles/ } \\
\text { Siemens Medical } \\
\text { Solutions Molecular } \\
\text { Imaging }\end{array}$ & 18F-FDDNP & Alzheimers disease & $\begin{array}{l}\text { Beta amyloid } \\
\text { modulator; PET } \\
\text { contrast agent }\end{array}$ & $\begin{array}{l}\text { Radiodiagnostic; } \\
\text { Imaging agent; } \\
\text { CNS diagnostic } \\
\text { agent }\end{array}$ \\
\hline 17. & ${ }^{* *}$ Phase 1 & $\begin{array}{l}\text { Bayer Schering Pharma } \\
\text { AG }\end{array}$ & 18F-FEDAA-1106 & Multiple sclerosis & $\begin{array}{l}\text { Translocator protein } \\
\text { modulator }\end{array}$ & $\begin{array}{l}\text { PET contrast } \\
\text { agent; } \\
\text { Radiodiagnostic; } \\
\text { CNS diagnostic } \\
\text { agent; } \\
\text { Autoimmune } \\
\text { diagnostic agent }\end{array}$ \\
\hline 18. & $\begin{array}{l}\text { *Pre- } \\
\text { registration } \\
(\text { Phase } 3)\end{array}$ & $\begin{array}{l}\text { Avid } \\
\text { Radiopharmaceuticals } \\
\text { Inc }\end{array}$ & $\begin{array}{l}\text { 18F-florbetapir; } \\
\text { former 18F-AV-45 }\end{array}$ & $\begin{array}{l}\text { Alzheimers disease; } \\
\text { Dementia; Mild } \\
\text { cognitive impairment }\end{array}$ & $\begin{array}{l}\text { Beta amyloid } \\
\text { modulator; PET } \\
\text { contrast agent }\end{array}$ & $\begin{array}{l}\text { Radiodiagnostic; } \\
\text { Imaging agent; } \\
\text { CNS diagnostic } \\
\text { agent }\end{array}$ \\
\hline
\end{tabular}




\begin{tabular}{|c|c|c|c|c|c|c|}
\hline & $\begin{array}{l}\text { Highest Dev. } \\
\text { Status }\end{array}$ & Company & Drug & Indication & Mode of Action & Drug Effect \\
\hline 19. & ${ }^{* *}$ Clinical & $\begin{array}{l}\text { Molecular } \\
\text { Neuroimaging Llc/ } \\
\text { Institute for } \\
\text { Neurodegenerative } \\
\text { Disorders }\end{array}$ & 18F-MNI-558 & Alzheimers disease & $\begin{array}{l}\text { Beta amyloid } \\
\text { modulator }\end{array}$ & $\begin{array}{l}\text { PET contrast } \\
\text { agent; CNS } \\
\text { diagnostic agent }\end{array}$ \\
\hline 20. & Phase 2 & Aposense Ltd & 18F-NST-ML-10 & $\begin{array}{l}\text { Breast tumor; Brain } \\
\text { tumor; Head and neck } \\
\text { tumor; Lung tumor; } \\
\text { Non-Hodgkin } \\
\text { lymphoma; Ovary } \\
\text { tumor; Small-cell lung } \\
\text { cancer; Stroke }\end{array}$ & PET contrast agent & $\begin{array}{l}\text { Radiodiagnostic; } \\
\text { Cardiovascular } \\
\text { diagnostic agent; } \\
\text { CNS diagnostic } \\
\text { agent; Endocrine } \\
\text { diagnostic agent; } \\
\text { Immune } \\
\text { diagnostic agent; } \\
\text { Neoplasm } \\
\text { diagnostic agent }\end{array}$ \\
\hline 22. & Phase 2 & GlaxoSmithKline plc & 249320 & $\begin{array}{l}\text { Stroke; Nervous system } \\
\text { injury }\end{array}$ & $\begin{array}{l}\text { Myelin associated } \\
\text { glycoprotein inhibitor }\end{array}$ & CNS modulator \\
\hline 23. & ${ }^{* *}$ Discovery & $\begin{array}{l}\text { Genzyme Corp } \\
\text { (Sanofi)/Isis } \\
\text { Pharmaceuticals Inc }\end{array}$ & $\begin{array}{l}\text { 2-MOE } \\
\text { phosphorothioate } \\
\text { gapmers (myotonic } \\
\text { dystrophy) }\end{array}$ & Myotonic dystrophy & $\begin{array}{l}\text { Muscle system agent; } \\
\text { DMPK gene inhibitor }\end{array}$ & Neuroprotectant \\
\hline 24. & ${ }^{* *}$ Discovery & $\begin{array}{l}\text { Prana Biotechnology } \\
\text { Ltd }\end{array}$ & $\begin{array}{l}\text { 4E10 (Alzheimer's } \\
\text { disease) }\end{array}$ & Alzheimers disease & & Nootropic agent \\
\hline 27. & Discovery & Pfizer Inc & $\begin{array}{l}\text { 5-HT 2c agonists } \\
\text { (neurological/ } \\
\text { psychiatric disease) }\end{array}$ & \begin{tabular}{|l|} 
Obesity; Neurological \\
disease; Psychiatric \\
disorder; Urinary \\
incontinence \\
\end{tabular} & $\begin{array}{l}\text { 5-HT 2c receptor } \\
\text { agonist }\end{array}$ & Psychomodulator \\
\hline 28. & ${ }^{* *}$ Discovery & Suven Life Sciences Ltd & $\begin{array}{l}\text { 5-HT } 4 \text { agonists/ } \\
\text { partial agonists } \\
\text { (neurogenerative } \\
\text { diseases) } \\
\end{array}$ & $\begin{array}{l}\text { Alzheimers disease; } \\
\text { Neurodegenerative } \\
\text { disease }\end{array}$ & $\begin{array}{l}\text { 5-HT } 4 \text { receptor partial } \\
\text { agonist; Antipsychotic; } \\
\text { 5-HT } 4 \text { receptor } \\
\text { agonist }\end{array}$ & Nootropic agent \\
\hline 29. & **Discovery & Suven Life Sciences Ltd & $\begin{array}{l}\text { 5-HT } 6 \text { antagonists } \\
\text { (cognitive disorder) }\end{array}$ & $\begin{array}{l}\text { Schizophrenia; } \\
\text { Neurological disease }\end{array}$ & $\begin{array}{l}\text { 5-HT } 6 \text { receptor } \\
\text { antagonist }\end{array}$ & $\begin{array}{l}\text { Neuroprotectant; } \\
\text { Nootropic agent; } \\
\text { Antipsychotic } \\
\end{array}$ \\
\hline 30. & ${ }^{* *}$ Discovery & Proximagen Group plc & $\begin{array}{l}\text { 5-HT } 6 \text { antagonists } \\
\text { (cognitive disorder/ } \\
\text { pain) }\end{array}$ & $\begin{array}{l}\text { Pain; Cognitive } \\
\text { disorder }\end{array}$ & $\begin{array}{l}\text { 5-HT } 6 \text { receptor } \\
\text { antagonist }\end{array}$ & $\begin{array}{l}\text { Nootropic agent; } \\
\text { Analgesic }\end{array}$ \\
\hline 31. & ${ }^{* *}$ Discovery & $\begin{array}{l}\text { Bristol-Myers Squibb } \\
\text { Co }\end{array}$ & $\begin{array}{l}\text { 5-HT } 6 \text { antagonists } \\
\text { (obesity, cognitive } \\
\text { disorder) }\end{array}$ & $\begin{array}{l}\text { Obesity; Cognitive } \\
\text { disorder }\end{array}$ & $\begin{array}{l}\text { 5-HT } 6 \text { receptor } \\
\text { antagonist }\end{array}$ & \begin{tabular}{|l} 
Appetite \\
suppressant; \\
Nootropic agent \\
\end{tabular} \\
\hline
\end{tabular}




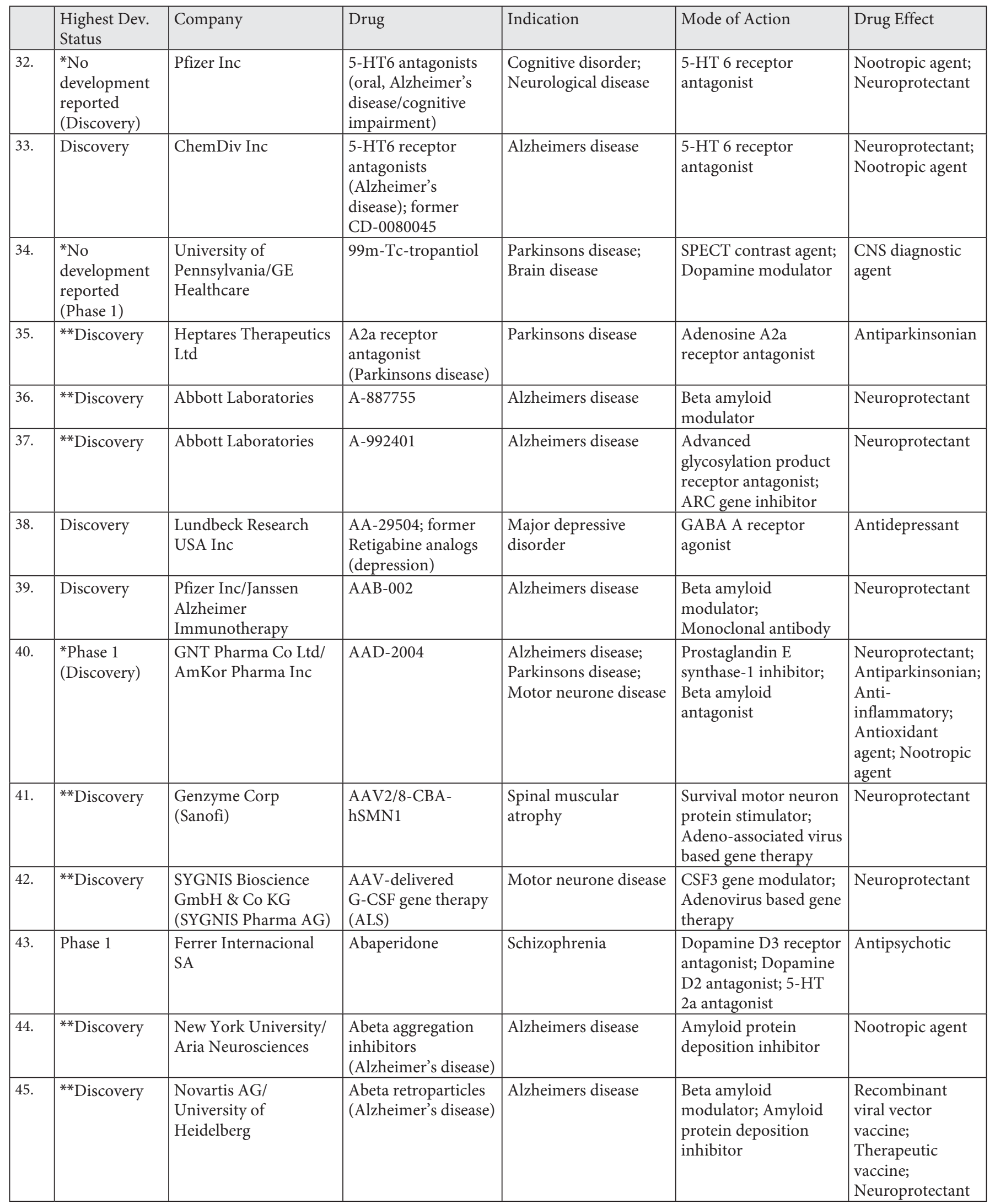




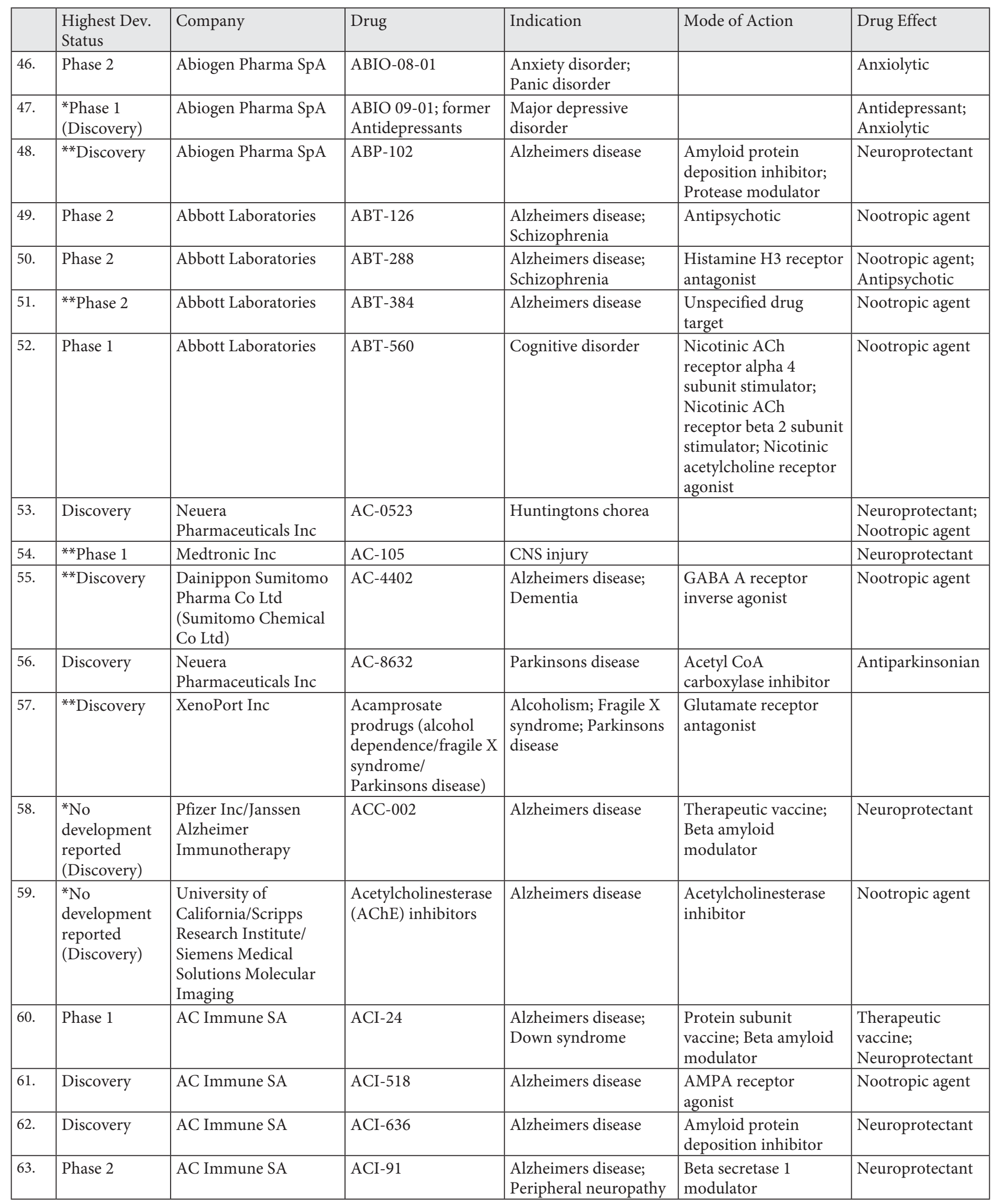




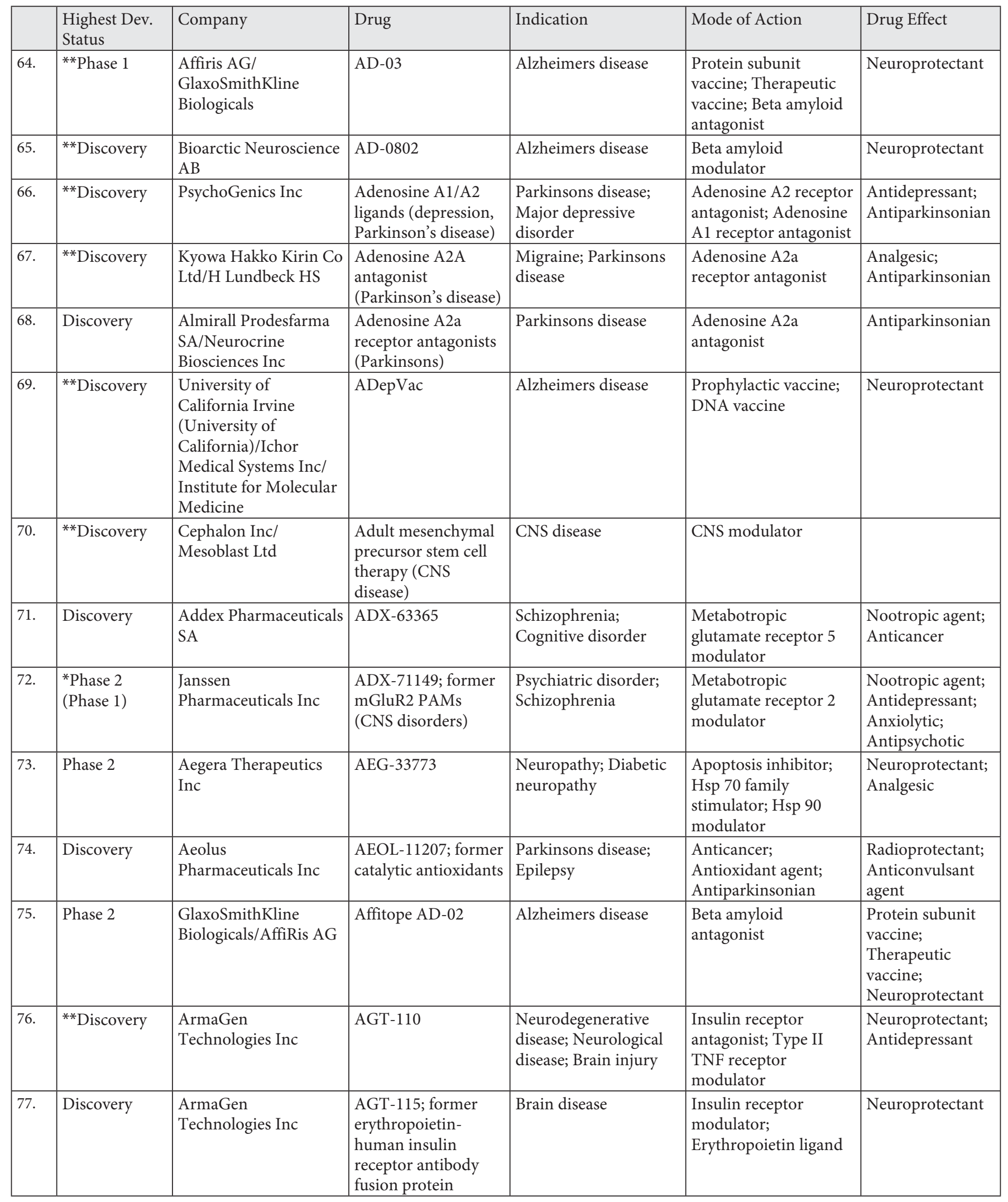




\begin{tabular}{|c|c|c|c|c|c|c|}
\hline & $\begin{array}{l}\text { Highest Dev. } \\
\text { Status }\end{array}$ & Company & Drug & Indication & Mode of Action & Drug Effect \\
\hline 79. & Discovery & $\begin{array}{l}\text { ArmaGen } \\
\text { Technologies Inc }\end{array}$ & AGT-160 & Alzheimers disease & $\begin{array}{l}\text { Amyloid protein } \\
\text { deposition inhibitor; } \\
\text { Beta amyloid } \\
\text { antagonist; Insulin } \\
\text { receptor modulator }\end{array}$ & Neuroprotectant \\
\hline 80. & **Discovery & $\begin{array}{l}\text { ArmaGen } \\
\text { Technologies Inc }\end{array}$ & AGT-185 & $\begin{array}{l}\text { Poison intoxication; } \\
\text { Central nervous system } \\
\text { disease }\end{array}$ & $\begin{array}{l}\text { PON1 gene modulator; } \\
\text { Phosphatase } \\
\text { stimulator; Insulin } \\
\text { receptor modulator }\end{array}$ & $\begin{array}{l}\text { Neuroprotectant; } \\
\text { Antidote }\end{array}$ \\
\hline 83. & **Discovery & $\begin{array}{l}\text { Reata Pharmaceuticals } \\
\text { Inc }\end{array}$ & $\begin{array}{l}\text { AIMs (CNS disease/ } \\
\text { respiratory disease/ } \\
\text { autoimmune disease) }\end{array}$ & $\begin{array}{l}\text { Autoimmune disease; } \\
\text { Central nervous system } \\
\text { disease; Respiratory } \\
\text { disease } \\
\end{array}$ & $\begin{array}{l}\text { NFE2L2 gene } \\
\text { stimulator; Nuclear } \\
\text { factor kappa B } \\
\text { inhibitor } \\
\end{array}$ & $\begin{array}{l}\text { Anti- } \\
\text { inflammatory; } \\
\text { Antioxidant agent }\end{array}$ \\
\hline 84. & Discovery & Allon Therapeutics Inc & AL-209 & $\begin{array}{l}\text { CNS disease; Ocular } \\
\text { disease }\end{array}$ & $\begin{array}{l}\text { PARP stimulator; } \\
\text { Tubulin binding agent }\end{array}$ & $\begin{array}{l}\text { Neuroprotectant; } \\
\text { CNS modulator }\end{array}$ \\
\hline 85. & Discovery & Allon Therapeutics Inc & AL-309 & CNS disease & PARP stimulator & $\begin{array}{l}\text { Neuroprotectant; } \\
\text { CNS modulator; } \\
\text { Analgesic }\end{array}$ \\
\hline 88. & **Discovery & $\begin{array}{l}\text { Zenobia Therapeutics } \\
\text { Inc/St Jude Children's } \\
\text { Research Hospital }\end{array}$ & $\begin{array}{l}\text { ALK inhibitors } \\
\text { (neuroblastoma) }\end{array}$ & Neuroblastoma & $\begin{array}{l}\text { Alk tyrosine kinase } \\
\text { receptor inhibitor }\end{array}$ & Anticancer \\
\hline 89. & ${ }^{* *}$ Discovery & Novartis AG & $\begin{array}{l}\text { Allosteric GABA B } \\
\text { receptor modulators }\end{array}$ & $\begin{array}{l}\text { Anxiety disorder; Drug } \\
\text { dependence; Central } \\
\text { nervous system disease }\end{array}$ & $\begin{array}{l}\text { GABA B receptor } \\
\text { modulator }\end{array}$ & $\begin{array}{l}\text { CNS modulator; } \\
\text { Anxiolytic }\end{array}$ \\
\hline 90. & **Discovery & SAGE Therapeutics & $\begin{array}{l}\text { Allosteric GABA } \\
\text { receptor modulators } \\
\text { (CNS disorders) }\end{array}$ & CNS disease & $\begin{array}{l}\text { GABA receptor } \\
\text { modulator }\end{array}$ & Neuroprotectant \\
\hline 91. & **Discovery & SAGE Therapeutics & $\begin{array}{l}\text { Allosteric glutamate } \\
\text { receptor modulators } \\
\text { (CNS disorders) }\end{array}$ & CNS disease & $\begin{array}{l}\text { Glutamate receptor } \\
\text { modulator }\end{array}$ & Neuroprotectant \\
\hline 92. & ${ }^{* *}$ Discovery & $\begin{array}{l}\text { Ligand } \\
\text { Pharmaceuticals Inc/ } \\
\text { SAGE Therapeutics }\end{array}$ & \begin{tabular}{|l|} 
Allosteric \\
modulators \\
(Captisol, CNS \\
disorders) \\
\end{tabular} & CNS disease & $\begin{array}{l}\text { Unspecified drug } \\
\text { target }\end{array}$ & CNS modulator \\
\hline 93. & **Discovery & Allosterix Ltd & \begin{tabular}{|l} 
Allosteric peptide \\
BACE-1 inhibitors \\
(Alzheimer's disease)
\end{tabular} & Alzheimers disease & $\begin{array}{l}\text { Beta amyloid synthesis } \\
\text { inhibitor; Beta } \\
\text { secretase } 1 \text { inhibitor }\end{array}$ & Nootropic agent \\
\hline
\end{tabular}




\begin{tabular}{|c|c|c|c|c|c|c|}
\hline & $\begin{array}{l}\text { Highest Dev. } \\
\text { Status }\end{array}$ & Company & Drug & Indication & Mode of Action & Drug Effect \\
\hline 94. & $\begin{array}{l}{ }^{*} \text { Discontinued } \\
\text { (Phase } 3)\end{array}$ & $\begin{array}{l}\text { Actelion Ltd/ } \\
\text { GlaxoSmithKline plc }\end{array}$ & Almorexant & $\begin{array}{l}\text { Neurological disease; } \\
\text { Insomnia; Eating } \\
\text { disorder }\end{array}$ & $\begin{array}{l}\text { Orexin } 1 \text { receptor } \\
\text { antagonist; Orexin } 2 \\
\text { receptor antagonist }\end{array}$ & $\begin{array}{l}\text { Appetite } \\
\text { modulator; } \\
\text { Hypnotic }\end{array}$ \\
\hline 95. & ${ }^{* *}$ Discovery & $\begin{array}{l}\text { Alnylam } \\
\text { Pharmaceuticals Inc } \\
\text { (Alnylam Holding Co)/ } \\
\text { Medtronic Inc } \\
\end{array}$ & ALN-HTT & Huntingtons chorea & $\begin{array}{l}\text { HTT gene inhibitor; } \\
\text { Huntingtin inhibitor }\end{array}$ & $\begin{array}{l}\text { Neuroprotectant; } \\
\text { siRNA agent }\end{array}$ \\
\hline 96. & **Discovery & ALSP Inc & $\begin{array}{l}\text { Aloxistatin } \\
\text { (Alzheimer's disease) }\end{array}$ & $\begin{array}{l}\text { Alzheimers disease; } \\
\text { Brain injury }\end{array}$ & $\begin{array}{l}\text { Cysteine protease } \\
\text { inhibitor; Cathepsin B } \\
\text { inhibitor } \\
\end{array}$ & $\begin{array}{l}\text { Neuroprotectant; } \\
\text { Nootropic agent }\end{array}$ \\
\hline 97. & **Discovery & Suven Life Sciences Ltd & $\begin{array}{l}\text { Alpha } 4 \text { beta } 2 \\
\text { nAChR antagonist } \\
\text { (neurological } \\
\text { disease/ } \\
\text { schizophrenia/ } \\
\text { obesity/metabolic } \\
\text { disorder/pain) }\end{array}$ & $\begin{array}{l}\text { Pain; Obesity; } \\
\text { Schizophrenia; } \\
\text { Metabolic disorder; } \\
\text { Neurological disease }\end{array}$ & $\begin{array}{l}\text { Nicotinic ACh } \\
\text { receptor alpha } 4 \\
\text { subunit inhibitor; } \\
\text { Nicotinic ACh } \\
\text { receptor beta } 2 \text { subunit } \\
\text { inhibitor; Nicotinic } \\
\text { acetylcholine receptor } \\
\text { antagonist } \\
\end{array}$ & $\begin{array}{l}\text { Neuroprotectant; } \\
\text { Nootropic agent; } \\
\text { Antipsychotic; } \\
\text { Analgesic }\end{array}$ \\
\hline 98. & **Discovery & Suven Life Sciences Ltd & $\begin{array}{l}\text { Alpha } 4 \text { beta } 2 \\
\text { nicotinic } \\
\text { acetylcholine } \\
\text { receptor (nAChR) } \\
\text { agonist (Alzheimer's } \\
\text { disease) }\end{array}$ & Alzheimers disease & $\begin{array}{l}\text { Nicotinic ACh } \\
\text { receptor alpha } 4 \\
\text { subunit stimulator; } \\
\text { Nicotinic ACh } \\
\text { receptor beta } 2 \text { subunit } \\
\text { stimulator; Nicotinic } \\
\text { acetylcholine receptor } \\
\text { agonist }\end{array}$ & Nootropic agent \\
\hline 99. & Discovery & Pfizer Inc & $\begin{array}{l}\text { Alpha 6/alpha } 4 \\
\left(\text { alpha- } 6^{*}\right) \text { beta } 4 \text { and } \\
\text { alpha } 3 \text { beta } 4 \\
\text { nAChR agonists } \\
\text { (CNS disorders) }\end{array}$ & $\begin{array}{l}\text { Psychotic disorder; } \\
\text { Neurological disease }\end{array}$ & $\begin{array}{l}\text { Nicotinic ACh } \\
\text { receptor alpha } 3 \\
\text { subunit stimulator; } \\
\text { Nicotinic ACh } \\
\text { receptor alpha } 4 \\
\text { subunit stimulator; } \\
\text { Nicotinic ACh } \\
\text { receptor alpha } 6 \\
\text { subunit stimulator; } \\
\text { Nicotinic ACh } \\
\text { receptor beta } 4 \text { subunit } \\
\text { stimulator }\end{array}$ & \\
\hline 100. & **Discovery & $\begin{array}{l}\text { University of } \\
\text { California Irvine } \\
\text { (University of } \\
\text { California) }\end{array}$ & $\begin{array}{l}\text { Alpha7 nAChR } \\
\text { modulators } \\
\text { (cognitive disorder) }\end{array}$ & Cognitive disorder & \begin{tabular}{|l} 
Nicotinic ACh \\
receptor alpha 7 \\
subunit stimulator; \\
Dopamine synthesis \\
stimulant; \\
Noradrenaline release \\
stimulator \\
\end{tabular} & Nootropic agent \\
\hline 101. & **Discovery & Novartis AG & $\begin{array}{l}\text { Alpha-7 nicotinic } \\
\text { acetylcholine } \\
\text { receptor agonists } \\
\text { (CNS disorders) }\end{array}$ & CNS disease & $\begin{array}{l}\text { Nicotinic ACh } \\
\text { receptor alpha } 7 \\
\text { subunit stimulator }\end{array}$ & CNS modulator \\
\hline 102. & ${ }^{* *}$ Discovery & Abbott Laboratories & $\begin{array}{l}\text { Alpha-7 nicotinic } \\
\text { acetylcholine } \\
\text { receptor positive } \\
\text { allosteric modulators } \\
\text { (cognitive disorders) }\end{array}$ & Cognitive disorder & $\begin{array}{l}\text { Nicotinic ACh } \\
\text { receptor alpha } 7 \\
\text { subunit modulator }\end{array}$ & $\begin{array}{l}\text { Neuroprotectant; } \\
\text { Nootropic agent }\end{array}$ \\
\hline
\end{tabular}




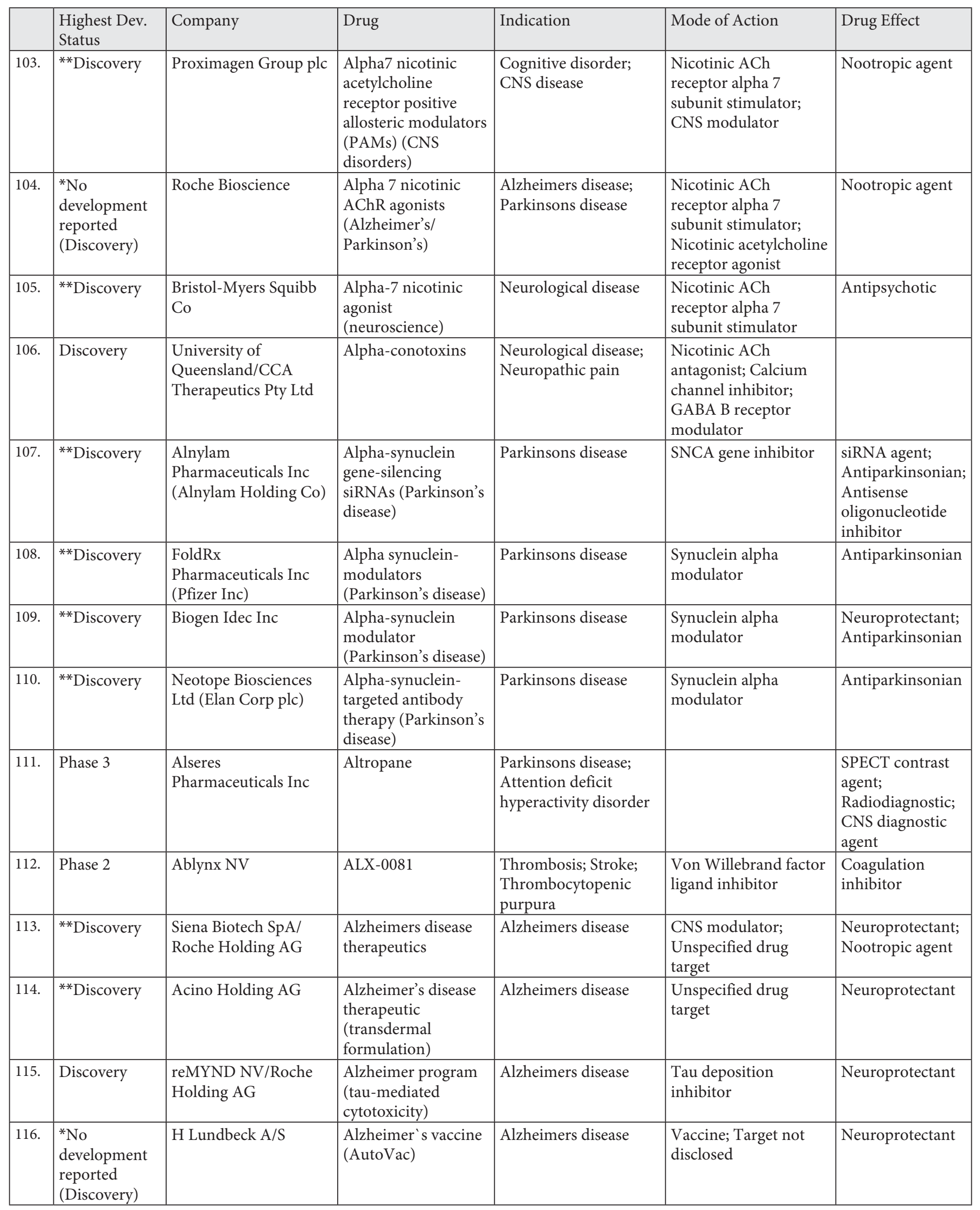




\begin{tabular}{|c|c|c|c|c|c|c|}
\hline & $\begin{array}{l}\text { Highest Dev. } \\
\text { Status }\end{array}$ & Company & Drug & Indication & Mode of Action & Drug Effect \\
\hline 117. & Discovery & $\begin{array}{l}\text { ACADIA } \\
\text { Pharmaceuticals Inc/ } \\
\text { Meiji Seika Kaisha Ltd }\end{array}$ & AM-831 & $\begin{array}{l}\text { Alzheimers disease; } \\
\text { Schizophrenia }\end{array}$ & $\begin{array}{l}\text { Muscarinic M1 } \\
\text { agonist; Dopamine } \\
\text { receptor antagonist; } \\
\text { 5-HT receptor } \\
\text { antagonist }\end{array}$ & $\begin{array}{l}\text { Nootropic agent; } \\
\text { Antipsychotic }\end{array}$ \\
\hline 118. & ${ }^{* *}$ Phase 3 & $\begin{array}{l}\text { Adamas } \\
\text { Pharmaceuticals Inc }\end{array}$ & $\begin{array}{l}\text { Amantadine } \\
\text { (extended release } \\
\text { formulation, } \\
\text { Parkinsons disease/ } \\
\text { movement disorder) }\end{array}$ & Parkinsons disease & & $\begin{array}{l}\text { Neuroprotectant; } \\
\text { Antiparkinsonian }\end{array}$ \\
\hline 119. & **Phase 1 & Amgen Inc & AMG-747 & $\begin{array}{l}\text { Schizophrenia; } \\
\text { Cognitive disorder }\end{array}$ & $\begin{array}{l}\text { Glycine transporter-1 } \\
\text { inhibitor }\end{array}$ & Antipsychotic \\
\hline 120. & ${ }^{* *}$ Discovery & Amgen Inc & AMG-889436 & Parkinsons disease & $\begin{array}{l}\text { Glutamate receptor } 4 \\
\text { modulator; Glutamate } \\
\text { receptor } 4 \text { agonist }\end{array}$ & Antiparkinsonian \\
\hline 122. & Discovery & Eli Lilly \& Co & AMPA modulators & Cognitive disorder & $\begin{array}{l}\text { AMPA receptor } \\
\text { modulator }\end{array}$ & Nootropic agent \\
\hline 123. & ${ }^{* *}$ Phase 1 & GlaxoSmithKline plc & $\begin{array}{l}\text { AMPA receptor } \\
\text { positive modulator }\end{array}$ & CNS disease & $\begin{array}{l}\text { AMPA receptor } \\
\text { modulator }\end{array}$ & \\
\hline 124. & Discovery & $\begin{array}{l}\text { University of } \\
\text { California Davis }\end{array}$ & $\begin{array}{l}\text { Amyloid beta } \\
\text { oligomers (imaging } \\
\text { agent) }\end{array}$ & Alzheimers disease & & $\begin{array}{l}\text { Imaging agent; } \\
\text { CNS diagnostic } \\
\text { agent }\end{array}$ \\
\hline 125. & ${ }^{* *}$ Discovery & $\begin{array}{l}\text { Bristol-Myers Squibb } \\
\text { Co }\end{array}$ & \begin{tabular}{|l|} 
Amyloid beta \\
peptide modulator \\
(Alzheimer's disease)
\end{tabular} & Alzheimers disease & $\begin{array}{l}\text { Beta amyloid } \\
\text { modulator }\end{array}$ & Nootropic agent \\
\hline 128. & ${ }^{* *}$ Discovery & $\begin{array}{l}\text { Ecole Polytechnique } \\
\text { Federale de Lausanne }\end{array}$ & \begin{tabular}{|l|} 
Amyloid precursor \\
protein C-terminal \\
fragment-targeted \\
monoclonal \\
antibodies \\
(Alzheimer's disease)
\end{tabular} & Alzheimers disease & $\begin{array}{l}\text { Amyloid protein } \\
\text { deposition inhibitor }\end{array}$ & Nootropic agent \\
\hline 129. & $\begin{array}{l}{ }^{*} \text { Discontinued } \\
(\text { Phase } 2)\end{array}$ & Xytis Inc & Anatibant & Head injury & $\begin{array}{l}\text { Bradykinin B2 } \\
\text { antagonist }\end{array}$ & $\begin{array}{l}\text { Anti- } \\
\text { inflammatory; } \\
\text { Neuroprotectant }\end{array}$ \\
\hline 130. & Discovery & $\begin{array}{l}\text { Anavex Life Sciences } \\
\text { Corp }\end{array}$ & ANAVEX-1-41 & $\begin{array}{l}\text { Alzheimers disease; } \\
\text { Major depressive } \\
\text { disorder; Stroke }\end{array}$ & $\begin{array}{l}\text { Sodium channel } \\
\text { modulator; Chloride } \\
\text { channel modulator; } \\
\text { Apoptosis inhibitor; } \\
\text { Muscarinic M1 } \\
\text { receptor agonist; } \\
\text { Muscarinic M2 } \\
\text { receptor antagonist; } \\
\text { Sigma-1 opioid } \\
\text { modulator }\end{array}$ & $\begin{array}{l}\text { Nootropic agent; } \\
\text { Anticonvulsant } \\
\text { agent; } \\
\text { Neuroprotectant; } \\
\text { Antidepressant }\end{array}$ \\
\hline
\end{tabular}




\begin{tabular}{|c|c|c|c|c|c|c|}
\hline & $\begin{array}{l}\text { Highest Dev. } \\
\text { Status }\end{array}$ & Company & Drug & Indication & Mode of Action & Drug Effect \\
\hline 131. & $\begin{array}{l}\text { *Phase } 1 \\
\text { (Discovery) }\end{array}$ & $\begin{array}{l}\text { Anavex Life Sciences } \\
\text { Corp }\end{array}$ & ANAVEX-2-73 & $\begin{array}{l}\text { Epilepsy; Alzheimers } \\
\text { disease; Stroke }\end{array}$ & $\begin{array}{l}\text { Sodium channel } \\
\text { modulator; NMDA } \\
\text { receptor modulator; } \\
\text { Opioid receptor sigma } \\
\text { modulator } 1\end{array}$ & $\begin{array}{l}\text { Anticonvulsant } \\
\text { agent; Nootropic } \\
\text { agent; } \\
\text { Neuroprotectant }\end{array}$ \\
\hline 132. & ${ }^{* *}$ Discovery & $\begin{array}{l}\text { Johns Hopkins } \\
\text { University/Mapp } \\
\text { Biopharmaceutical Inc }\end{array}$ & $\begin{array}{l}\text { Anti-Abeta } \\
\text { monoclonal } \\
\text { antibodies } \\
\text { (Alzheimer's disease) }\end{array}$ & Alzheimers disease & $\begin{array}{l}\text { Amyloid beta A4 } \\
\text { binding protein } \\
\text { inhibitor }\end{array}$ & Neuroprotectant \\
\hline 133. & Discovery & $\begin{array}{l}\text { Acumen } \\
\text { Pharmaceuticals Inc/ } \\
\text { Merck \& Co Inc }\end{array}$ & $\begin{array}{l}\text { Anti-ADDL } \\
\text { antibodies } \\
\text { (Alzheimers disease) }\end{array}$ & Alzheimers disease & $\begin{array}{l}\text { Amyloid protein } \\
\text { deposition inhibitor }\end{array}$ & $\begin{array}{l}\text { Biological } \\
\text { therapeutic }\end{array}$ \\
\hline 134. & **Discovery & $\begin{array}{l}\text { Kyowa Hakko Kirin Co } \\
\text { Ltd }\end{array}$ & $\begin{array}{l}\text { Anti-amyloid beta } \\
\text { antibodies } \\
\text { (Alzheimers disease) }\end{array}$ & Alzheimers disease & $\begin{array}{l}\text { Beta amyloid } \\
\text { antagonist }\end{array}$ & Nootropic agent \\
\hline 136. & **Discovery & Neuronex Inc & $\begin{array}{l}\text { Anti-epileptic } \\
\text { program }\end{array}$ & Epilepsy & $\begin{array}{l}\text { Unspecified drug } \\
\text { target }\end{array}$ & $\begin{array}{l}\text { Anticonvulsant } \\
\text { agent }\end{array}$ \\
\hline 137. & ${ }^{* *}$ Phase 1 & Biogen Idec Inc & $\begin{array}{l}\text { Anti-LINGO-1 } \\
\text { antibody (multiple } \\
\text { sclerosis) }\end{array}$ & $\begin{array}{l}\text { Multiple sclerosis; } \\
\text { Demyelinating disease }\end{array}$ & $\begin{array}{l}\text { Nogo receptor } \\
\text { modulator }\end{array}$ & \\
\hline 138. & **Discovery & Acino Holding AG & $\begin{array}{l}\text { Antiparkinsonian } \\
\text { agent (oral) }\end{array}$ & Parkinsons disease & $\begin{array}{l}\text { Unspecified drug } \\
\text { target }\end{array}$ & Antiparkinsonian \\
\hline 139. & **Discovery & Acino Holding AG & $\begin{array}{l}\text { Antiparkinsonian } \\
\text { agent (transdermal } \\
\text { formulation) }\end{array}$ & Parkinsons disease & $\begin{array}{l}\text { Unspecified drug } \\
\text { target }\end{array}$ & Antiparkinsonian \\
\hline 142. & ${ }^{* *}$ Discovery & $\begin{array}{l}\text { TauRx Therapeutics } \\
\text { Pte Ltd }\end{array}$ & $\begin{array}{l}\text { Anti-synuclein } \\
\text { compounds } \\
\text { (Parkinson's disease) }\end{array}$ & Parkinsons disease & Synuclein inhibitor & Antiparkinsonian \\
\hline 143. & Discovery & Antoxis Ltd & $\begin{array}{l}\mathrm{AO}-1 \text { antioxidants; } \\
\text { former } \mathrm{AO}-1-530\end{array}$ & Stroke & $\begin{array}{l}\text { Antioxidant agent; } \\
\text { Free radical scavenger }\end{array}$ & Neuroprotectant \\
\hline 144. & ${ }^{* *}$ Discovery & Antoxis Ltd & AO-2 antioxidants & $\begin{array}{l}\text { Stroke; Neurological } \\
\text { disease; Diabetes } \\
\text { mellitus }\end{array}$ & & $\begin{array}{l}\text { Neuroprotectant; } \\
\text { Hypoglycemic } \\
\text { agent; } \\
\text { Unspecified drug } \\
\text { target; } \\
\text { Antioxidant } \\
\text { agent; } \\
\text { Cardiovascular } \\
\text { agent }\end{array}$ \\
\hline
\end{tabular}




\begin{tabular}{|c|c|c|c|c|c|c|}
\hline & $\begin{array}{l}\text { Highest Dev. } \\
\text { Status }\end{array}$ & Company & Drug & Indication & Mode of Action & Drug Effect \\
\hline 145. & **Discovery & Antoxis Ltd & AO-3 antioxidants & $\begin{array}{l}\text { Stroke; Neurological } \\
\text { disease; Diabetes } \\
\text { mellitus }\end{array}$ & & $\begin{array}{l}\text { Neuroprotectant; } \\
\text { Hypoglycemic } \\
\text { agent; } \\
\text { Unspecified drug } \\
\text { target; } \\
\text { Antioxidant } \\
\text { agent; } \\
\text { Cardiovascular } \\
\text { agent } \\
\end{array}$ \\
\hline 146. & ${ }^{* *}$ Discovery & $\begin{array}{l}\text { Hangzhou Adamerck } \\
\text { Pharmlabs Inc }\end{array}$ & Aom-0937 & $\begin{array}{l}\text { Cerebrovascular } \\
\text { disease; Stroke; } \\
\text { Neurological disease }\end{array}$ & $\begin{array}{l}\text { Chelating agent; } \\
\text { Calcium metabolism } \\
\text { modulator; } \\
\text { Metalloprotease-2 } \\
\text { inhibitor; } \\
\text { Metalloprotease-9 } \\
\text { inhibitor }\end{array}$ & $\begin{array}{l}\text { Neuroprotectant; } \\
\text { Antioxidant agent }\end{array}$ \\
\hline 147. & $\begin{array}{l}\text { *No } \\
\text { development } \\
\text { reported } \\
\text { (Discovery) }\end{array}$ & AcurePharma AB & AP-267 & $\begin{array}{l}\text { Alzheimers disease; } \\
\text { Acute stress disorder; } \\
\text { Opiate dependence }\end{array}$ & $\begin{array}{l}\text { 5-HT 2c receptor } \\
\text { modulator }\end{array}$ & Neuroprotectant \\
\hline 148. & Phase 2 & Apogenix GmbH & APG-101 & $\begin{array}{l}\text { Graft versus host } \\
\text { disease; Glioblastoma; } \\
\text { Cancer }\end{array}$ & $\begin{array}{l}\text { Apoptosis inhibitor; } \\
\text { CD95 antagonist }\end{array}$ & $\begin{array}{l}\text { Anticancer; } \\
\text { Immuno- } \\
\text { suppressant; } \\
\text { Cerebro- } \\
\text { protectant; } \\
\text { Cardiovascular } \\
\text { agent } \\
\end{array}$ \\
\hline 149. & **Phase 2 & $\begin{array}{l}\text { Ligand } \\
\text { Pharmaceuticals Inc }\end{array}$ & Aplindore & $\begin{array}{l}\text { Restless legs syndrome; } \\
\text { Parkinsons disease }\end{array}$ & $\begin{array}{l}\text { Dopamine D2 receptor } \\
\text { partial agonist }\end{array}$ & $\begin{array}{l}\text { Antipsychotic; } \\
\text { Antiparkinsonian }\end{array}$ \\
\hline 150. & Discovery & Cognosci Inc & $\begin{array}{l}\text { Apolipoprotein E } \\
\text { agonist series } \\
\text { (Alzheimer's/ } \\
\text { Parkinsons disease) } \\
\end{array}$ & $\begin{array}{l}\text { Alzheimers disease; } \\
\text { Parkinsons disease }\end{array}$ & $\begin{array}{l}\text { Apolipoprotein E } \\
\text { modulator }\end{array}$ & $\begin{array}{l}\text { Neuroprotectant; } \\
\text { Antiparkinsonian }\end{array}$ \\
\hline 151. & Phase 2 & Novartis AG & AQW-051 & $\begin{array}{l}\text { Alzheimers disease; } \\
\text { Schizophrenia; Mild } \\
\text { cognitive impairment }\end{array}$ & $\begin{array}{l}\text { Unspecified drug } \\
\text { target }\end{array}$ & $\begin{array}{l}\text { Nootropic agent; } \\
\text { Antipsychotic }\end{array}$ \\
\hline 152. & **Phase 3 & $\begin{array}{l}\text { Seaside Therapeutics } \\
\text { Inc }\end{array}$ & Arbaclofen & $\begin{array}{l}\text { Fragile X syndrome; } \\
\text { Autism }\end{array}$ & $\begin{array}{l}\text { GABA B receptor } \\
\text { agonist }\end{array}$ & CNS modulator \\
\hline 153. & Phase 2 & $\begin{array}{l}\text { Archer } \\
\text { Pharmaceuticals }\end{array}$ & $\begin{array}{l}\text { ARC-029; former } \\
\text { Nilvadipine (blood- } \\
\text { brain-barrier } \\
\text { penetrative, } \\
\text { Alzheimer's disease) }\end{array}$ & Alzheimers disease & $\begin{array}{l}\text { Amyloid protein } \\
\text { deposition inhibitor }\end{array}$ & Neuroprotectant \\
\hline 154. & $\begin{array}{l}{ }^{*} \text { No } \\
\text { development } \\
\text { reported } \\
\text { (Discovery) }\end{array}$ & $\begin{array}{l}\text { Archer } \\
\text { Pharmaceuticals }\end{array}$ & ARC-050 & Alzheimers disease & Beta secretase inhibitor & \\
\hline 155. & **Discovery & $\begin{array}{l}\text { Archer } \\
\text { Pharmaceuticals }\end{array}$ & ARC-069 & Alzheimers disease & $\begin{array}{l}\text { Gamma-secretase } \\
\text { inhibitor }\end{array}$ & Neuroprotectant \\
\hline 156. & Phase 3 & Orphazyme ApS & Arimoclomol & $\begin{array}{l}\text { Motor neurone disease; } \\
\text { Stroke; Hypoxia; } \\
\text { Neuropathy }\end{array}$ & $\begin{array}{l}\text { Hypoglycemic agent; } \\
\text { Chaperonin stimulator }\end{array}$ & Neuroprotectant \\
\hline 157. & $\begin{array}{l}\text { *No } \\
\text { development } \\
\text { reported } \\
\text { (Phase 3) }\end{array}$ & $\begin{array}{l}\text { Ono Pharmaceutical } \\
\text { Co Ltd }\end{array}$ & $\begin{array}{l}\text { Arundic acid } \\
\text { (injectable } \\
\text { formulation) }\end{array}$ & $\begin{array}{l}\text { Alzheimers disease; } \\
\text { Motor neurone disease; } \\
\text { Parkinsons disease; } \\
\text { Cerebral infarction; } \\
\text { Stroke }\end{array}$ & Astrocyte modulator & $\begin{array}{l}\text { Neuroprotectant; } \\
\text { Antiparkinsonian }\end{array}$ \\
\hline
\end{tabular}




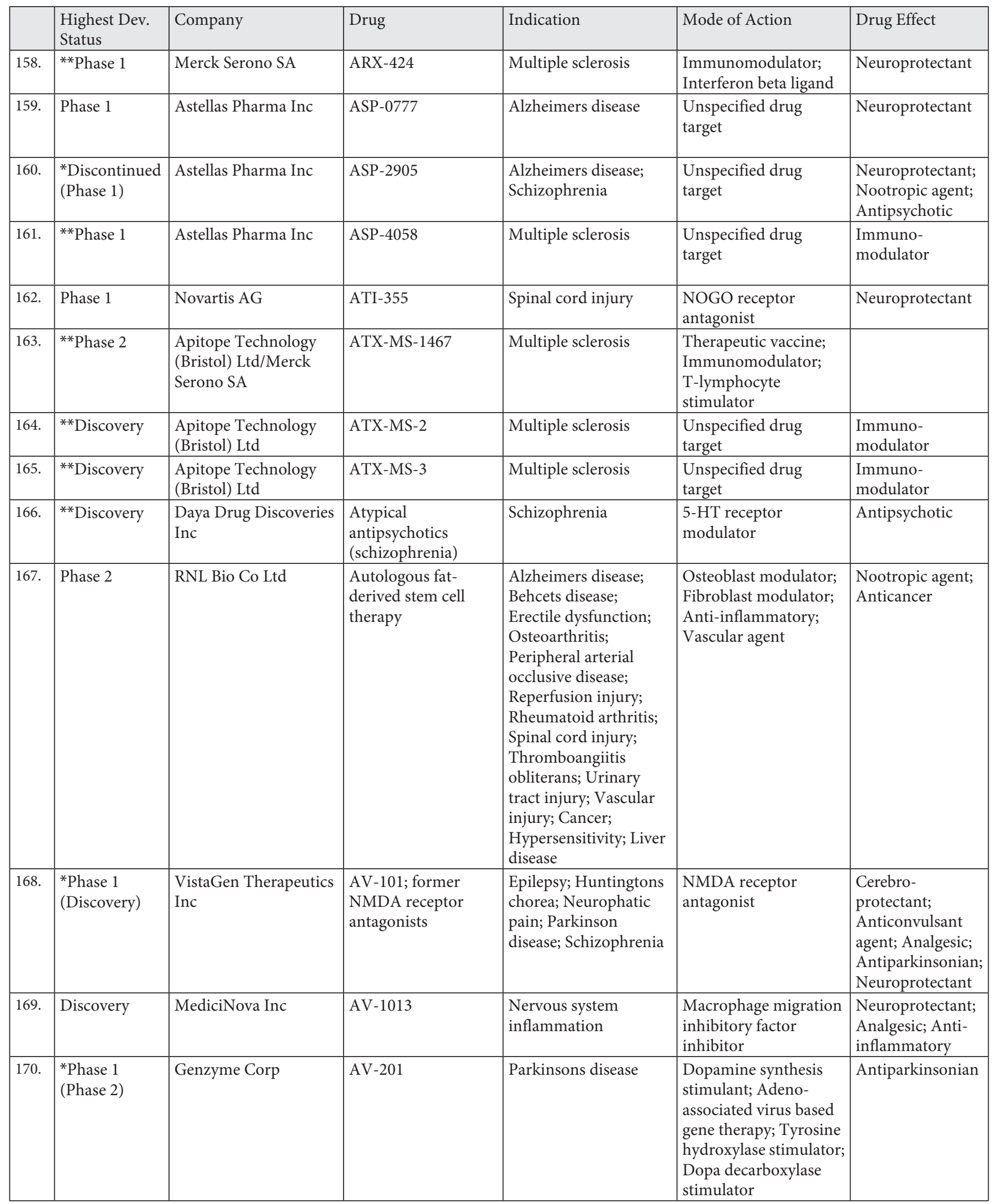




\begin{tabular}{|c|c|c|c|c|c|c|}
\hline & $\begin{array}{l}\text { Highest Dev. } \\
\text { Status }\end{array}$ & Company & Drug & Indication & Mode of Action & Drug Effect \\
\hline 171. & $\begin{array}{l}{ }^{*} \text { No } \\
\text { development } \\
\text { reported } \\
\text { (Discovery) } \\
\end{array}$ & Avigen Inc & AV-333 & Neurophatic pain & $\begin{array}{l}\text { IL-10 agonist; Adeno- } \\
\text { associated virus based } \\
\text { gene therapy }\end{array}$ & $\begin{array}{l}\text { Analgesic; Anti- } \\
\text { inflammatory }\end{array}$ \\
\hline 172. & Phase 2 & $\begin{array}{l}\text { Bristol-Myers Squibb } \\
\text { Co }\end{array}$ & $\begin{array}{l}\text { Avagacestat; former } \\
\text { BMS-708163 }\end{array}$ & $\begin{array}{l}\text { Alzheimers disease; } \\
\text { Mild cognitive } \\
\text { impairment }\end{array}$ & $\begin{array}{l}\text { Beta amyloid synthesis } \\
\text { inhibitor; Gamma- } \\
\text { secretase inhibitor }\end{array}$ & Neuroprotectant \\
\hline 173. & Phase 2 & $\begin{array}{l}\text { Avineuro } \\
\text { Pharmaceuticals Inc/ } \\
\text { ChemDiv Inc } \\
\end{array}$ & AVN-101 & $\begin{array}{l}\text { Alzheimers disease; } \\
\text { Anxiety disorder }\end{array}$ & $\begin{array}{l}\text { 5-HT } 6 \text { receptor } \\
\text { antagonist }\end{array}$ & $\begin{array}{l}\text { Antidepressant; } \\
\text { Nootropic agent; } \\
\text { Anxiolytic }\end{array}$ \\
\hline 174. & Phase 2 & $\begin{array}{l}\text { Avineuro } \\
\text { Pharmaceuticals Inc/ } \\
\text { ChemDiv Inc }\end{array}$ & AVN-211 & Schizophrenia & $\begin{array}{l}\text { 5-HT } 6 \text { receptor } \\
\text { antagonist }\end{array}$ & $\begin{array}{l}\text { Neuroprotectant; } \\
\text { Nootropic agent }\end{array}$ \\
\hline 177. & **Discovery & \begin{tabular}{|l} 
Avineuro \\
Pharmaceuticals Inc \\
\end{tabular} & AVN-458 & Cognitive disorder & $\begin{array}{l}\text { Unspecified drug } \\
\text { target }\end{array}$ & Nootropic agent \\
\hline 178. & **Discovery & $\begin{array}{l}\text { Avineuro } \\
\text { Pharmaceuticals Inc }\end{array}$ & AVN-492 & Cognitive disorder & $\begin{array}{l}\text { Unspecified drug } \\
\text { target }\end{array}$ & Nootropic agent \\
\hline 179. & Phase 2 & $\begin{array}{l}\text { Sygnis Bioscience } \\
\text { GmbH \& Co KG }\end{array}$ & AX-200 & $\begin{array}{l}\text { Motor neurone disease; } \\
\text { Spinal cord injury; } \\
\text { Parkinsons disease; } \\
\text { Peripheral arterial } \\
\text { occlusive disease; Stroke }\end{array}$ & $\begin{array}{l}\text { Neuronal growth } \\
\text { factor; GCSF receptor } \\
\text { agonist }\end{array}$ & $\begin{array}{l}\text { Neuroprotectant; } \\
\text { Vascular agent }\end{array}$ \\
\hline 180. & $\begin{array}{l}\text { *Suspended } \\
\text { (Discovery) }\end{array}$ & $\begin{array}{l}\text { SYGNIS Bioscience } \\
\text { GmbH \& Co KG }\end{array}$ & AX-201 & $\begin{array}{l}\text { Spinal cord injury; } \\
\text { Stroke; } \\
\text { Neurodegenerative } \\
\text { disease }\end{array}$ & $\begin{array}{l}\text { Unspecified drug } \\
\text { target }\end{array}$ & Neuroprotectant \\
\hline 182. & Phase 2 & $\begin{array}{l}\text { AstraZeneca plc/ } \\
\text { Targacept Inc }\end{array}$ & AZD-1446 & $\begin{array}{l}\text { Alzheimers disease; } \\
\text { Cognitive disorder }\end{array}$ & $\begin{array}{l}\text { Nicotinic ACh } \\
\text { receptor alpha } 4 \\
\text { subunit modulator; } \\
\text { Nicotinic ACh } \\
\text { receptor beta } 2 \text { subunit } \\
\text { modulator }\end{array}$ & Nootropic agent \\
\hline 183. & ${ }^{* *}$ Discovery & $\begin{array}{l}\text { INSERM/AlzProtect/ } \\
\text { Universite du Droit et } \\
\text { de la Sante de Lille II }\end{array}$ & AZP-2006 & Alzheimers disease & & Neuroprotectant \\
\hline 184. & Discovery & $\begin{array}{l}\text { Massachusetts General } \\
\text { Hospital/ } \\
\text { FluoroPharma Inc }\end{array}$ & $\begin{array}{l}\text { AZPET; former } \\
\text { Molecular imaging } \\
\text { agents (Alzheimer's } \\
\text { disease) }\end{array}$ & Alzheimers disease & $\begin{array}{l}\text { PET contrast agent; } \\
\text { Amyloid protein } \\
\text { deposition inhibitor; } \\
\text { Muscarinic receptor } \\
\text { agonist; Imaging agent }\end{array}$ & Imaging agent \\
\hline 185. & ${ }^{* *}$ Discovery & Biogen Idec Inc & BIIB-042 & Alzheimers disease & $\begin{array}{l}\text { Beta amyloid synthesis } \\
\text { inhibitor; Gamma- } \\
\text { secretase inhibitor }\end{array}$ & Neuroprotectant \\
\hline 186. & Discovery & Amgen Inc & BACE inhibitors & Alzheimers disease & $\begin{array}{l}\text { Beta secretase } 1 \\
\text { inhibitor; Amyloid } \\
\text { protein deposition } \\
\text { inhibitor }\end{array}$ & \\
\hline
\end{tabular}




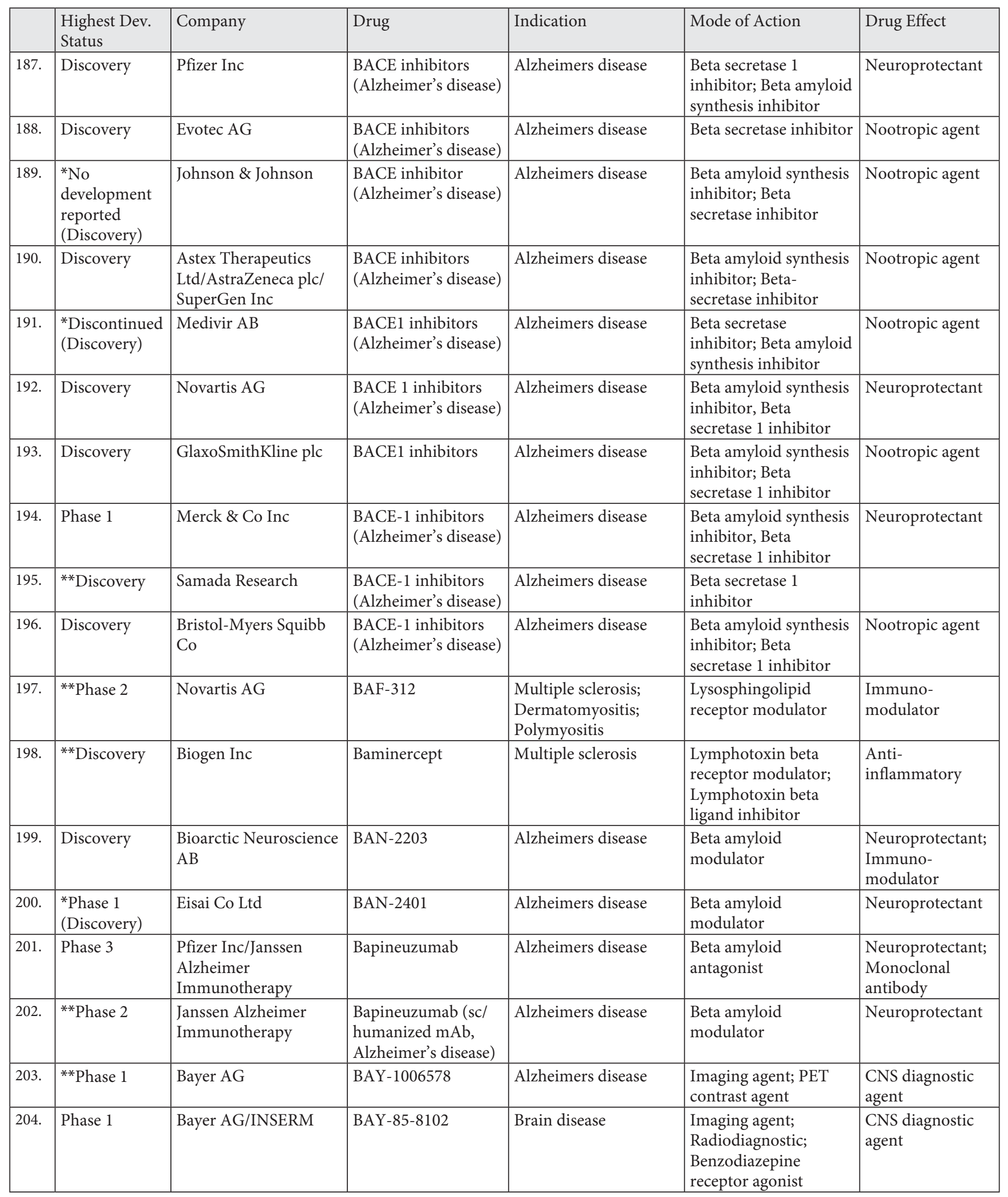




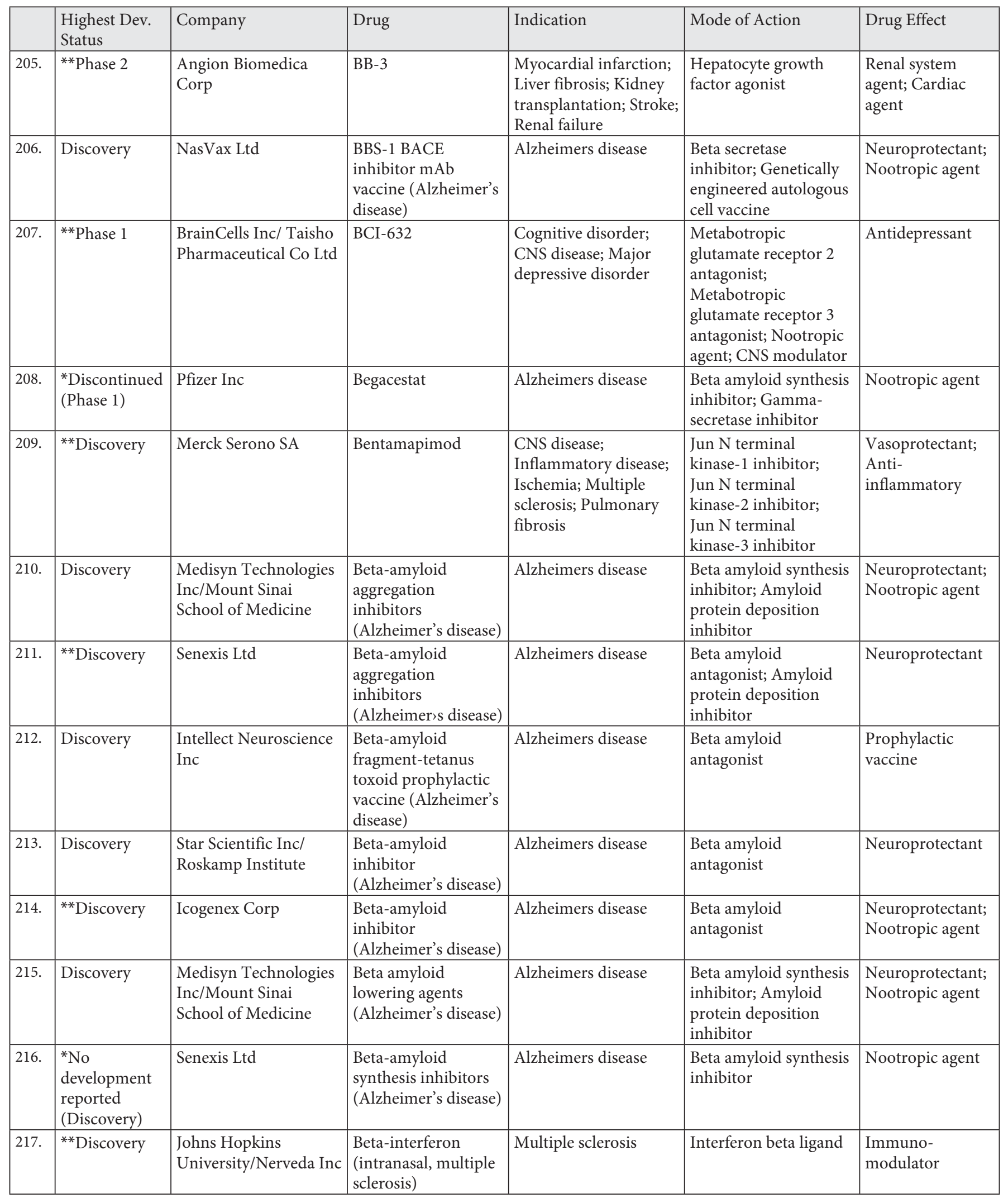




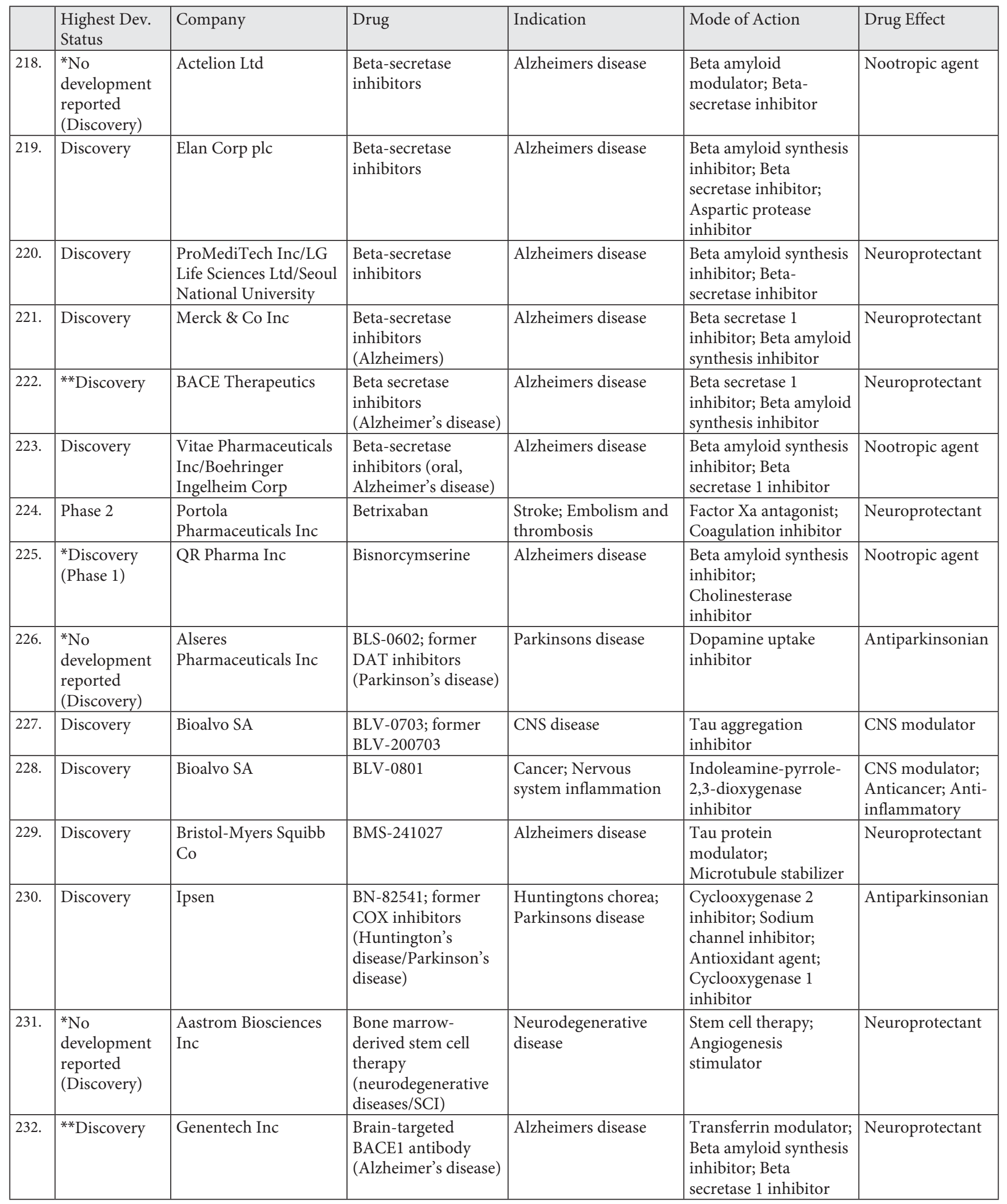




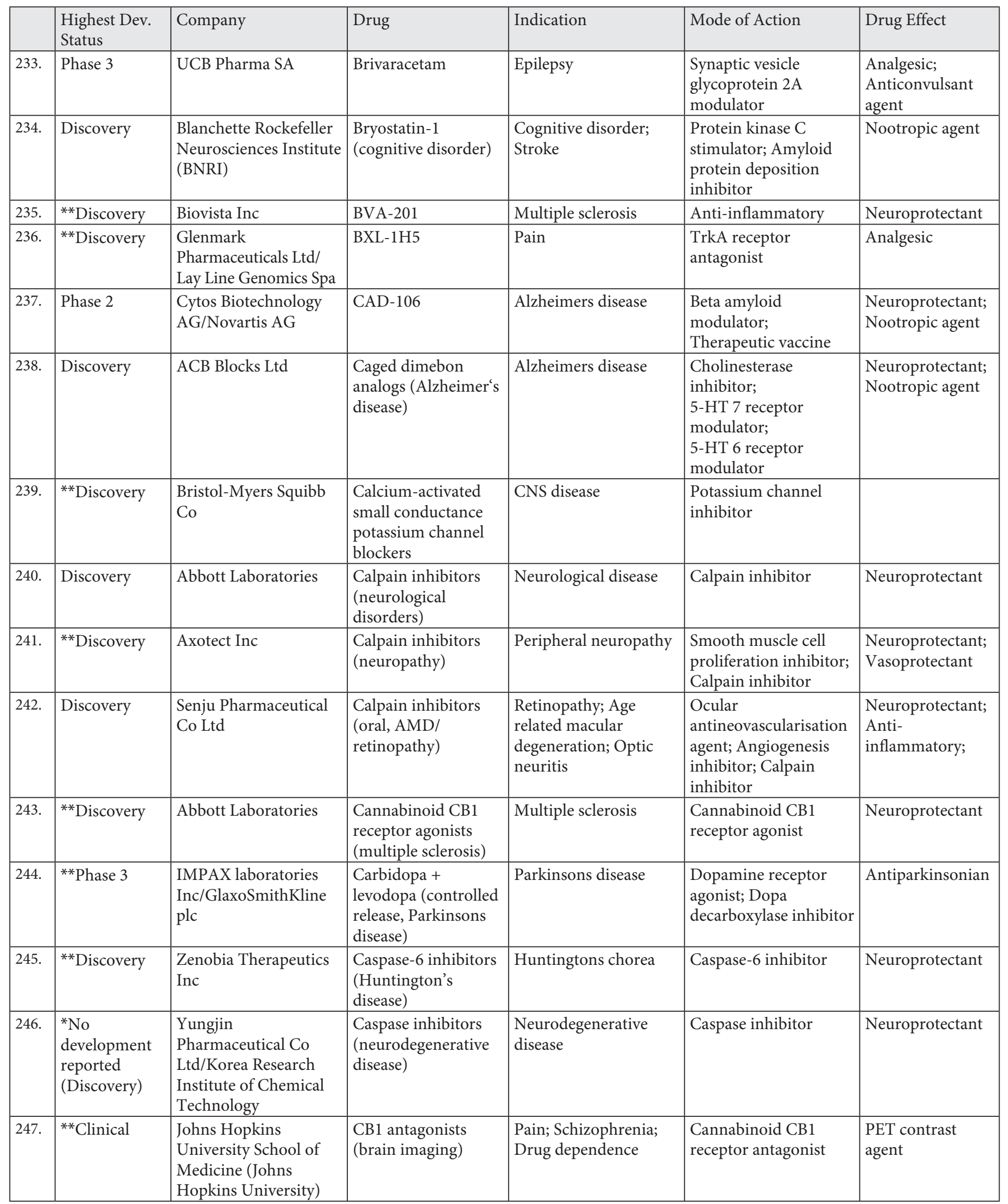




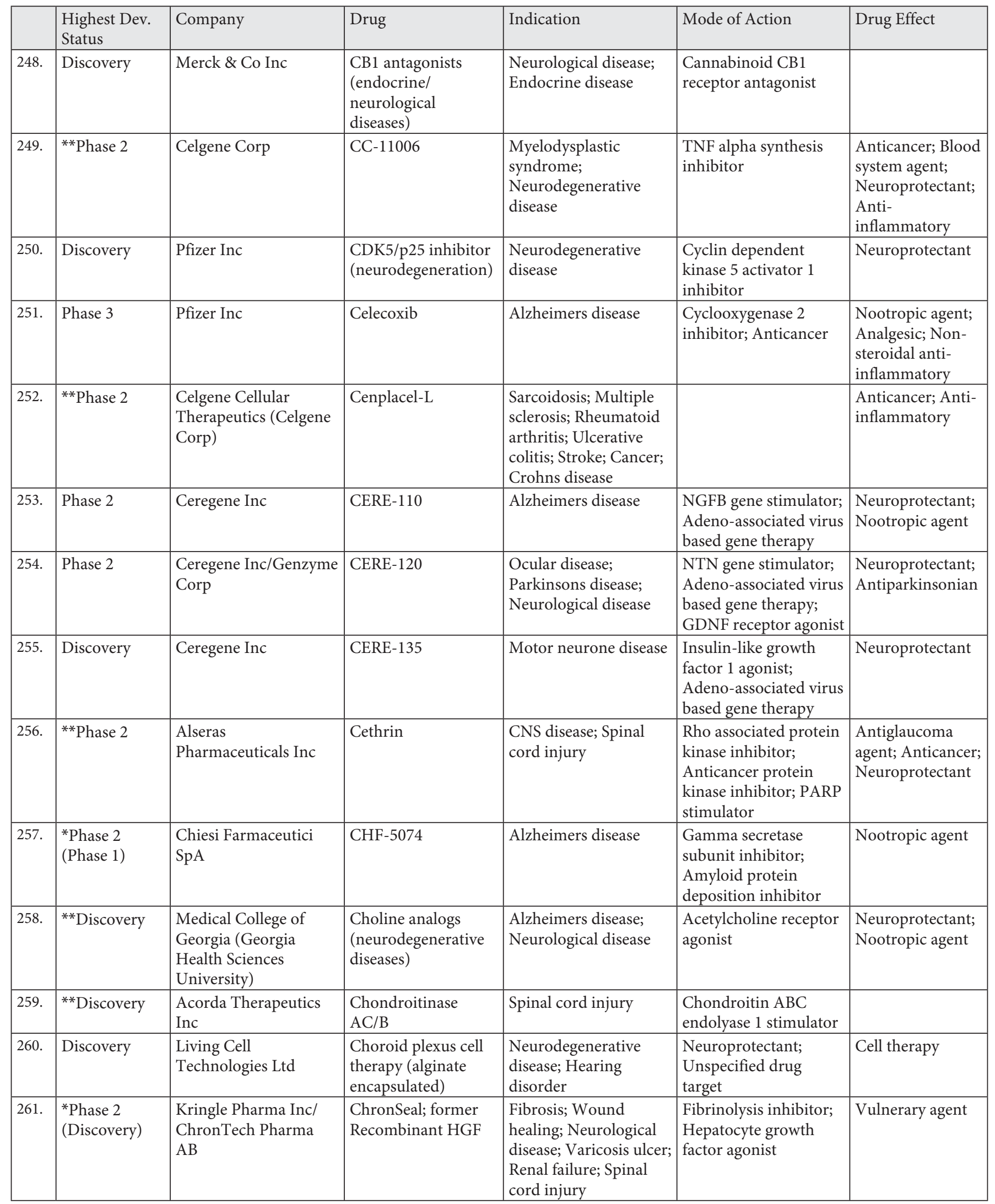




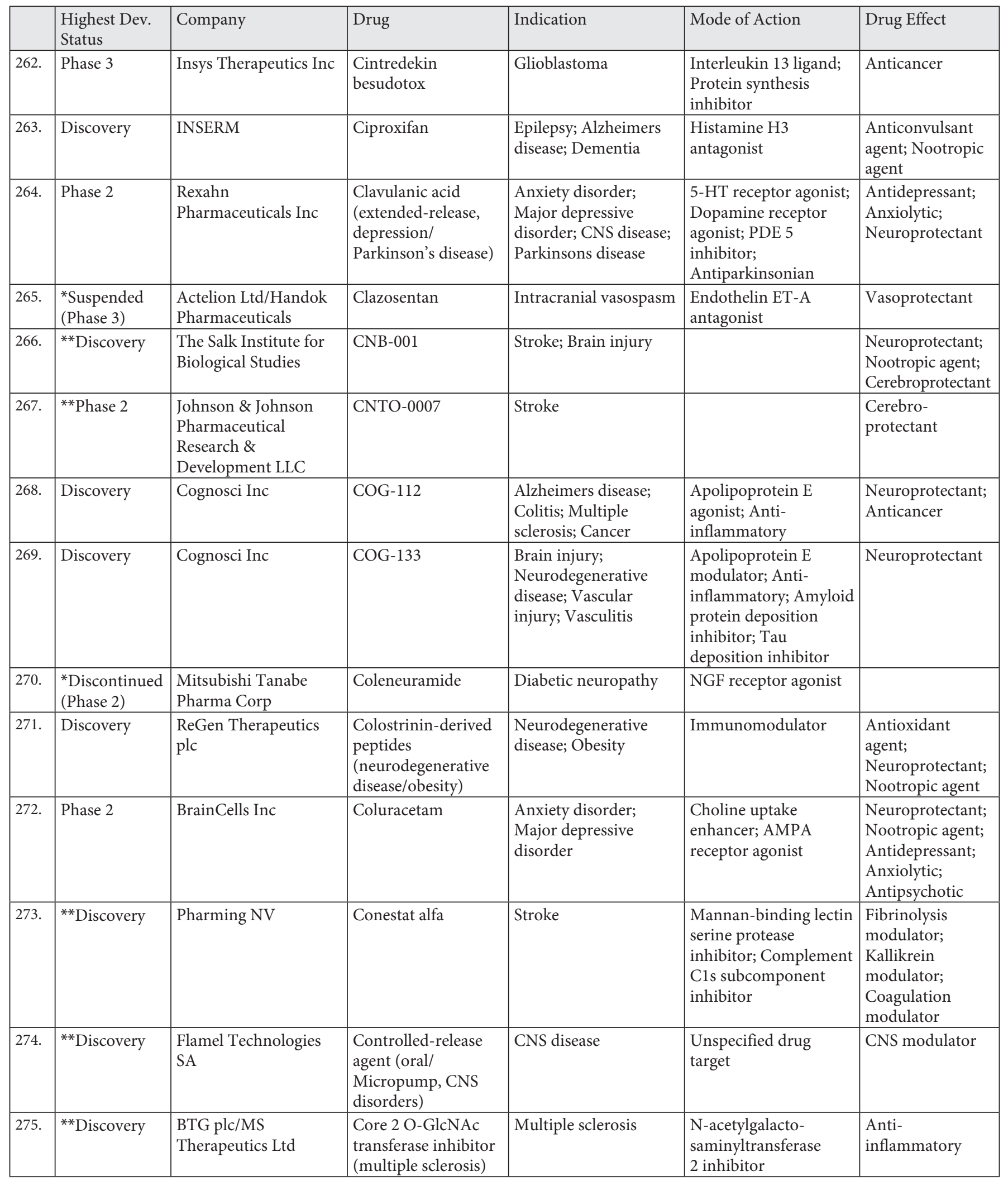




\begin{tabular}{|c|c|c|c|c|c|c|}
\hline & $\begin{array}{l}\text { Highest Dev. } \\
\text { Status }\end{array}$ & Company & Drug & Indication & Mode of Action & Drug Effect \\
\hline 276. & Clinical & Pfizer Inc & CP-810123 & Cognitive disorder & $\begin{array}{l}\text { Nicotinic ACh agonist; } \\
\text { Nicotinic Ach receptor } \\
\text { alpha } 7 \text { subunit } \\
\text { stimulator } \\
\end{array}$ & $\begin{array}{l}\text { Nootropic agent; } \\
\text { Anxiolytic; } \\
\text { Antipsychotic }\end{array}$ \\
\hline 277. & $\begin{array}{l}{ }^{*} \text { Discovery } \\
(\text { Phase } 1)\end{array}$ & $\begin{array}{l}\text { Chase Pharmaceuticals } \\
\text { Corp }\end{array}$ & CPC-001 & Alzheimers disease & $\begin{array}{l}\text { Unspecified drug } \\
\text { target }\end{array}$ & Neuroprotectant \\
\hline 279. & Discovery & \begin{tabular}{|l|} 
Catalyst \\
Pharmaceutical \\
Partners Inc \\
\end{tabular} & $\begin{array}{l}\text { CPP-115; former } \\
\text { Vigabatrin } \\
\text { derivatives (oral) } \\
\end{array}$ & $\begin{array}{l}\text { Epilepsy; Neuropathic } \\
\text { pain; Drug dependence }\end{array}$ & $\begin{array}{l}\text { GABA transaminase } \\
\text { inhibitor }\end{array}$ & $\begin{array}{l}\text { Antipsychotic; } \\
\text { Analgesic; Anti- } \\
\text { convulsant agent }\end{array}$ \\
\hline 280. & ${ }^{* *}$ Discovery & Abiogen Pharma SpA & CRAM 1-2 & CNS disease & $\begin{array}{l}\begin{array}{l}\text { Unspecified drug } \\
\text { target }\end{array} \\
\end{array}$ & $\begin{array}{l}\text { Neuroprotectant; } \\
\text { Antioxidant agent }\end{array}$ \\
\hline 282. & $\begin{array}{l}{ }^{*} \text { Phase } 2 \\
(\text { Phase } 1) \\
\end{array}$ & $\begin{array}{l}\text { AC Immune SA/ } \\
\text { Genentech Inc/Roche }\end{array}$ & $\begin{array}{l}\text { Crenezumab; former } \\
\text { MABT-5102A }\end{array}$ & Alzheimers disease & $\begin{array}{l}\text { Beta amyloid } \\
\text { antagonist }\end{array}$ & Neuroprotectant \\
\hline 283. & $\begin{array}{l}{ }^{*} \text { No } \\
\text { development } \\
\text { reported } \\
\text { (Discovery) } \\
\end{array}$ & CSL Behring & CSL-111 & Atherosclerosis; Stroke & $\begin{array}{l}\text { HDL cholesterol } \\
\text { enhancer }\end{array}$ & Neuroprotectant \\
\hline 284. & Discovery & $\begin{array}{l}\text { British Canadian } \\
\text { Biosciences Corp }\end{array}$ & CTCE-0501 & Stroke & $\begin{array}{l}\text { Unspecified } \\
\text { chemokine modulator }\end{array}$ & Neuroprotectant \\
\hline 285. & **Discovery & $\begin{array}{l}\text { F Hoffmann-La Roche } \\
\text { Ltd (Roche Holding } \\
\text { AG) }\end{array}$ & CTEP & $\begin{array}{l}\text { Fragile X syndrome; } \\
\text { Parkinsons disease; } \\
\text { Major depressive } \\
\text { disorder } \\
\end{array}$ & $\begin{array}{l}\text { Metabotropic } \\
\text { glutamate receptor } 5 \\
\text { antagonist }\end{array}$ & $\begin{array}{l}\text { Nootropic agent; } \\
\text { Antidepressant; } \\
\text { Antiparkinsonian }\end{array}$ \\
\hline 288. & Clinical & $\begin{array}{l}\text { CardioVascular } \\
\text { BioTherapeutics Inc }\end{array}$ & CVBT-141D & Ischemia & FGF-1 ligand & $\begin{array}{l}\text { Angiogenesis } \\
\text { stimulator }\end{array}$ \\
\hline 289. & $\begin{array}{l}{ }^{*} \mathrm{No} \\
\text { development } \\
\text { reported } \\
\text { (Discovery) } \\
\end{array}$ & $\begin{array}{l}\text { CardioVascular } \\
\text { BioTherapeutics Inc }\end{array}$ & CVBT-141F & Stroke & FGF-1 ligand & Neuroprotectant \\
\hline 290. & ${ }^{* *}$ Discovery & $\begin{array}{l}\text { JW Pharmaceutical } \\
\text { Corp }\end{array}$ & CWF-0804 & Alzheimers disease & $\begin{array}{l}\text { Unspecified drug } \\
\text { target }\end{array}$ & Nootropic agent \\
\hline 291. & Phase 2 & $\begin{array}{l}\text { Cortex } \\
\text { Pharmaceuticals Inc }\end{array}$ & CX-1739 & $\begin{array}{l}\text { Sleep apnea; Attention } \\
\text { deficit hyperactivity } \\
\text { disorder } \\
\end{array}$ & $\begin{array}{l}\text { CNS modulator; } \\
\text { AMPA receptor } \\
\text { modulator }\end{array}$ & \\
\hline 292. & $\begin{array}{l}{ }^{*} \text { No } \\
\text { development } \\
\text { reported } \\
\text { (Discovery) } \\
\end{array}$ & $\begin{array}{l}\text { Cortex } \\
\text { Pharmaceuticals Inc }\end{array}$ & CX-1796 & $\begin{array}{l}\text { Alzheimers disease; } \\
\text { Attention deficit } \\
\text { hyperactivity disorder; } \\
\text { Respiratory disorder }\end{array}$ & $\begin{array}{l}\text { AMPA receptor } \\
\text { modulator; CNS } \\
\text { modulator }\end{array}$ & $\begin{array}{l}\text { Respiratory } \\
\text { system agent }\end{array}$ \\
\hline
\end{tabular}




\begin{tabular}{|c|c|c|c|c|c|c|}
\hline & $\begin{array}{l}\text { Highest Dev. } \\
\text { Status }\end{array}$ & Company & Drug & Indication & Mode of Action & Drug Effect \\
\hline 293. & $\begin{array}{l}{ }^{*} \text { No } \\
\text { development } \\
\text { reported } \\
\text { (Discovery) }\end{array}$ & $\begin{array}{l}\text { Cortex } \\
\text { Pharmaceuticals Inc }\end{array}$ & CX-1837 & $\begin{array}{l}\text { Fragile X syndrome; } \\
\text { Hungtingtons chorea; } \\
\text { Rett syndrome; } \\
\text { Parkinsons disease; } \\
\text { Alzheimers disease } \\
\end{array}$ & $\begin{array}{l}\text { AMPA receptor } \\
\text { modulator; Brain } \\
\text { derived neurotrophic } \\
\text { factor ligand } \\
\text { modulator } \\
\end{array}$ & $\begin{array}{l}\text { Neuroprotectant; } \\
\text { Nootropic agent; } \\
\text { Antiparkinsonian }\end{array}$ \\
\hline 294. & **Discovery & \begin{tabular}{|l|} 
Cortex \\
Pharmaceuticals Inc \\
\end{tabular} & CX-1846 & Parkinsons disease & $\begin{array}{l}\text { AMPA receptor } \\
\text { modulator }\end{array}$ & Antiparkinsonian \\
\hline 295. & Discovery & $\begin{array}{l}\text { Cortex } \\
\text { Pharmaceuticals Inc/ } \\
\text { Biovail Laboratories } \\
\text { International Srl } \\
\end{array}$ & CX-1942 & $\begin{array}{l}\text { Sleep apnea; } \\
\text { Respiratory disorder }\end{array}$ & $\begin{array}{l}\text { AMPA receptor } \\
\text { modulator }\end{array}$ & $\begin{array}{l}\text { Respiratory } \\
\text { system agent }\end{array}$ \\
\hline 296. & Discovery & $\begin{array}{l}\text { Cortex } \\
\text { Pharmaceuticals Inc }\end{array}$ & CX-2007 & $\begin{array}{l}\text { Alzheimers disease; } \\
\text { Attention deficit } \\
\text { hyperactivity disorder }\end{array}$ & $\begin{array}{l}\text { AMPA receptor } \\
\text { modulator }\end{array}$ & CNS modulator \\
\hline 298. & ${ }^{* *}$ Clinical & $\begin{array}{l}\text { Cortex } \\
\text { Pharmaceuticals Inc }\end{array}$ & CX-717 (iv) & $\begin{array}{l}\text { Alzheimers disease; } \\
\text { Attention deficit } \\
\text { hyperactivity disorder; } \\
\text { Respiratory disorder } \\
\end{array}$ & $\begin{array}{l}\text { AMPA receptor } \\
\text { modulator }\end{array}$ & $\begin{array}{l}\text { Neuroprotectant; } \\
\text { Respiratory } \\
\text { system agent }\end{array}$ \\
\hline 299. & $\begin{array}{l}{ }^{*} \mathrm{No} \\
\text { development } \\
\text { reported } \\
\text { (Discovery) } \\
\end{array}$ & $\begin{array}{l}\text { Cortex } \\
\text { Pharmaceuticals Inc }\end{array}$ & CX-929 & $\begin{array}{l}\text { Fragile X syndrome; } \\
\text { Hungtingtons chorea; } \\
\text { Rett syndrome }\end{array}$ & $\begin{array}{l}\text { AMPA receptor } \\
\text { modulator }\end{array}$ & \\
\hline 300. & Discovery & $\begin{array}{l}\text { Isotechnika Pharma } \\
\text { Inc }\end{array}$ & $\begin{array}{l}\text { Cyclosporine analogs } \\
\text { (HCV infection/ } \\
\text { neurological disease) }\end{array}$ & \begin{tabular}{|l|} 
Hepatitis C virus \\
infection; Neurological \\
disease
\end{tabular} & $\begin{array}{l}\text { Peptidylprolyl } \\
\text { isomerase inhibitor }\end{array}$ & $\begin{array}{l}\text { Neuroprotectant; } \\
\text { Antiviral }\end{array}$ \\
\hline 303. & ${ }^{* *}$ Discovery & $\begin{array}{l}\text { Promentis } \\
\text { Pharmaceuticals Inc/ } \\
\text { University of } \\
\text { Wisconsin-Milwaukee/ } \\
\text { Marquette University } \\
\end{array}$ & $\begin{array}{l}\text { Cystine analogs } \\
\text { (schizophrenia/CNS } \\
\text { disease) }\end{array}$ & $\begin{array}{l}\text { Schizophrenia; CNS } \\
\text { disease }\end{array}$ & $\begin{array}{l}\text { Neurotransmitter } \\
\text { modulator }\end{array}$ & Antipsychotic \\
\hline 304. & **Phase 3 & $\begin{array}{l}\text { Abbott Laboratories/ } \\
\text { Biogen Idec Inc }\end{array}$ & $\begin{array}{l}\text { Daclizumab } \\
\text { (subcutaneous, } \\
\text { multiple sclerosis) }\end{array}$ & Multiple sclerosis & $\begin{array}{l}\text { IL-2 antagonist; IL-2 } \\
\text { receptor alpha subunit } \\
\text { inhibitor }\end{array}$ & $\begin{array}{l}\text { Immuno- } \\
\text { suppressant }\end{array}$ \\
\hline 305. & Phase 2 & Allon Therapeutics Inc & $\begin{array}{l}\text { Davunetide (iv/sc } \\
\text { Alzheimer's disease) }\end{array}$ & $\begin{array}{l}\text { Alzheimers disease; } \\
\text { Schizophrenia; } \\
\text { Parkinsons disease; } \\
\text { Dementia }\end{array}$ & $\begin{array}{l}\text { Tau deposition } \\
\text { inhibitor; Microtubule } \\
\text { stabilizer; Amyloid } \\
\text { protein deposition } \\
\text { inhibitor; PARP } \\
\text { stimulator; Glycogen } \\
\text { synthase kinase-3 } \\
\text { inhibitor } \\
\end{array}$ & $\begin{array}{l}\text { Neuroprotectant; } \\
\text { Nootropic agent; } \\
\text { Antiparkinsonian }\end{array}$ \\
\hline
\end{tabular}




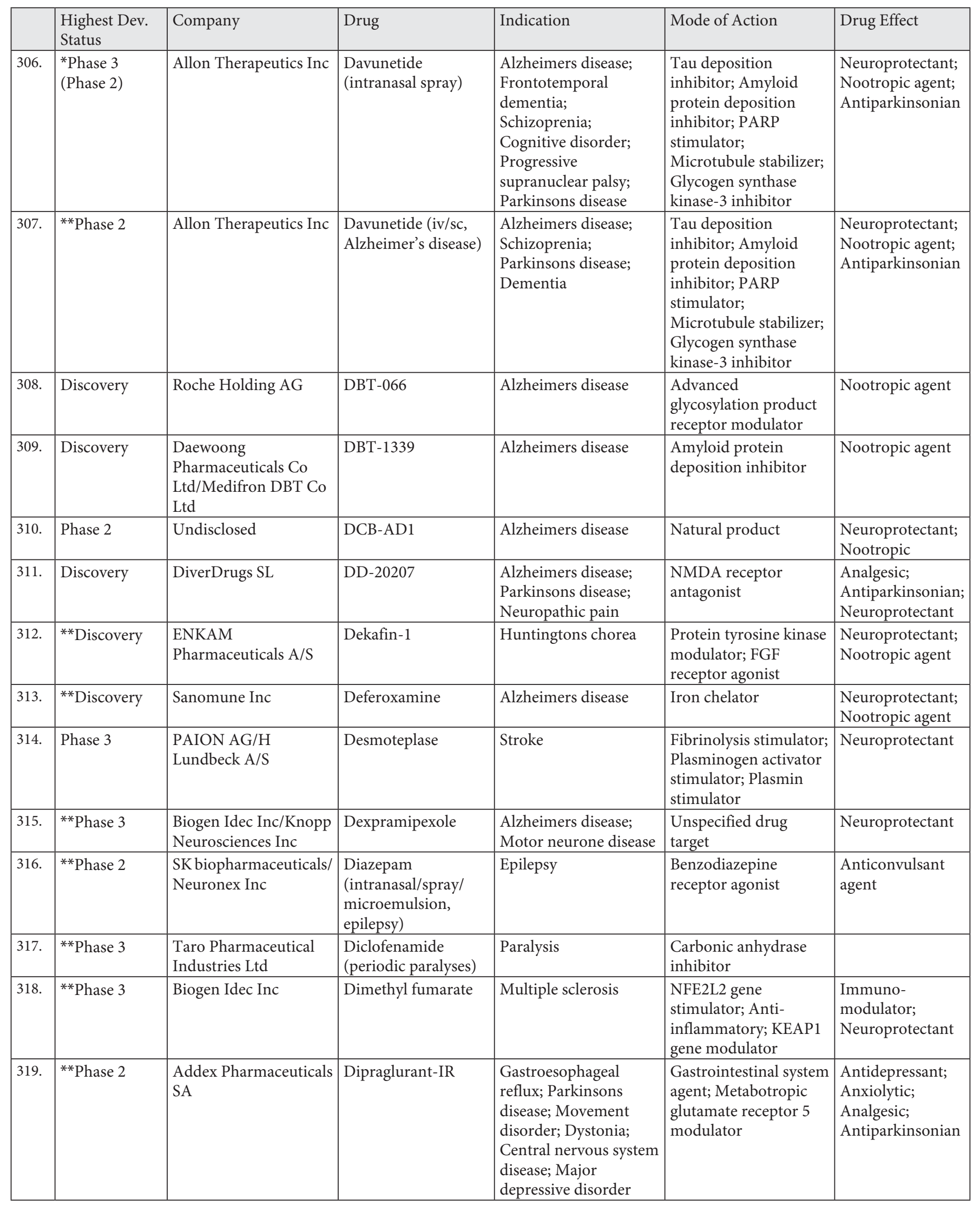




\begin{tabular}{|c|c|c|c|c|c|c|}
\hline & $\begin{array}{l}\text { Highest Dev. } \\
\text { Status }\end{array}$ & Company & Drug & Indication & Mode of Action & Drug Effect \\
\hline 320. & **Discovery & Biogen Idec Inc & $\begin{array}{l}\text { Disease specific } \\
\text { epitope-targeting } \\
\text { monoclonal } \\
\text { antibodies } \\
\text { (amyotrophic lateral } \\
\text { sclerosis) } \\
\end{array}$ & Motor neurone disease & $\begin{array}{l}\text { Superoxide dismutase } \\
\text { modulator }\end{array}$ & Neuroprotectant \\
\hline 323. & Discovery & Ikerchem & $\begin{array}{l}\text { DMNT inhibitors } \\
\text { (cancer, neurological } \\
\text { disorders), former } \\
\text { DNA } \\
\text { methyltransferase } 1 \\
\text { inhibitors (cancer/ } \\
\text { neurological } \\
\text { disorders) } \\
\end{array}$ & $\begin{array}{l}\text { Cancer; Neurological } \\
\text { disease }\end{array}$ & $\begin{array}{l}\text { Anticancer; DNA } \\
\text { cytosine-5 } \\
\text { methyltransferase } 1 \\
\text { inhibitor }\end{array}$ & Neuroprotectant \\
\hline 327. & $\begin{array}{l}\text { *Discovery } \\
\text { (No } \\
\text { development } \\
\text { reported) } \\
\end{array}$ & Organix Inc & $\begin{array}{l}\text { Dopamine } \\
\text { transporter } \\
\text { modulator }\end{array}$ & $\begin{array}{l}\text { Parkinsons disease; } \\
\text { Schizophrenia; Cocaine } \\
\text { addiction; Drug } \\
\text { dependence }\end{array}$ & $\begin{array}{l}\text { Dopamine transporter } \\
\text { modulator }\end{array}$ & $\begin{array}{l}\text { Antipsychotic; } \\
\text { Antiparkinsonian }\end{array}$ \\
\hline 328. & $\begin{array}{l}{ }^{*} \mathrm{No} \\
\text { development } \\
\text { reported } \\
\text { (Discovery) } \\
\end{array}$ & Purdue University & Doxanthrine & $\begin{array}{l}\text { Parkinsons disease; } \\
\text { Schizophrenia }\end{array}$ & Dopamine D1 agonist & $\begin{array}{l}\text { Antipsychotic; } \\
\text { Antiparkinsonian }\end{array}$ \\
\hline 329. & ${ }^{* *}$ Phase 2 & $\begin{array}{l}\text { to-BBB technologies } \\
\text { BV/Netherlands } \\
\text { Kanker Instituut- } \\
\text { Antoni van } \\
\text { Leeuwenhoek } \\
\text { Ziekenhuis }\end{array}$ & $\begin{array}{l}\text { Doxorubicin } \\
\text { (PEGylated } \\
\text { liposomal, } \\
\text { G-technology) }\end{array}$ & Brain tumor & $\begin{array}{l}\text { DNA polymerase } \\
\text { inhibitor; } \\
\text { Topoisomerase II } \\
\text { inhibitor }\end{array}$ & $\begin{array}{l}\text { Anticancer; DNA } \\
\text { intercalator; } \\
\text { Glutathione } \\
\text { modulator }\end{array}$ \\
\hline
\end{tabular}




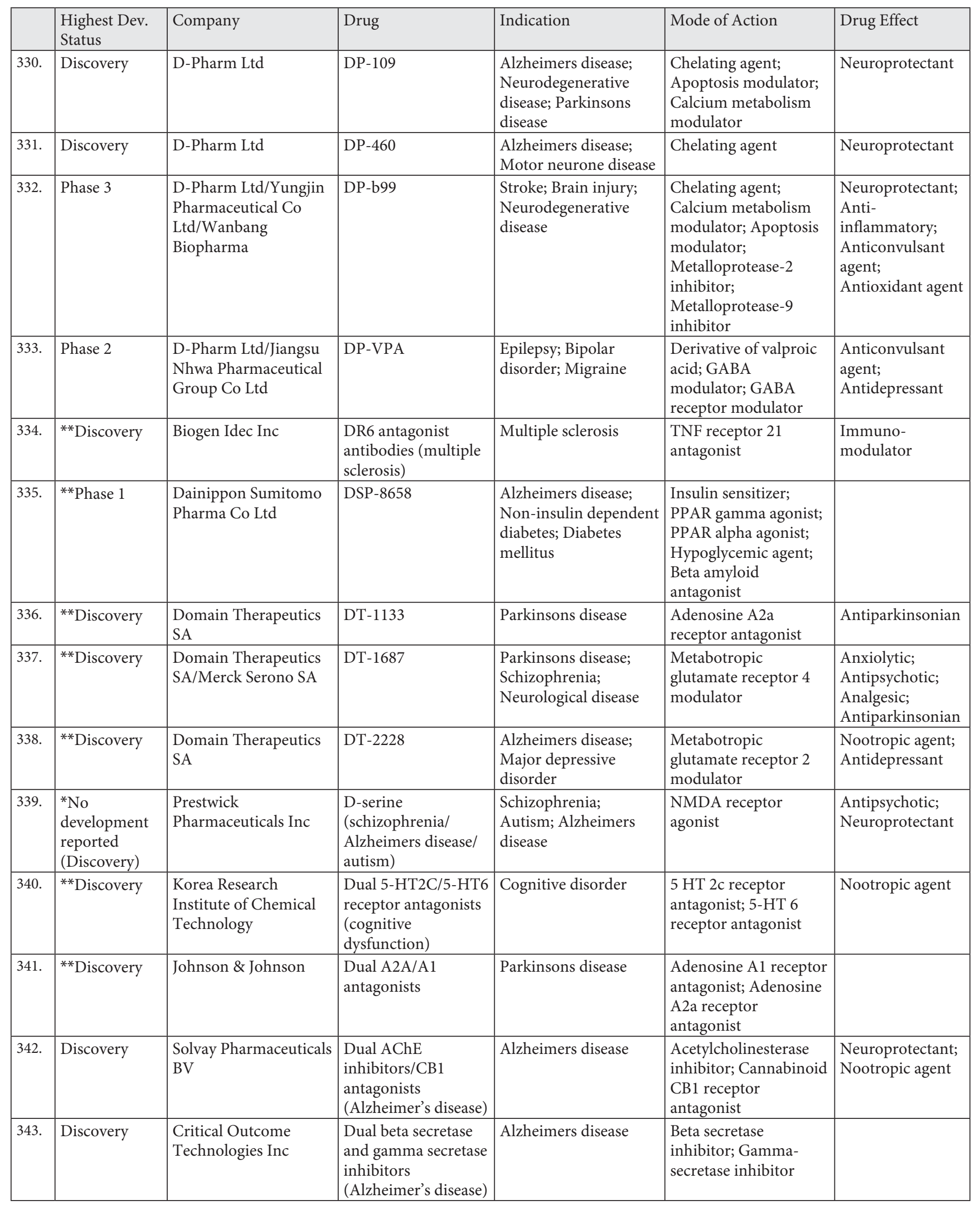




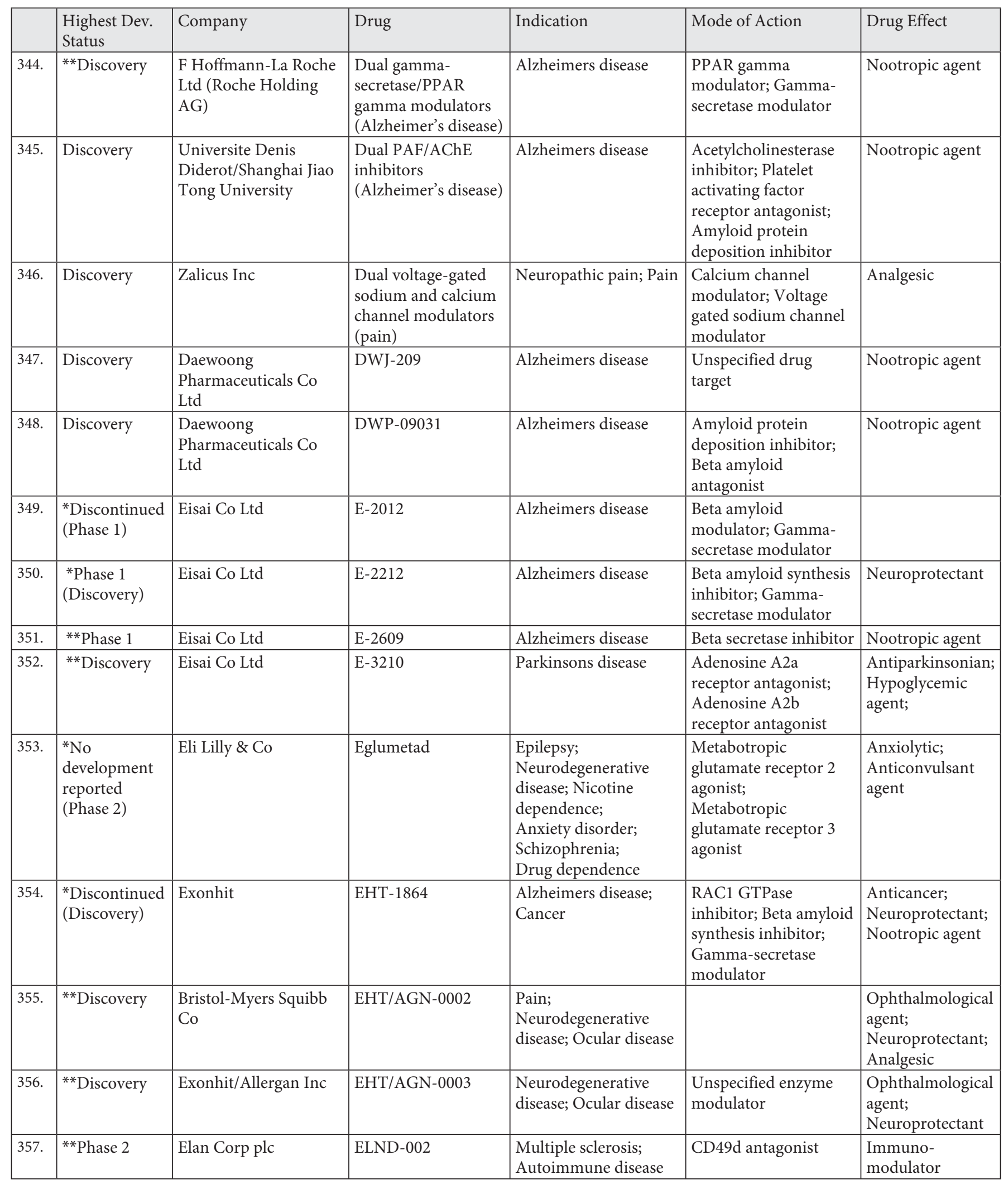




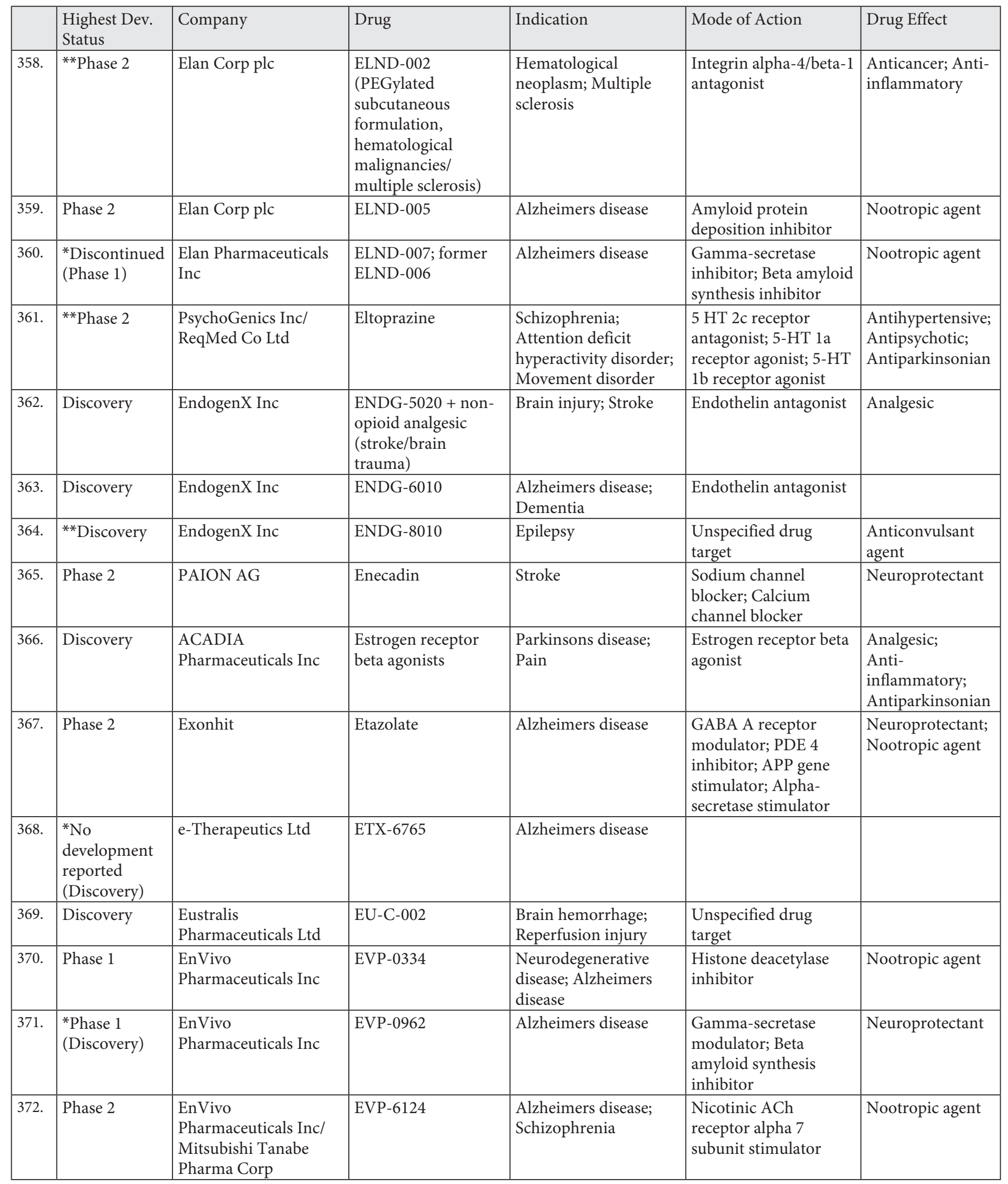




\begin{tabular}{|c|c|c|c|c|c|c|}
\hline & $\begin{array}{l}\text { Highest Dev. } \\
\text { Status }\end{array}$ & Company & Drug & Indication & Mode of Action & Drug Effect \\
\hline 373. & $\begin{array}{l}\text { *No } \\
\text { development } \\
\text { reported } \\
(\text { Phase 1) } \\
\end{array}$ & Evotec AG & EVT-101 & $\begin{array}{l}\text { Neuropathic pain; } \\
\text { Alzheimers disease; } \\
\text { Major depressive } \\
\text { disorder }\end{array}$ & $\begin{array}{l}\text { NMDA receptor } \\
\text { epsilon } 2 \text { subunit } \\
\text { inhibitor }\end{array}$ & $\begin{array}{l}\text { Neuroprotectant; } \\
\text { Nootropic agent; } \\
\text { Analgesic; } \\
\text { Antidepressant }\end{array}$ \\
\hline 374. & Phase 1 & $\begin{array}{l}\text { Evotec Neurosciences } \\
\text { GmbH }\end{array}$ & EVT-103 & $\begin{array}{l}\text { Major depressive } \\
\text { disorder }\end{array}$ & $\begin{array}{l}\text { NMDA receptor } \\
\text { epsilon } 2 \text { subunit } \\
\text { inhibitor } \\
\end{array}$ & Antidepressant \\
\hline 375. & $\begin{array}{l}{ }^{*} \text { Discovery } \\
\text { (Discontinued) }\end{array}$ & Roche Holding AG & EVT-302 & $\begin{array}{l}\text { Alzheimers disease; } \\
\text { Nicotine dependence; } \\
\text { Parkinsons disease } \\
\end{array}$ & MAO B inhibitor & $\begin{array}{l}\text { Neuroprotectant; } \\
\text { Antiparkinsonian; } \\
\text { Nootropic agent } \\
\end{array}$ \\
\hline 376. & Discovery & Evotec AG & $\begin{array}{l}\text { EVT-501; former } \mathrm{H} 3 \\
\text { antagonists }\end{array}$ & \begin{tabular}{|l} 
Sleep disorder; \\
Cognitive disorder
\end{tabular} & \begin{tabular}{|l}
$\begin{array}{l}\text { Histamine H3 } \\
\text { antagonist }\end{array}$ \\
\end{tabular} & $\begin{array}{l}\text { Nootropic agent; } \\
\text { Hypnotic } \\
\end{array}$ \\
\hline 377. & Phase 1 & $\begin{array}{l}\text { ProteoTech Inc/Tasly } \\
\text { Pharmaceuticals Ltd }\end{array}$ & Exebryl-1 & Alzheimers disease & $\begin{array}{l}\text { Amyloid protein } \\
\text { deposition inhibitor }\end{array}$ & Neuroprotectant \\
\hline 379. & **Discovery & $\begin{array}{l}\text { University of } \\
\text { Queensland }\end{array}$ & $\begin{array}{l}\text { FC29 peptide } \\
\text { (neurodegenerative } \\
\text { disease) }\end{array}$ & $\begin{array}{l}\text { Neurodegenerative } \\
\text { disease }\end{array}$ & $\begin{array}{l}\text { Trk tyrosine kinase } \\
\text { receptor modulator; } \\
\text { Type II TNF receptor } \\
\text { modulator } \\
\end{array}$ & Neuroprotectant \\
\hline 380. & **Discovery & Buck Institute & $\begin{array}{l}\text { FGF-2 agonist } \\
\text { (Huntington's } \\
\text { disease) }\end{array}$ & Huntingtons chorea & FGF-2 ligand & Neuroprotectant \\
\hline 381. & Phase 1 & $\begin{array}{l}\text { Enkam } \\
\text { Pharmaceuticals A/S }\end{array}$ & FGLL & Alzheimers disease & $\begin{array}{l}\text { Beta amyloid } \\
\text { modulator; FGF } \\
\text { receptor modulator; } \\
\text { CNS modulator }\end{array}$ & Neuroprotectant \\
\hline 384. & $\begin{array}{l}\text { *No } \\
\text { development } \\
\text { reported } \\
\text { (Discovery) } \\
\end{array}$ & Astellas Pharma Inc & FK-1706 & Neurological disease & $\begin{array}{l}\text { NGF agonist; MAP } \\
\text { kinase stimulator }\end{array}$ & Neuroprotectant \\
\hline 385. & Phase 2 & $\begin{array}{l}\text { Avid } \\
\text { Radiopharmaceuticals } \\
\text { Inc }\end{array}$ & $\begin{array}{l}\text { Florbenazine F } 18 \text {; } \\
\text { former } 18 \mathrm{~F}-\mathrm{AV}-133\end{array}$ & $\begin{array}{l}\text { Alzheimers disease; } \\
\text { Parkinsons disease; } \\
\text { Lewy body dementia; } \\
\text { Diabetes mellitus }\end{array}$ & $\begin{array}{l}\text { Synaptic vesicular } \\
\text { amine transporter } \\
\text { modulator }\end{array}$ & $\begin{array}{l}\text { PET contrast } \\
\text { agent; } \\
\text { Radiodiagnostic }\end{array}$ \\
\hline 386. & Phase 3 & Bayer AG & Florbetaben $(18 \mathrm{~F})$ & $\begin{array}{l}\text { Alzheimers disease; } \\
\text { Mild cognitive } \\
\text { impairment }\end{array}$ & $\begin{array}{l}\text { Beta amyloid } \\
\text { modulator; PET } \\
\text { contrast agent }\end{array}$ & $\begin{array}{l}\text { Radiodiagnostic; } \\
\text { Imaging agent; } \\
\text { CNS diagnostic } \\
\text { agent }\end{array}$ \\
\hline 387. & Phase 1 & $\begin{array}{l}\text { Alseres } \\
\text { Pharmaceuticals Inc }\end{array}$ & Fluoratec & $\begin{array}{l}\text { Parkinsons disease; } \\
\text { Attention deficit } \\
\text { hyperactivity disorder }\end{array}$ & $\begin{array}{l}\text { Dopamine uptake } \\
\text { modulator }\end{array}$ & $\begin{array}{l}\text { SPECT contrast } \\
\text { agent; CNS } \\
\text { diagnostic agent }\end{array}$ \\
\hline 388. & **Discovery & Johnson \& Johnson & $\begin{array}{l}\text { Fluorine-18-based } \\
\text { PET imaging agents } \\
\text { (neuropsychiatric } \\
\text { disorders) }\end{array}$ & CNS disease & PDE 10 inhibitor & $\begin{array}{l}\text { PET contrast } \\
\text { agent; CNS } \\
\text { diagnostic agent }\end{array}$ \\
\hline
\end{tabular}




\begin{tabular}{|c|c|c|c|c|c|c|}
\hline & $\begin{array}{l}\text { Highest Dev. } \\
\text { Status }\end{array}$ & Company & Drug & Indication & Mode of Action & Drug Effect \\
\hline 389. & \begin{tabular}{|l|} 
*No \\
development \\
reported \\
(Discovery) \\
\end{tabular} & $\begin{array}{l}\text { Avid } \\
\text { Radiopharmaceuticals } \\
\text { Inc }\end{array}$ & \begin{tabular}{|l|} 
Fluoropegylated \\
indolylphenyl- \\
acetylenes \\
(Alzheimer's disease)
\end{tabular} & Alzheimers disease & $\begin{array}{l}\text { Beta amyloid } \\
\text { modulator; PET } \\
\text { contrast agent }\end{array}$ & $\begin{array}{l}\text { Radiodiagnostic; } \\
\text { CNS diagnostic } \\
\text { agent }\end{array}$ \\
\hline 390. & Discovery & $\begin{array}{l}\text { Kyungpook National } \\
\text { University }\end{array}$ & \begin{tabular}{|l|} 
Fluorovinyl- \\
oxyacetamide anti- \\
inflammatory drugs \\
(neuroinflammation/ \\
neurodegeneration)
\end{tabular} & $\begin{array}{l}\text { Nervous system } \\
\text { inflammation; } \\
\text { Neurodegenerative } \\
\text { disease }\end{array}$ & $\begin{array}{l}\text { Unspecified drug } \\
\text { target; Anti- } \\
\text { inflammatory }\end{array}$ & Neuroprotectant \\
\hline 391. & Phase 3 & $\begin{array}{l}\text { University of } \\
\text { Pittsburgh/Uppsala } \\
\text { Imanet } \mathrm{AB}\end{array}$ & Flutemetamol $(18 \mathrm{~F})$ & Alzheimers disease & $\begin{array}{l}\text { Beta amyloid } \\
\text { modulator; PET } \\
\text { contrast agent }\end{array}$ & $\begin{array}{l}\text { Radiodiagnostic; } \\
\text { CNS diagnostic } \\
\text { agent }\end{array}$ \\
\hline 392. & ${ }^{* *}$ Discovery & $\begin{array}{l}\text { Zenobia Therapeutics } \\
\text { Inc/Johns Hopkins } \\
\text { University }\end{array}$ & $\begin{array}{l}\text { G-2019S LRRK2 } \\
\text { program } \\
\text { (Parkinson's disease) }\end{array}$ & Parkinsons disease & $\begin{array}{l}\text { Leucine rich serine } \\
\text { threonine kinase } 2 \\
\text { inhibitor }\end{array}$ & $\begin{array}{l}\text { Neuroprotectant; } \\
\text { Antiparkinsonian }\end{array}$ \\
\hline 394. & ${ }^{* *}$ Discovery & $\begin{array}{l}\text { F Hoffmann-La Roche } \\
\text { Ltd }\end{array}$ & \begin{tabular}{|l|} 
GABA-A alpha-5 \\
inverse agonists \\
(cognitive \\
impairment) \\
\end{tabular} & Cognitive disorder & $\begin{array}{l}\text { GABA A receptor } \\
\text { inverse agonist }\end{array}$ & Nootropic agent \\
\hline 395. & **Discovery & $\begin{array}{l}\text { Kyowa Hakko Kirin Co } \\
\text { Ltd }\end{array}$ & $\begin{array}{l}\text { GABA A alpha } 5 \\
\text { receptor inverse } \\
\text { agonists (cognitive } \\
\text { disorders) }\end{array}$ & $\begin{array}{l}\text { Alzheimers disease; } \\
\text { Cognitive disorder }\end{array}$ & $\begin{array}{l}\text { GABA A receptor } \\
\text { alpha-5 subunit } \\
\text { modulator; GABA A } \\
\text { receptor inverse } \\
\text { agonist }\end{array}$ & Nootropic agent \\
\hline 399. & **Discovery & ProteoTech Inc & $\begin{array}{l}\text { GAG/carbohydrate } \\
\text { compounds } \\
\text { (oligosaccharide, } \\
\text { Alzheimers disease) }\end{array}$ & Alzheimers disease & $\begin{array}{l}\text { Glycosaminoglycan } \\
\text { modulator }\end{array}$ & Neuroprotectant \\
\hline 400. & Discovery & Gaia BioPharma Ltd & GAI-122 & $\begin{array}{l}\text { Neurological disease; } \\
\text { Liver disease }\end{array}$ & Apoptosis inhibitor & $\begin{array}{l}\text { Neuroprotectant; } \\
\text { Anti- } \\
\text { inflammatory; } \\
\text { ATP modulator }\end{array}$ \\
\hline 401. & Phase 2 & \begin{tabular}{|l} 
Sanochemia \\
Pharmazeutika AG
\end{tabular} & $\begin{array}{l}\text { Galantamine } \\
\text { (liposomal) }\end{array}$ & Neuropathic pain & $\begin{array}{l}\text { Acetylcholinesterase } \\
\text { inhibitor }\end{array}$ & Analgesic \\
\hline 402. & Discovery & Merck \& Co Inc & $\begin{array}{l}\text { Gamma-secretase } \\
\text { inhibitors } \\
\text { (Alzheimers) }\end{array}$ & Alzheimers disease & $\begin{array}{l}\text { Amyloid protein } \\
\text { deposition inhibitor; } \\
\text { Gamma-secretase } \\
\text { inhibitor }\end{array}$ & Neuroprotectant \\
\hline
\end{tabular}




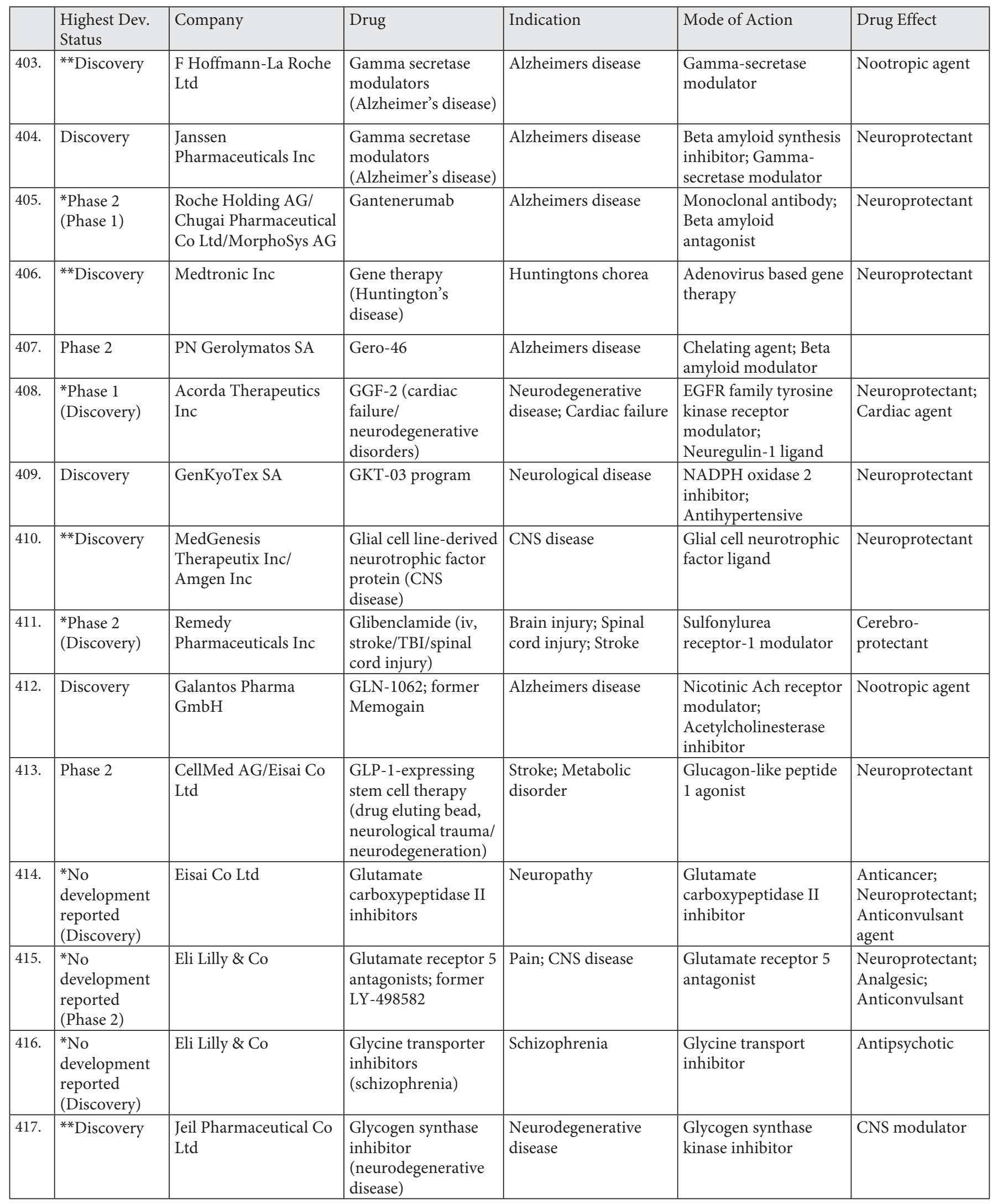




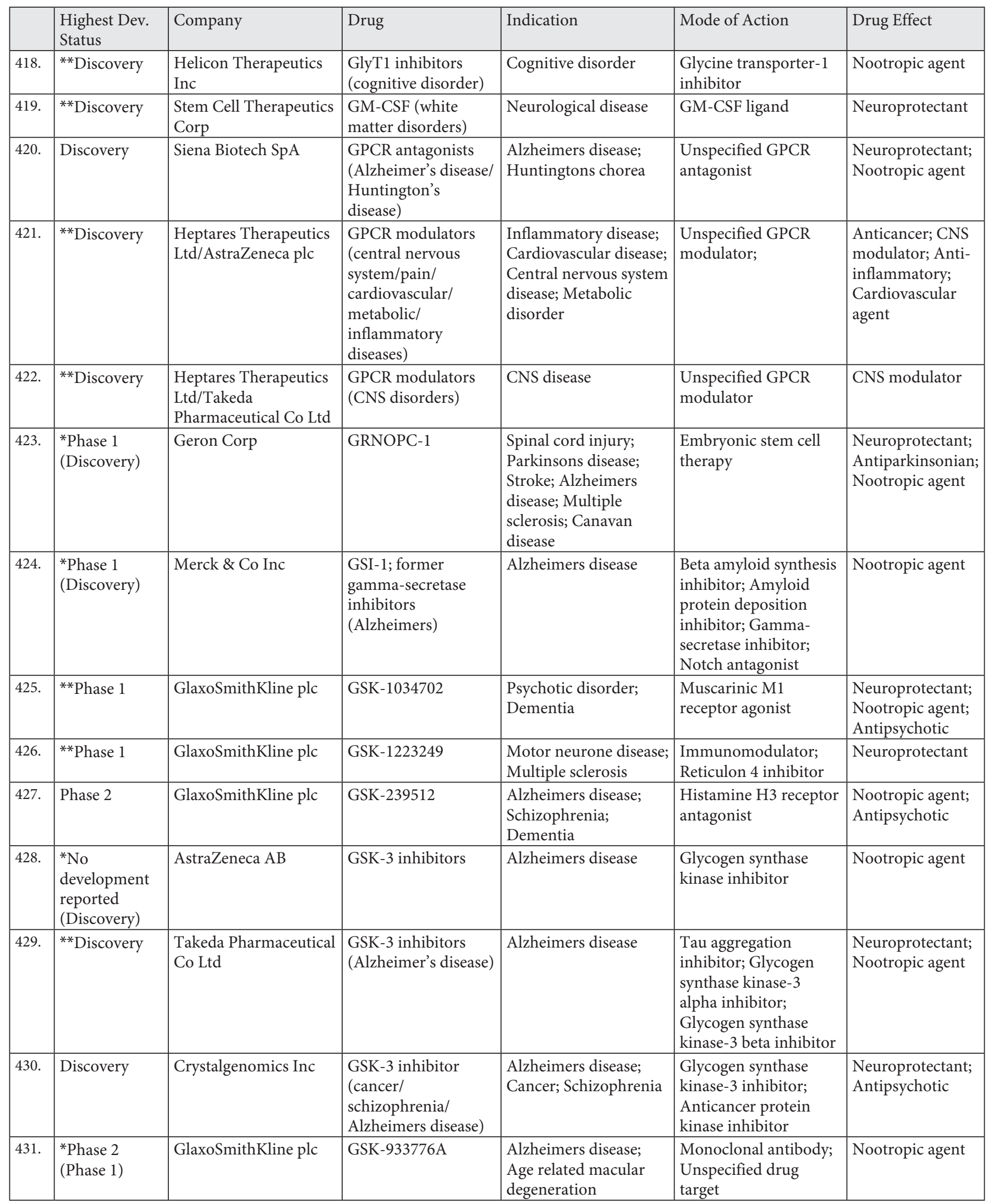




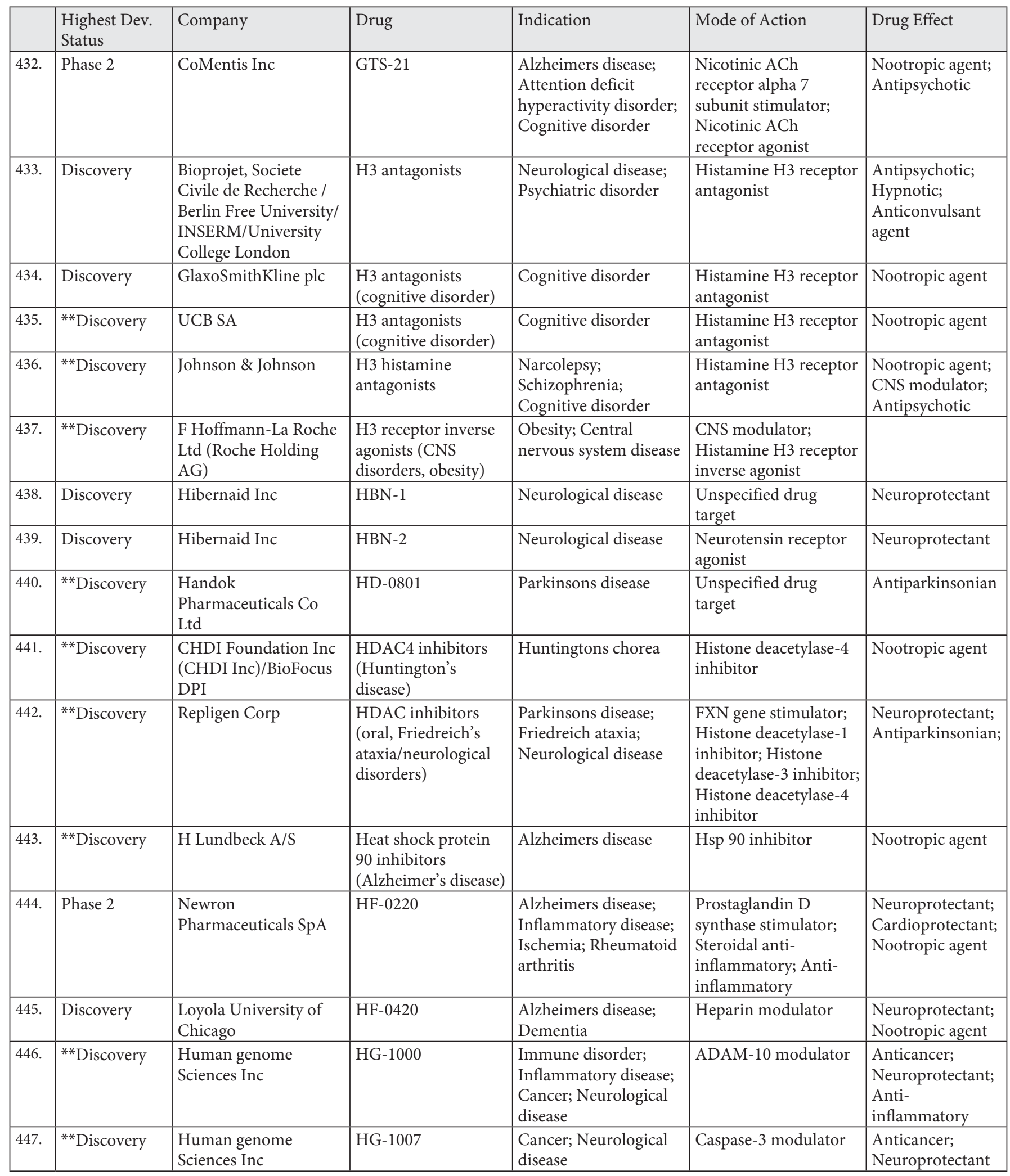




\begin{tabular}{|c|c|c|c|c|c|c|}
\hline & $\begin{array}{l}\text { Highest Dev. } \\
\text { Status }\end{array}$ & Company & Drug & Indication & Mode of Action & Drug Effect \\
\hline 448. & ${ }^{* *}$ Discovery & $\begin{array}{l}\text { Human genome } \\
\text { Sciences Inc }\end{array}$ & HG-1015 & Neurological disease & $\begin{array}{l}\text { Acetylcholine } \\
\text { transferase modulator; } \\
\text { Carnitine } \\
\text { O-acetyltransferase } \\
\text { modulator }\end{array}$ & Neuroprotectant \\
\hline 449. & **Discovery & $\begin{array}{l}\text { Human genome } \\
\text { Sciences Inc }\end{array}$ & HG-1027 & $\begin{array}{l}\text { Cancer; Neurological } \\
\text { disease }\end{array}$ & $\begin{array}{l}\text { Brain fatty acid } \\
\text { binding protein } \\
\text { modulator }\end{array}$ & $\begin{array}{l}\text { Anticancer; } \\
\text { Neuroprotectant }\end{array}$ \\
\hline 450. & ${ }^{* *}$ Discovery & $\begin{array}{l}\text { Human genome } \\
\text { Sciences Inc }\end{array}$ & HG-1029 & Neurological disease & $\begin{array}{l}\text { FGF-11 ligand } \\
\text { modulator; FGF-14 } \\
\text { ligand modulator }\end{array}$ & Neuroprotectant \\
\hline 451. & **Discovery & $\begin{array}{l}\text { Human genome } \\
\text { Sciences Inc }\end{array}$ & HG-1031 & Neurological disease & $\begin{array}{l}\text { FGF-11 ligand } \\
\text { modulator; FGF-13 } \\
\text { ligand modulator }\end{array}$ & Neuroprotectant \\
\hline 453. & **Discovery & $\begin{array}{l}\text { Human genome } \\
\text { Sciences Inc }\end{array}$ & HG-1033 & Neurological disease & $\begin{array}{l}\text { GABA A receptor } \\
\text { subunit modulator }\end{array}$ & Neuroprotectant \\
\hline 454. & ***Discovery & $\begin{array}{l}\text { Human genome } \\
\text { Sciences Inc }\end{array}$ & HG-1034 & Neurological disease & $\begin{array}{l}\text { GABA A receptor pi } \\
\text { subunit modulator }\end{array}$ & Neuroprotectant \\
\hline 455. & **Discovery & $\begin{array}{l}\text { Human genome } \\
\text { Sciences Inc }\end{array}$ & HG-1035 & Neurological disease & $\begin{array}{l}\text { UDP glucose } \\
\text { 4-epimerase modulator }\end{array}$ & Neuroprotectant \\
\hline 456. & **Discovery & $\begin{array}{l}\text { Human genome } \\
\text { Sciences Inc }\end{array}$ & HG-1042 & Neurological disease & $\begin{array}{l}\text { Endothelin receptor } \\
\text { modulator; Bombesin } \\
\text { receptor modulator }\end{array}$ & Neuroprotectant \\
\hline 457. & ${ }^{* *}$ Discovery & $\begin{array}{l}\text { Human genome } \\
\text { Sciences Inc }\end{array}$ & HG-1044 & Neurological disease & $\begin{array}{l}\text { Orexin } 1 \text { receptor } \\
\text { modulator }\end{array}$ & Neuroprotectant \\
\hline 461. & **Discovery & $\begin{array}{l}\text { Human genome } \\
\text { Sciences Inc }\end{array}$ & HG-1056 & $\begin{array}{l}\text { Cardiovascular disease; } \\
\text { Neurological disease }\end{array}$ & $\begin{array}{l}\text { Voltage gated } \\
\text { potassium channel } \\
\text { modulator; } \\
\text { Cardiovascular agent } \\
\end{array}$ & Neuroprotectant \\
\hline 462. & ${ }^{* *}$ Discovery & $\begin{array}{l}\text { Human genome } \\
\text { Sciences Inc }\end{array}$ & HG-1075 & Neurological disease & $\begin{array}{l}\text { Neuroserpin } \\
\text { modulator }\end{array}$ & Neuroprotectant \\
\hline 463. & **Discovery & $\begin{array}{l}\text { Human genome } \\
\text { Sciences Inc }\end{array}$ & HG-1082 & $\begin{array}{l}\text { Cancer; Neurological } \\
\text { disease }\end{array}$ & $\begin{array}{l}\text { RXRG gene modulator; } \\
\text { Retinoid X receptor } \\
\text { gamma modulator }\end{array}$ & $\begin{array}{l}\text { Anticancer; } \\
\text { Neuroprotectant }\end{array}$ \\
\hline 464. & **Discovery & $\begin{array}{l}\text { Human genome } \\
\text { Sciences Inc }\end{array}$ & HG-1098 & Neurological disease & $\begin{array}{l}\text { Chromaffin granule } \\
\text { amine transporter } \\
\text { modulator }\end{array}$ & Neuroprotectant \\
\hline 465. & **Discovery & $\begin{array}{l}\text { Human genome } \\
\text { Sciences Inc }\end{array}$ & HG-1099 & $\begin{array}{l}\text { Cancer; Neurological } \\
\text { disease }\end{array}$ & $\begin{array}{l}\text { Synuclein gamma } \\
\text { modulator }\end{array}$ & $\begin{array}{l}\text { Anticancer; } \\
\text { Neuroprotectant }\end{array}$ \\
\hline 466. & ${ }^{* *}$ Discovery & $\begin{array}{l}\text { Human genome } \\
\text { Sciences Inc }\end{array}$ & HG-1000 & $\begin{array}{l}\text { Cardiovascular disease; } \\
\text { Neurological disease }\end{array}$ & $\begin{array}{l}\text { Stanniocalcin } 1 \text { ligand } \\
\text { modulator }\end{array}$ & $\begin{array}{l}\text { Neuroprotectant; } \\
\text { Cardiovascular } \\
\text { agent }\end{array}$ \\
\hline
\end{tabular}




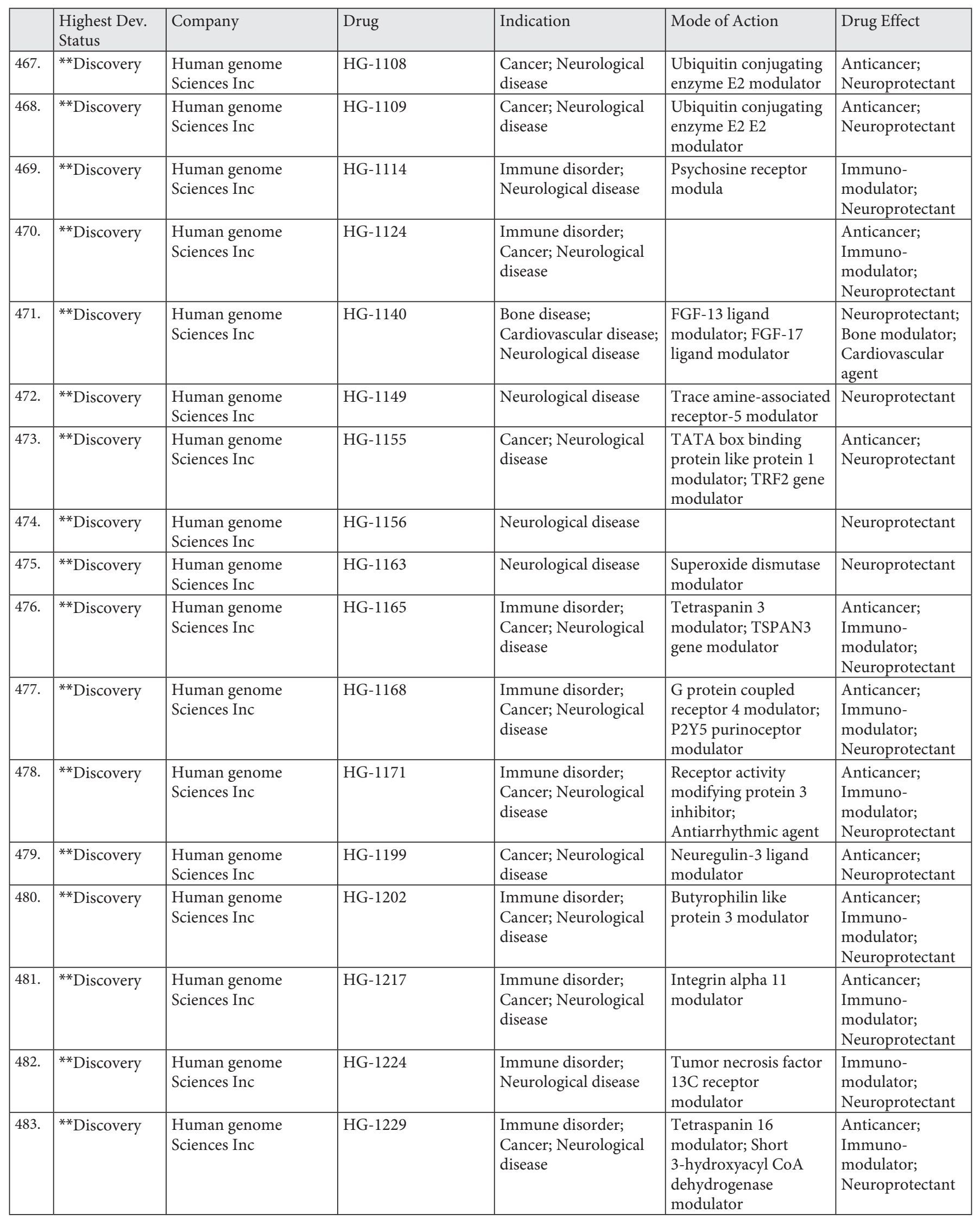




\begin{tabular}{|c|c|c|c|c|c|c|}
\hline & $\begin{array}{l}\text { Highest Dev. } \\
\text { Status }\end{array}$ & Company & Drug & Indication & Mode of Action & Drug Effect \\
\hline 484. & ${ }^{* *}$ Discovery & $\begin{array}{l}\text { Human genome } \\
\text { Sciences Inc }\end{array}$ & HG-1230 & $\begin{array}{l}\text { Immune disorder; } \\
\text { Cancer; Neurological } \\
\text { disease }\end{array}$ & $\begin{array}{l}\text { Sialic acid-binding Ig- } \\
\text { like lectin } 7 \text { modulator; } \\
\text { Sialic acid-binding Ig- } \\
\text { like lectin } 9 \text { modulator }\end{array}$ & $\begin{array}{l}\text { Anticancer; } \\
\text { Immuno- } \\
\text { modulator; } \\
\text { Neuroprotectant }\end{array}$ \\
\hline 485. & ${ }^{* *}$ Discovery & $\begin{array}{l}\text { Human genome } \\
\text { Sciences Inc }\end{array}$ & HG-1232 & $\begin{array}{l}\text { Cancer; Neurological } \\
\text { disease }\end{array}$ & $\begin{array}{l}\text { Dickkopf-3 ligand } \\
\text { modulator }\end{array}$ & $\begin{array}{l}\text { Anticancer; } \\
\text { Neuroprotectant }\end{array}$ \\
\hline 487. & **Discovery & $\begin{array}{l}\text { Human genome } \\
\text { Sciences Inc }\end{array}$ & HG-1249 & Neurological disease & $\begin{array}{l}\text { Vanilloid VR2 receptor } \\
\text { modulator }\end{array}$ & Neuroprotectant \\
\hline 488. & **Discovery & $\begin{array}{l}\text { Human genome } \\
\text { Sciences Inc }\end{array}$ & HG-1251 & Neurological disease & & Neuroprotectant \\
\hline 490. & **Discovery & $\begin{array}{l}\text { Human genome } \\
\text { Sciences Inc }\end{array}$ & HG-1259 & $\begin{array}{l}\text { Cancer; Neurological } \\
\text { disease }\end{array}$ & \begin{tabular}{|l} 
Mammalian \\
ependymin related \\
protein 1 modulator
\end{tabular} & $\begin{array}{l}\text { Anticancer; } \\
\text { Neuroprotectant }\end{array}$ \\
\hline 491. & **Discovery & $\begin{array}{l}\text { Human genome } \\
\text { Sciences Inc }\end{array}$ & HG-1287 & $\begin{array}{l}\text { Cardiovascular disease; } \\
\text { Neurological disease }\end{array}$ & $\begin{array}{l}\text { Membrane metallo- } \\
\text { endopeptidase-like } 1 \\
\text { modulator }\end{array}$ & $\begin{array}{l}\text { Cardiovascular } \\
\text { agent; } \\
\text { Neuroprotectant }\end{array}$ \\
\hline 492. & **Discovery & $\begin{array}{l}\text { Human genome } \\
\text { Sciences Inc }\end{array}$ & HG-1291 & $\begin{array}{l}\text { Immune disorder; } \\
\text { Cancer; Neurological } \\
\text { disease }\end{array}$ & & $\begin{array}{l}\text { Anticancer; } \\
\text { Immuno- } \\
\text { modulator; } \\
\text { Neuroprotectant }\end{array}$ \\
\hline 493. & ${ }^{* *}$ Discovery & $\begin{array}{l}\text { Human genome } \\
\text { Sciences Inc }\end{array}$ & HG-1308 & $\begin{array}{l}\text { Immune disorder; } \\
\text { Cancer; Neurological } \\
\text { disease }\end{array}$ & $\begin{array}{l}\text { Sialic acid-binding Ig- } \\
\text { like lectin } 10 \\
\text { modulator; Sialic acid- } \\
\text { binding Ig-like lectin } \\
11 \text { modulator } \\
\end{array}$ & $\begin{array}{l}\text { Anticancer; } \\
\text { Immuno- } \\
\text { modulator; } \\
\text { Neuroprotectant }\end{array}$ \\
\hline 495. & ${ }^{* *}$ Discovery & $\begin{array}{l}\text { Human genome } \\
\text { Sciences Inc }\end{array}$ & HG-1336 & Neurological disease & \begin{tabular}{|l|} 
NTT4 \\
neurotransmitter \\
transporter modulator
\end{tabular} & Neuroprotectant \\
\hline 496. & **Discovery & $\begin{array}{l}\text { Human genome } \\
\text { Sciences Inc }\end{array}$ & HG-1344 & $\begin{array}{l}\text { Cancer; Neurological } \\
\text { disease }\end{array}$ & $\begin{array}{l}\text { Ubiquitin conjugating } \\
\text { enzyme E2L3 } \\
\text { modulator } \\
\end{array}$ & $\begin{array}{l}\text { Anticancer; } \\
\text { Neuroprotectant }\end{array}$ \\
\hline 497. & ${ }^{* *}$ Discovery & $\begin{array}{l}\text { Human genome } \\
\text { Sciences Inc }\end{array}$ & HG-1345 & $\begin{array}{l}\text { Cancer; Neurological } \\
\text { disease }\end{array}$ & $\begin{array}{l}\text { Cysteine protease } \\
\text { modulator; Caspase-7 } \\
\text { modulator; } \mathrm{MCH} \\
\text { receptor-1 modulator }\end{array}$ & $\begin{array}{l}\text { Anticancer; } \\
\text { Neuroprotectant }\end{array}$ \\
\hline 498. & **Discovery & $\begin{array}{l}\text { Human genome } \\
\text { Sciences Inc }\end{array}$ & HG-1359 & $\begin{array}{l}\text { Immune disorder; } \\
\text { Cancer; Neurological } \\
\text { disease }\end{array}$ & $\begin{array}{l}\text { G protein coupled } 1 \\
\text { receptor modulator }\end{array}$ & $\begin{array}{l}\text { Anticancer; } \\
\text { Immuno- } \\
\text { modulator; } \\
\text { Neuroprotectant }\end{array}$ \\
\hline 499. & ${ }^{* *}$ Discovery & $\begin{array}{l}\text { Human genome } \\
\text { Sciences Inc }\end{array}$ & HG-1383 & $\begin{array}{l}\text { Immune disorder; } \\
\text { Cancer; Neurological } \\
\text { disease }\end{array}$ & Opticin modulator & $\begin{array}{l}\text { Anticancer; } \\
\text { Immuno- } \\
\text { modulator; } \\
\text { Neuroprotectant } \\
\end{array}$ \\
\hline 500. & ${ }^{* *}$ Discovery & $\begin{array}{l}\text { Human genome } \\
\text { Sciences Inc }\end{array}$ & HG-1436 & $\begin{array}{l}\text { Cancer; Neurological } \\
\text { disease }\end{array}$ & & $\begin{array}{l}\text { Anticancer; } \\
\text { Neuroprotectant }\end{array}$ \\
\hline
\end{tabular}




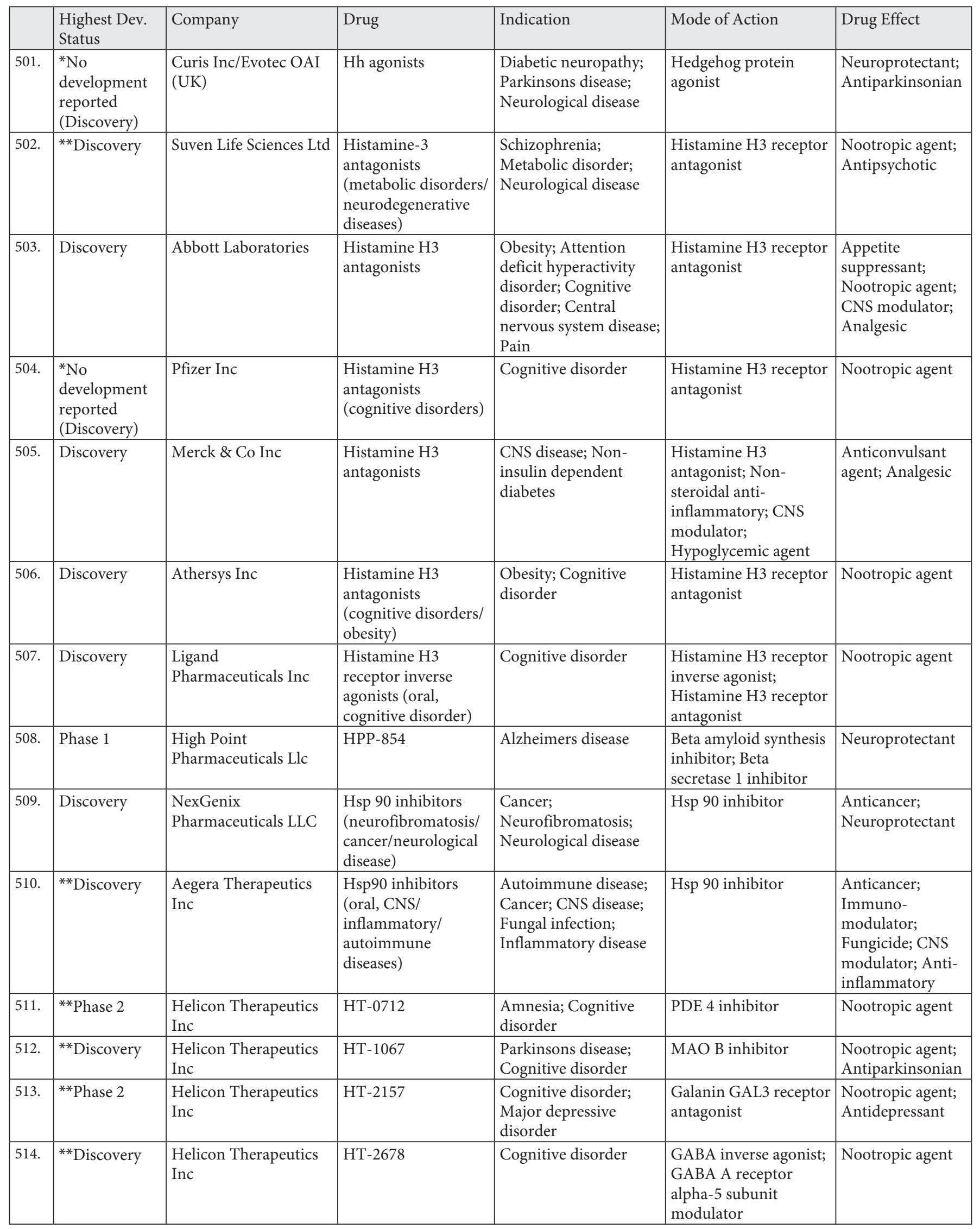




\begin{tabular}{|c|c|c|c|c|c|c|}
\hline & $\begin{array}{l}\text { Highest Dev. } \\
\text { Status }\end{array}$ & Company & Drug & Indication & Mode of Action & Drug Effect \\
\hline 515. & **Discovery & Siena Biotech SpA & \begin{tabular}{|l|} 
Htt-mediated \\
toxicity inhibitors \\
(Huntington's \\
disease) \\
\end{tabular} & Huntingtons chorea & Huntingtin inhibitor & Neuroprotectant \\
\hline 516. & Phase 2 & Global Biotech Inc & HTU-PA & $\begin{array}{l}\text { Myocardial infarction; } \\
\text { Stroke }\end{array}$ & $\begin{array}{l}\text { Kallikrein modulator; } \\
\text { Urokinase } \\
\text { plasminogen activator } \\
\text { stimulator }\end{array}$ & \\
\hline 517. & Phase 2 & $\begin{array}{l}\text { Stem Cell Therapeutics } \\
\text { Corp }\end{array}$ & $\begin{array}{l}\text { Human chorionic } \\
\text { gonadotropin + } \\
\text { erythropoietin (im, } \\
\text { stroke/brain injury/ } \\
\text { neurodegenerative } \\
\text { diseases/multiple } \\
\text { sclerosis/myocardial } \\
\text { infarction) } \\
\end{array}$ & $\begin{array}{l}\text { Neurodegenerative } \\
\text { disease; Stroke; } \\
\text { Multiple sclerosis; } \\
\text { Myocardial infarction; } \\
\text { Brain injury }\end{array}$ & $\begin{array}{l}\text { Chorionic } \\
\text { gonadotropin ligand; } \\
\text { Erythropoietin ligand }\end{array}$ & $\begin{array}{l}\text { Neuroprotectant; } \\
\text { Cardiac agent }\end{array}$ \\
\hline 519. & Discovery & Probiodrug AG & $\begin{array}{l}\text { Human glutaminyl } \\
\text { cyclase inhibitors } \\
\text { (Alzheimer's disease) }\end{array}$ & Alzheimers disease & $\begin{array}{l}\text { Amyloid protein } \\
\text { deposition inhibitor; } \\
\text { Glutaminyl peptide } \\
\text { cyclotransferase } \\
\text { inhibitor } \\
\end{array}$ & Neuroprotectant \\
\hline 520. & $\begin{array}{l}{ }^{*} \text { Phase } 2 \\
\text { (Phase } 1)\end{array}$ & StemCells Inc & $\begin{array}{l}\text { Human neural stem } \\
\text { cell therapy }\end{array}$ & $\begin{array}{l}\text { Central nervous system } \\
\text { disease; Spinal cord } \\
\text { injury; Retinopathy; } \\
\text { Demyelinating disease; } \\
\text { Jansky-Bielschowsky } \\
\text { disease; Santavuori- } \\
\text { Haltia disease; } \\
\text { Alzheimers disease } \\
\end{array}$ & Stem cell stimulator & $\begin{array}{l}\text { Neuroprotectant; } \\
\text { Nootropic agent }\end{array}$ \\
\hline 522. & $\begin{array}{l}{ }^{*} \mathrm{No} \\
\text { development } \\
\text { reported } \\
\text { (Discovery) }\end{array}$ & Auril AB & $\begin{array}{l}\text { Hypothermic } \\
\text { therapy (ischemia) }\end{array}$ & Ischemia & $\begin{array}{l}\text { Unspecified drug } \\
\text { target }\end{array}$ & Protectant \\
\hline 523. & Phase 2 & MediciNova Inc & $\begin{array}{l}\text { Ibudilast (oral, } \\
\text { neuropathic pain/ } \\
\text { opiate dependence/ } \\
\text { neurodegeneration) }\end{array}$ & $\begin{array}{l}\text { Neurodegenerative } \\
\text { disease; Amphetamine } \\
\text { dependence; Opiate } \\
\text { dependence }\end{array}$ & $\begin{array}{l}\text { IL-1 beta ligand } \\
\text { inhibitor; TNF alpha } \\
\text { ligand inhibitor; IL-6 } \\
\text { antagonist; TLR-4 } \\
\text { antagonist; IL-10 } \\
\text { modulator }\end{array}$ & $\begin{array}{l}\text { Neuroprotectant; } \\
\text { Analgesic; Anti- } \\
\text { inflammatory }\end{array}$ \\
\hline 524. & Phase 2 & MediciNova Inc & Ibudilast & $\begin{array}{l}\text { Multiple sclerosis; } \\
\text { Neurological disease }\end{array}$ & $\begin{array}{l}\text { Leukotriene D4 } \\
\text { antagonist; PDE } 10 \\
\text { inhibitor; PDE } 11 \\
\text { inhibitor; NO synthesis } \\
\text { inhibitor; PDE } 4 \\
\text { inhibitor; Platelet } \\
\text { activating factor } \\
\text { receptor antagonist; } \\
\text { Macrophage migration } \\
\text { inhibitory factor } \\
\text { inhibitor }\end{array}$ & $\begin{array}{l}\text { Neuroprotectant; } \\
\text { Vasodilator }\end{array}$ \\
\hline
\end{tabular}




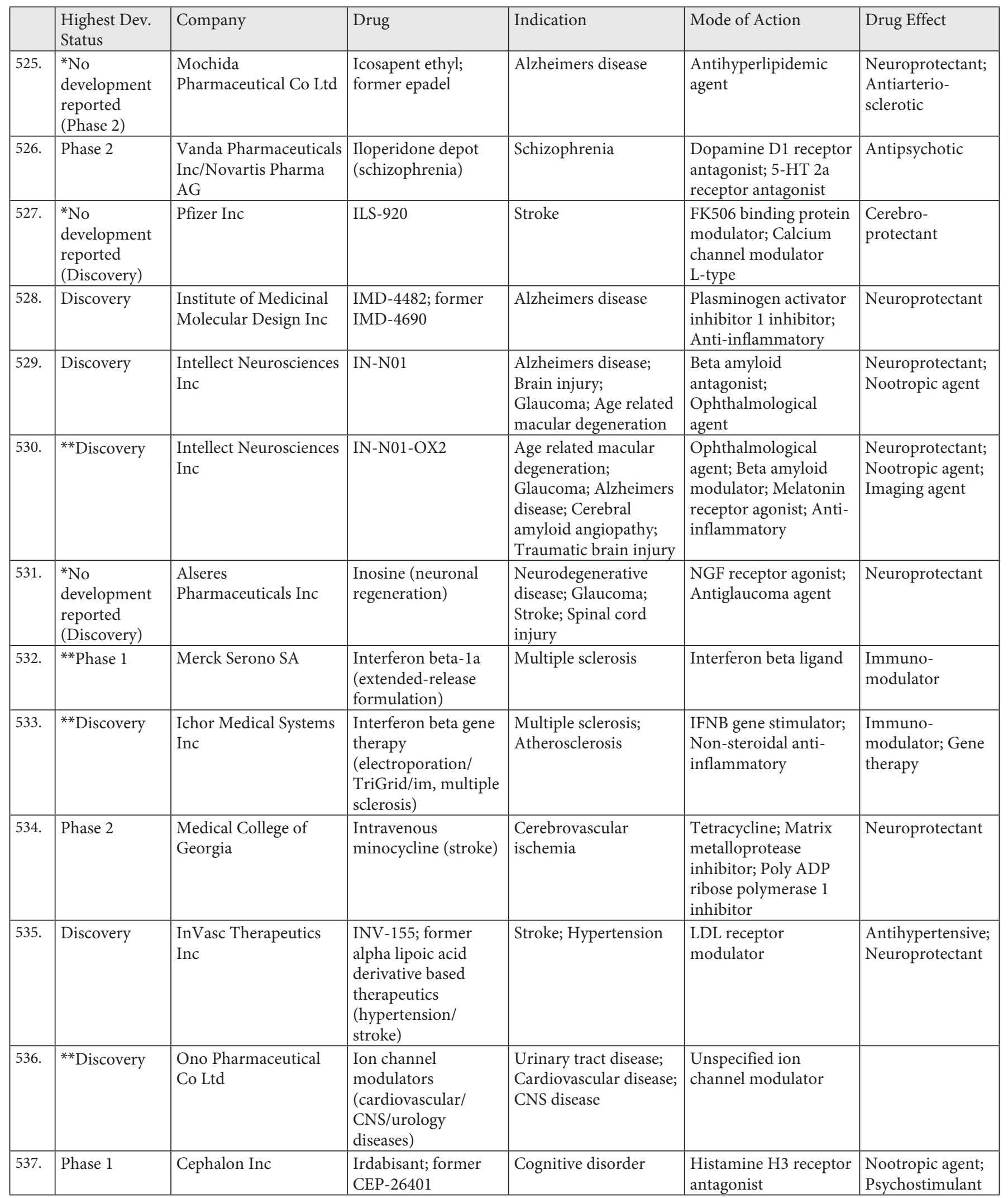




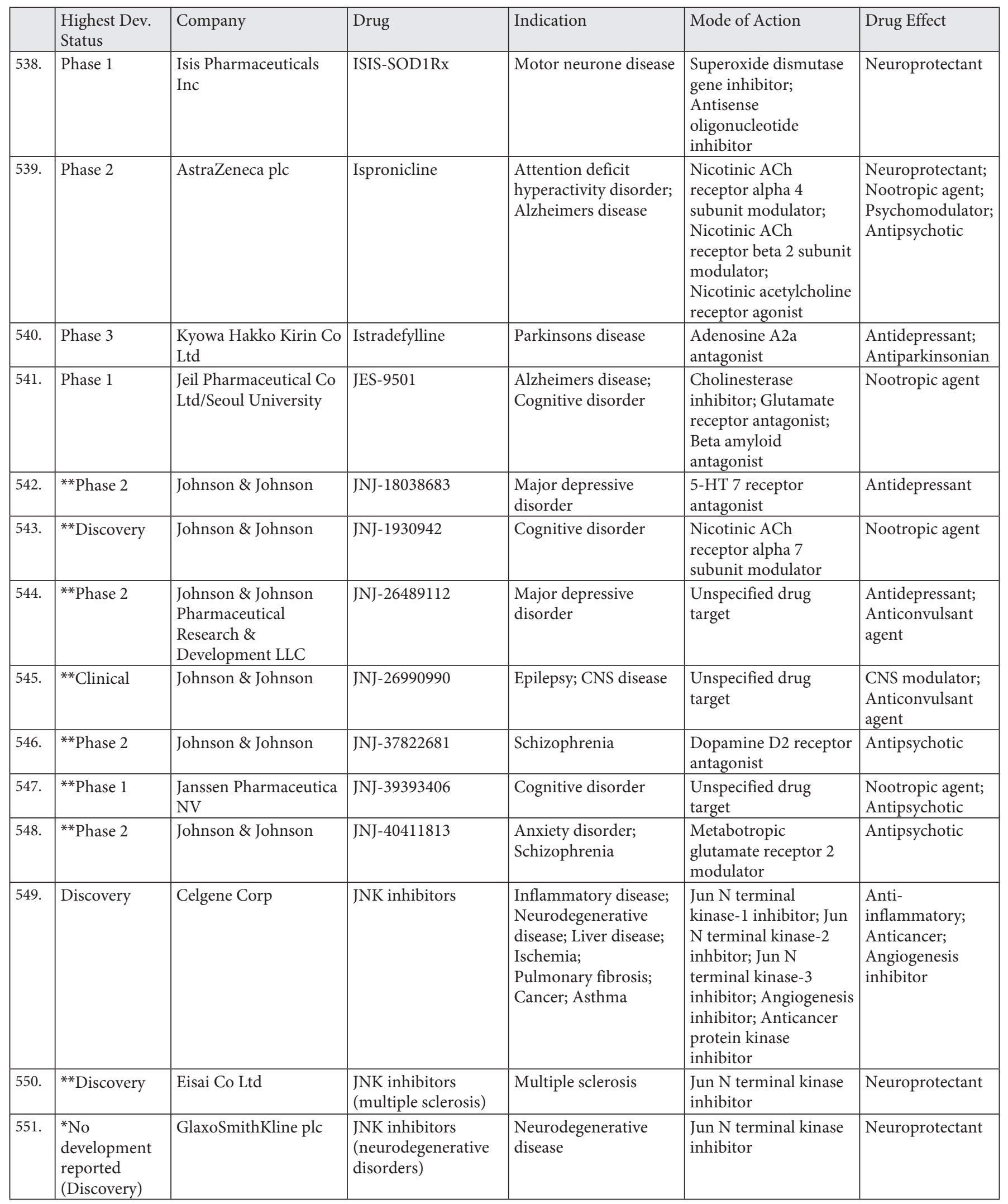




\begin{tabular}{|c|c|c|c|c|c|c|}
\hline & $\begin{array}{l}\text { Highest Dev. } \\
\text { Status }\end{array}$ & Company & Drug & Indication & Mode of Action & Drug Effect \\
\hline 552. & Discovery & Elan Corp plc & \begin{tabular}{|l} 
JNK3 inhibitors \\
(neuronal injury/ \\
neurodegenerative \\
disease)
\end{tabular} & $\begin{array}{l}\text { Central nervous system } \\
\text { injury; } \\
\text { Neurodegenerative } \\
\text { disease } \\
\end{array}$ & $\begin{array}{l}\text { Jun } \mathrm{N} \text { terminal } \\
\text { kinase-3 inhibitor }\end{array}$ & Neuroprotectant \\
\hline 553. & Phase 2 & $\begin{array}{l}\text { Kwang Dong } \\
\text { Pharmaceutical Co Ltd }\end{array}$ & KD-501 & Alzheimers disease & $\begin{array}{l}\text { Unspecified drug } \\
\text { target }\end{array}$ & Nootropic agent \\
\hline 555. & ${ }^{* *}$ Discovery & $\begin{array}{l}\text { Kyowa Hakko Kirin Co } \\
\text { Ltd }\end{array}$ & Ki-20227 & $\begin{array}{l}\text { Bone metastases; } \\
\text { Multiple sclerosis; } \\
\text { Bone disease }\end{array}$ & $\begin{array}{l}\text { CSF-1 antagonist; } \\
\text { Protein tyrosine kinase } \\
\text { inhibitor }\end{array}$ & Anticancer \\
\hline 556. & Discovery & Amnestix Inc & $\begin{array}{l}\text { KIBRA pathway } \\
\text { modulators } \\
\text { (cognitive } \\
\text { impairment) } \\
\end{array}$ & Cognitive disorder & $\begin{array}{l}\text { WW domain } \\
\text { containing protein } \\
\text { modulator }\end{array}$ & Nootropic agent \\
\hline 558. & ${ }^{* *}$ Discovery & Cellceutix Corp & KM-362 & Neurological disease & $\begin{array}{l}\text { Unspecified drug } \\
\text { target }\end{array}$ & Neuroprotectant \\
\hline 559. & ${ }^{* *}$ Discovery & $\begin{array}{l}\text { Korea Institute of } \\
\text { Science and } \\
\text { Technology/Seoul } \\
\text { National University/ } \\
\text { Hanmi Pharmaceutical } \\
\text { Co Ltd } \\
\end{array}$ & KMS-88 series & Alzheimers disease & $\begin{array}{l}\text { Beta amyloid } \\
\text { antagonist }\end{array}$ & Neuroprotectant \\
\hline 560. & Phase 2 & $\begin{array}{l}\text { KeyNeurotek } \\
\text { Pharmaceuticals AG }\end{array}$ & KN-38-7271 & Stroke; Brain injury & $\begin{array}{l}\text { Cannabinoid CB1 } \\
\text { receptor agonist; } \\
\text { Cannabinoid CB2 } \\
\text { receptor agonist } \\
\end{array}$ & $\begin{array}{l}\text { Neuroprotectant; } \\
\text { Analgesic }\end{array}$ \\
\hline 564. & **Discovery & $\begin{array}{l}\text { Kyungpook National } \\
\text { University }\end{array}$ & KR-31360 & $\begin{array}{l}\text { Nervous system } \\
\text { inflammation }\end{array}$ & $\begin{array}{l}\text { Unspecified drug } \\
\text { target }\end{array}$ & $\begin{array}{l}\text { Anti- } \\
\text { inflammatory }\end{array}$ \\
\hline 565. & ${ }^{* *}$ Phase 2 & $\begin{array}{l}\text { Kyorin Pharmaceutical } \\
\text { Co Ltd (Kyorin } \\
\text { Holdings Inc)/Novartis } \\
\text { AG }\end{array}$ & KRP-203 & $\begin{array}{l}\text { Inflammatory bowel } \\
\text { disease; Multiple } \\
\text { sclerosis; Cutaneous } \\
\text { lupus erythematosus; } \\
\text { Ulcerative colitis; } \\
\text { Transplant rejection; } \\
\text { Graft versus host } \\
\text { disease } \\
\end{array}$ & $\begin{array}{l}\text { Sphingosine-1- } \\
\text { phosphate receptor-1 } \\
\text { agonist }\end{array}$ & $\begin{array}{l}\text { Immuno- } \\
\text { suppressant; }\end{array}$ \\
\hline 566. & Discovery & $\begin{array}{l}\text { Kareus Therapeutics } \\
\text { Llc/Connexios Life } \\
\text { Sciences Pvt Ltd }\end{array}$ & $\begin{array}{l}\text { KU-046; former drug } \\
\text { combination } \\
\text { (Alzheimer's disease) }\end{array}$ & Alzheimers disease & $\begin{array}{l}\text { Unspecified drug } \\
\text { target }\end{array}$ & Neuroprotectant \\
\hline 567. & **Discovery & Merck Serono SA & $\begin{array}{l}\text { Kv1.3 potassium } \\
\text { channel blockers } \\
\text { (multiple sclerosis) }\end{array}$ & $\begin{array}{l}\text { Multiple sclerosis; } \\
\text { Autoimmune disease }\end{array}$ & $\begin{array}{l}\text { KCNA voltage-gated } \\
\text { potassium channel-3 } \\
\text { inhibitor; Anti- } \\
\text { inflammatory }\end{array}$ & Neuroprotectant \\
\hline
\end{tabular}




\begin{tabular}{|c|c|c|c|c|c|c|}
\hline & $\begin{array}{l}\text { Highest Dev. } \\
\text { Status }\end{array}$ & Company & Drug & Indication & Mode of Action & Drug Effect \\
\hline 568. & **Discovery & $\begin{array}{l}\text { CHDI Foundation Inc } \\
\text { (CHDI Inc)/Evotec AG }\end{array}$ & \begin{tabular}{|l|} 
Kynurenine mono- \\
oxygenase inhibitors \\
(Huntington's \\
disease) \\
\end{tabular} & Huntingtons chorea & $\begin{array}{l}\text { Kynurenine } \\
\text { 3-hydroxylase } \\
\text { inhibitor }\end{array}$ & Nootropic agent \\
\hline 569. & $\begin{array}{l}{ }^{*} \text { No } \\
\text { development } \\
\text { reported } \\
\text { (Phase 3) }\end{array}$ & Schwarz Pharma AG & Lacosamide & $\begin{array}{l}\text { Neuropathic pain; } \\
\text { Migraine }\end{array}$ & $\begin{array}{l}\text { Sodium channel } \\
\text { modulator; } \\
\text { Dihydropyrimidinase } \\
\text { related protein } 2\end{array}$ & $\begin{array}{l}\text { Analgesic; } \\
\text { Anticonvulsant } \\
\text { agent }\end{array}$ \\
\hline 570. & Phase 2 & $\begin{array}{l}\text { Avraham } \\
\text { Pharmaceuticals Ltd }\end{array}$ & Ladostigil & $\begin{array}{l}\text { Alzheimers disease; } \\
\text { Mild cognitive } \\
\text { impairment }\end{array}$ & $\begin{array}{l}\text { Acetylcholinesterase } \\
\text { inhibitor; MAO B } \\
\text { inhibitor }\end{array}$ & $\begin{array}{l}\text { Neuroprotectant; } \\
\text { Nootropic agent }\end{array}$ \\
\hline 571. & **Phase 3 & $\begin{array}{l}\text { Teva Pharmaceutical } \\
\text { Industries Ltd }\end{array}$ & Laquinimod & $\begin{array}{l}\text { Multiple sclerosis; } \\
\text { Lupus nephritis; } \\
\text { Systemic lupus } \\
\text { erythematosus; Crohns } \\
\text { disease }\end{array}$ & $\begin{array}{l}\text { Unspecified drug } \\
\text { target }\end{array}$ & $\begin{array}{l}\text { Neuroprotectant; } \\
\text { Anti- } \\
\text { inflammatory; } \\
\text { Immuno- } \\
\text { suppressant }\end{array}$ \\
\hline 573. & ${ }^{* *}$ Discovery & $\begin{array}{l}\text { Almirall Prodesfarma } \\
\text { SA }\end{array}$ & LAS-189913 & Multiple sclerosis & Immunomodulator & $\begin{array}{l}\text { Sphingosine 1 } \\
\text { phosphate } \\
\text { phosphatase 1 } \\
\text { inhibitor } \\
\end{array}$ \\
\hline 574. & Phase 3 & $\begin{array}{l}\text { Medivation Inc/Pfizer } \\
\text { Inc }\end{array}$ & Latrepirdine & Alzheimers disease & $\begin{array}{l}\text { Energy metabolism } \\
\text { modulator }\end{array}$ & Nootropic agent \\
\hline 575. & ** Discovery & Biovista Inc & $\begin{array}{l}\text { Latrepirdine (oral, } \\
\text { epilepsy) }\end{array}$ & Epilepsy & Anticonvulsant agent & Neuroprotectant \\
\hline 576. & ${ }^{* *}$ Discovery & Biovista Inc & $\begin{array}{l}\text { Latrepirdine (oral, } \\
\text { multiple sclerosis) }\end{array}$ & Multiple sclerosis & Immunomodulator & $\begin{array}{l}\text { Neuroprotectant; } \\
\text { Anticonvulsant } \\
\text { agent }\end{array}$ \\
\hline 578. & Discovery & Neurotez Inc & $\begin{array}{l}\text { Leptin (Alzheimer's } \\
\text { disease) }\end{array}$ & Alzheimers disease & $\begin{array}{l}\text { Beta amyloid synthesis } \\
\text { inhibitor; Leptin ligand }\end{array}$ & \\
\hline 579. & $\begin{array}{l}{ }^{*} \text { No } \\
\text { development } \\
\text { reported } \\
\text { (Discovery) } \\
\end{array}$ & $\begin{array}{l}\text { Spectrum } \\
\text { Pharmaceuticals Inc }\end{array}$ & Leteprinim & Neuropathy & $\begin{array}{l}\text { FGF receptor agonist; } \\
\text { NGF receptor agonist }\end{array}$ & $\begin{array}{l}\text { Neuroprotectant; } \\
\text { Nootropic agent; } \\
\text { Antiparkinsonian }\end{array}$ \\
\hline 580. & **Discovery & $\begin{array}{l}\text { Sirtris Pharmaceuticals } \\
\text { Inc (GlaxoSmithKline } \\
\text { plc) }\end{array}$ & $\begin{array}{l}\text { Leucine-rich repeat } \\
\text { kinase 2 (LRRK2) } \\
\text { inhibitors } \\
\text { (Parkinson's disease) }\end{array}$ & Parkinsons disease & $\begin{array}{l}\text { Leucine rich serine } \\
\text { threonine kinase } 2 \\
\text { inhibitor }\end{array}$ & Antiparkinsonian \\
\hline 581. & $\begin{array}{l}\text { *Phase } 3 \\
\text { (No } \\
\text { development } \\
\text { reported) } \\
\end{array}$ & $\begin{array}{l}\text { Curaxis } \\
\text { Pharmaceutical Corp/ } \\
\text { DURECT Corp }\end{array}$ & $\begin{array}{l}\text { Leuprolide acetate } \\
\text { implant (Alzheimer's } \\
\text { disease) }\end{array}$ & $\begin{array}{l}\text { Alzheimers disease; } \\
\text { Cancer }\end{array}$ & $\begin{array}{l}\text { GNRH agonist; } \\
\text { Amyloid protein } \\
\text { deposition inhibitor }\end{array}$ & $\begin{array}{l}\text { Nootropic agent; } \\
\text { Anticancer; Anti- } \\
\text { inflammatory }\end{array}$ \\
\hline 582. & Phase 2 & AgeneBio Inc & $\begin{array}{l}\text { Levetiracetam } \\
\text { (amnestic mild } \\
\text { cognitive } \\
\text { impairment) } \\
\end{array}$ & Cognitive disorder & $\begin{array}{l}\text { Synaptic vesicle } \\
\text { glycoprotein } 2 \mathrm{~A} \\
\text { inhibitor }\end{array}$ & Nootropic agent \\
\hline 583. & **Phase 1 & Orion Corp & $\begin{array}{l}\text { Levodopa (optimized } \\
\text { formulation, } \\
\text { Parkinson's disease) }\end{array}$ & Parkinsons disease & $\begin{array}{l}\text { Dopamine receptor } \\
\text { agonist }\end{array}$ & Antiparkinsonian \\
\hline
\end{tabular}




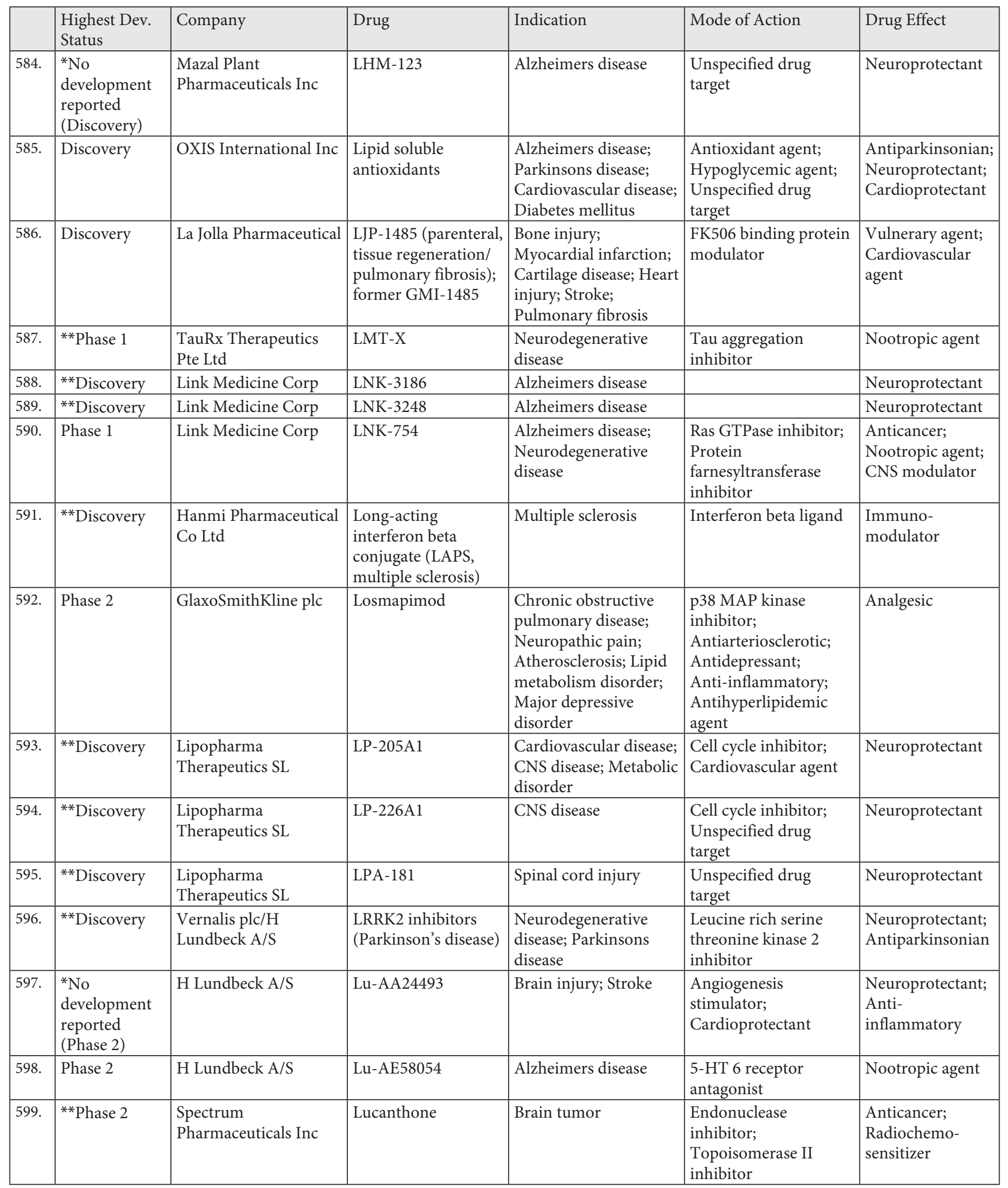




\begin{tabular}{|c|c|c|c|c|c|c|}
\hline & $\begin{array}{l}\text { Highest Dev. } \\
\text { Status }\end{array}$ & Company & Drug & Indication & Mode of Action & Drug Effect \\
\hline 600. & $\begin{array}{l}{ }^{*} \text { Launched } \\
\text { (Pre- } \\
\text { registration) }\end{array}$ & $\begin{array}{l}\text { Dainippon Sumitomo } \\
\text { Pharma Co Ltd }\end{array}$ & Lurasidone & $\begin{array}{l}\text { Schizophrenia; Bipolar } \\
\text { disorder; Major } \\
\text { depressive disorder }\end{array}$ & $\begin{array}{l}\text { Dopamine D2 receptor } \\
\text { antagonist; 5-HT 1a } \\
\text { receptor partial } \\
\text { agonist; 5-HT } 7 \\
\text { receptor antagonist; } \\
\text { 5-HT 2a receptor } \\
\text { antagonist; Alpha 2C } \\
\text { adrenoceptor } \\
\text { modulator }\end{array}$ & $\begin{array}{l}\text { Antipsychotic; } \\
\text { Antidepressant }\end{array}$ \\
\hline 601. & **Discovery & $\begin{array}{l}\text { Dainippon Sumitomo } \\
\text { Pharma Co Ltd }\end{array}$ & $\begin{array}{l}\text { Lurasidone } \\
\text { (extended release/ } \\
\text { injectable, } \\
\text { schizophrenia) }\end{array}$ & Schizophrenia & $\begin{array}{l}\text { Dopamine D2 receptor } \\
\text { antagonist; 5-HT } 7 \\
\text { receptor antagonist; } \\
\text { 5-HT 2a receptor } \\
\text { antagonist; Alpha 2C } \\
\text { adrenoceptor } \\
\text { modulator; 5-HT 1a } \\
\text { receptor antagonist } \\
\end{array}$ & Antipsychotic \\
\hline 602. & Discovery & AstraZeneca plc & $\begin{array}{l}\text { LXR agonists } \\
\text { (atherosclerosis/ } \\
\text { dyslipidemia/ } \\
\text { Alzheimer's disease) } \\
\end{array}$ & $\begin{array}{l}\text { Alzheimers disease; } \\
\text { Atherosclerosis; } \\
\text { Lipid metabolism } \\
\text { disorder } \\
\end{array}$ & \begin{tabular}{|l|} 
Lipid metabolism \\
modulator; \\
Liver X receptor \\
agonist \\
\end{tabular} & $\begin{array}{l}\text { Antiarterio- } \\
\text { sclerotic; } \\
\text { Nootropic agent }\end{array}$ \\
\hline 603. & $\begin{array}{l}\text { *Discontinued } \\
(\text { Phase } 2)\end{array}$ & Eli Lilly \& Co & LY-545694 & Pain & $\begin{array}{l}\text { Ionotropic glutamate } \\
\text { receptor antagonist }\end{array}$ & Analgesic \\
\hline 604. & **Discovery & Eli Lilly \& Co & LY-554862 & Parkinsons disease & PPAR gamma agonist & Antiparkinsonian \\
\hline 605. & ${ }^{* *}$ Discovery & $\begin{array}{l}\text { Acorda Therapeutics } \\
\text { Inc/Mayo Foundation }\end{array}$ & $\begin{array}{l}\text { M1 monoclonal } \\
\text { antibodies }\end{array}$ & CNS disease & $\begin{array}{l}\text { Unspecified drug } \\
\text { target }\end{array}$ & $\begin{array}{l}\text { Neuroprotectant; } \\
\text { CNS modulator }\end{array}$ \\
\hline 606. & Discovery & Merck \& Co Inc & $\begin{array}{l}\text { M1 muscarinic } \\
\text { acetylcholine } \\
\text { receptor agonist } \\
\text { (Alzheimer's } \\
\text { disease); former } \\
\text { BQCA }\end{array}$ & Neurological disease & $\begin{array}{l}\text { Muscarinic M1 } \\
\text { receptor agonist }\end{array}$ & $\begin{array}{l}\text { Neuroprotectant; } \\
\text { Nootropic agent }\end{array}$ \\
\hline 609. & $\begin{array}{l}{ }^{*} \text { Phase } 3 \\
\text { (Phase } 2)\end{array}$ & Novartis AG & $\begin{array}{l}\text { Mavoglurant; former } \\
\text { AFQ-056 }\end{array}$ & $\begin{array}{l}\text { Fragile X syndrome; } \\
\text { Huntingtons chorea; } \\
\text { Movement disorder }\end{array}$ & $\begin{array}{l}\text { Gastrointestinal system } \\
\text { agent; Metabotropic } \\
\text { glutamate receptor } 5 \\
\text { antagonist } \\
\end{array}$ & Anxiolytic \\
\hline 610. & **Discovery & M's Science Corp & MC-113 & CNS disease & $\begin{array}{l}\text { Sigma opioid receptor } \\
\text { agonist }\end{array}$ & CNS modulator \\
\hline 611. & ** Discovery & M's Science Corp & MC-116 & CNS disease & $\begin{array}{l}\text { Opioid receptor sigma } \\
\text { agonist } 1\end{array}$ & CNS modulator \\
\hline 612. & $\begin{array}{l}\text { *No } \\
\text { development } \\
\text { reported } \\
\text { (Discovery) } \\
\end{array}$ & Mithridion Inc & $\begin{array}{l}\text { MCD-386 (high dose } \\
\text { transdermal, } \\
\text { Alzheimer's disease/ } \\
\text { schizophrenia) }\end{array}$ & $\begin{array}{l}\text { Alzheimers disease; } \\
\text { Schizophrenia }\end{array}$ & $\begin{array}{l}\text { Muscarinic M1 } \\
\text { receptor agonist }\end{array}$ & $\begin{array}{l}\text { Nootropic agent; } \\
\text { Neuroprotectant; } \\
\text { Antipsychotic }\end{array}$ \\
\hline 613. & $\begin{array}{l}{ }^{*} \mathrm{No} \\
\text { development } \\
\text { reported } \\
\text { (Discovery) } \\
\end{array}$ & Mithridion Inc & $\begin{array}{l}\text { MCD-386 (high } \\
\text { dose, Alzheimer's } \\
\text { disease/ } \\
\text { schizophrenia) } \\
\end{array}$ & $\begin{array}{l}\text { Alzheimers disease; } \\
\text { Schizophrenia }\end{array}$ & $\begin{array}{l}\text { Muscarinic M1 } \\
\text { receptor agonist }\end{array}$ & $\begin{array}{l}\text { Nootropic agent; } \\
\text { Neuroprotectant; } \\
\text { Antipsychotic }\end{array}$ \\
\hline
\end{tabular}




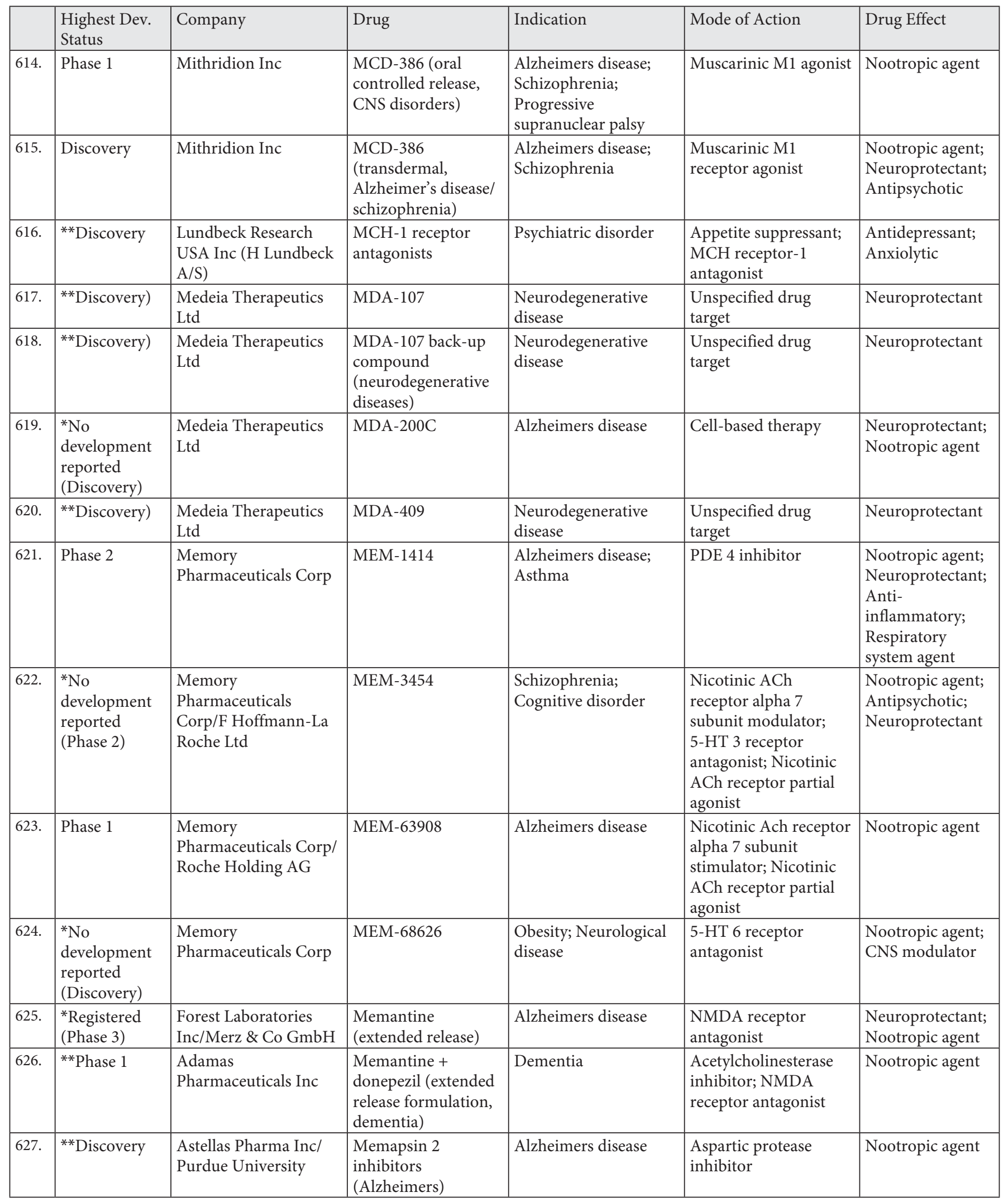




\begin{tabular}{|c|c|c|c|c|c|c|}
\hline & $\begin{array}{l}\text { Highest Dev. } \\
\text { Status }\end{array}$ & Company & Drug & Indication & Mode of Action & Drug Effect \\
\hline 628. & ${ }^{* *}$ Phase 3 & $\begin{array}{l}\text { Raptor } \\
\text { Pharmaceuticals Corp }\end{array}$ & Mercaptamine & $\begin{array}{l}\text { Huntingtons chorea; } \\
\text { Non-alcoholic } \\
\text { steatohepatitis; } \\
\text { Nephropathic } \\
\text { cystinosis }\end{array}$ & $\begin{array}{l}\text { Renal system agent; } \\
\text { Transglutaminase } \\
\text { inhibitor; Gastric } \\
\text { secretion stimulator }\end{array}$ & Neuroprotectant \\
\hline 629. & $\begin{array}{l}{ }^{*} \text { Phase } 2 \\
\text { (Clinical) }\end{array}$ & $\begin{array}{l}\text { Stemedica Cell } \\
\text { Technologies Inc }\end{array}$ & \begin{tabular}{|l|} 
Mesenchymal bone \\
marrow-derived \\
stem cell therapy \\
(intravenous, stroke) \\
\end{tabular} & Stroke & & $\begin{array}{l}\text { Cerebro- } \\
\text { protectant }\end{array}$ \\
\hline 630. & Discovery & Eli Lilly \& Co & $\begin{array}{l}\text { Metabotropic } \\
\text { glutamate receptor } \\
\text { agonists }\end{array}$ & $\begin{array}{l}\text { Neurodegenerative } \\
\text { disease; Anxiety } \\
\text { disorder; Pain; } \\
\text { Epilepsy; } \\
\text { Schizophrenia; Drug } \\
\text { dependence; Major } \\
\text { depressive disorder } \\
\end{array}$ & $\begin{array}{l}\text { Metabotropic } \\
\text { glutamate receptor } 2 \\
\text { agonist; Metabotropic } \\
\text { glutamate receptor } 3 \\
\text { agonist }\end{array}$ & $\begin{array}{l}\text { Anxiolytic; } \\
\text { Analgesic; } \\
\text { Antipsychotic; } \\
\text { Anticonvulsant } \\
\text { agent; } \\
\text { Antidepressant }\end{array}$ \\
\hline 632. & $\begin{array}{l}{ }^{*} \text { No } \\
\text { development } \\
\text { reported } \\
\text { (Discovery) }\end{array}$ & $\begin{array}{l}\text { Taisho Pharmaceutical } \\
\text { Co Ltd/Merck \& Co } \\
\text { Inc }\end{array}$ & $\begin{array}{l}\text { Metabotropic } \\
\text { glutamate receptor } \\
\text { ligands }\end{array}$ & $\begin{array}{l}\text { Psychotic disorder; } \\
\text { Schizophrenia; Major } \\
\text { depressive disorder }\end{array}$ & $\begin{array}{l}\text { Metabotropic } \\
\text { glutamate receptor } \\
\text { modulator; } \\
\text { Metabotropic } \\
\text { glutamate receptor } 1 \\
\text { antagonist } \\
\end{array}$ & $\begin{array}{l}\text { Antipsychotic; } \\
\text { Antidepressant }\end{array}$ \\
\hline 633. & Discovery & $\begin{array}{l}\text { Neurosciences Victoria } \\
\text { Ltd/ University of } \\
\text { Tasmania }\end{array}$ & $\begin{array}{l}\text { Metallothionein } \\
\text { (neurodegenerative } \\
\text { disorder) }\end{array}$ & $\begin{array}{l}\text { Brain injury; } \\
\text { Neurodegenerative } \\
\text { disease; Spinal cord } \\
\text { injury } \\
\end{array}$ & $\begin{array}{l}\text { Chelating agent; } \\
\text { Free radical scavenger; } \\
\text { Metallothionein } \\
\text { modulator } \\
\end{array}$ & Neuroprotectant \\
\hline 636. & Discovery & AstraZeneca plc & $\begin{array}{l}\text { mGluR1 antagonists; } \\
\text { former Metabotropic } \\
\text { glutamate receptor } \\
\text { modulators } \\
\text { (CNS disorders) } \\
\end{array}$ & Neurological disease & $\begin{array}{l}\text { Metabotropic } \\
\text { glutamate receptor } 1 \\
\text { antagonist; CNS } \\
\text { modulator }\end{array}$ & Analgesic \\
\hline 637. & $\begin{array}{l}{ }^{*} \mathrm{No} \\
\text { development } \\
\text { reported } \\
\text { (Discovery) } \\
\end{array}$ & $\begin{array}{l}\text { Banyu Pharmaceuticals } \\
\text { Co Ltd }\end{array}$ & $\begin{array}{l}\text { mGluR1 antagonists } \\
\text { (neurological/ } \\
\text { psychiatric diseases) }\end{array}$ & $\begin{array}{l}\text { Psychiatric disorder; } \\
\text { Neurological disease }\end{array}$ & $\begin{array}{l}\text { Metabotropic } \\
\text { glutamate receptor } 1 \\
\text { antagonist }\end{array}$ & CNS modulator \\
\hline 638. & Discovery & Pfizer Inc & $\begin{array}{l}\text { mGluR2 PAMs (CNS } \\
\text { disorders) }\end{array}$ & CNS disease & $\begin{array}{l}\text { Metabotropic } \\
\text { glutamate receptor } 2 \\
\text { modulator }\end{array}$ & CNS modulator \\
\hline 639. & **Discovery & $\begin{array}{l}\text { Addex Pharmaceuticals } \\
\text { SA }\end{array}$ & $\begin{array}{l}\text { mGluR4 PAM } \\
\text { modulators (oral, } \\
\text { Parkinson's disease/ } \\
\text { anxiety) }\end{array}$ & $\begin{array}{l}\text { Anxiety disorder; } \\
\text { Parkinsons disease }\end{array}$ & $\begin{array}{l}\text { Metabotropic } \\
\text { glutamate receptor } 4 \\
\text { modulator }\end{array}$ & $\begin{array}{l}\text { Anxiolytic; } \\
\text { Antiparkinsonian }\end{array}$ \\
\hline
\end{tabular}




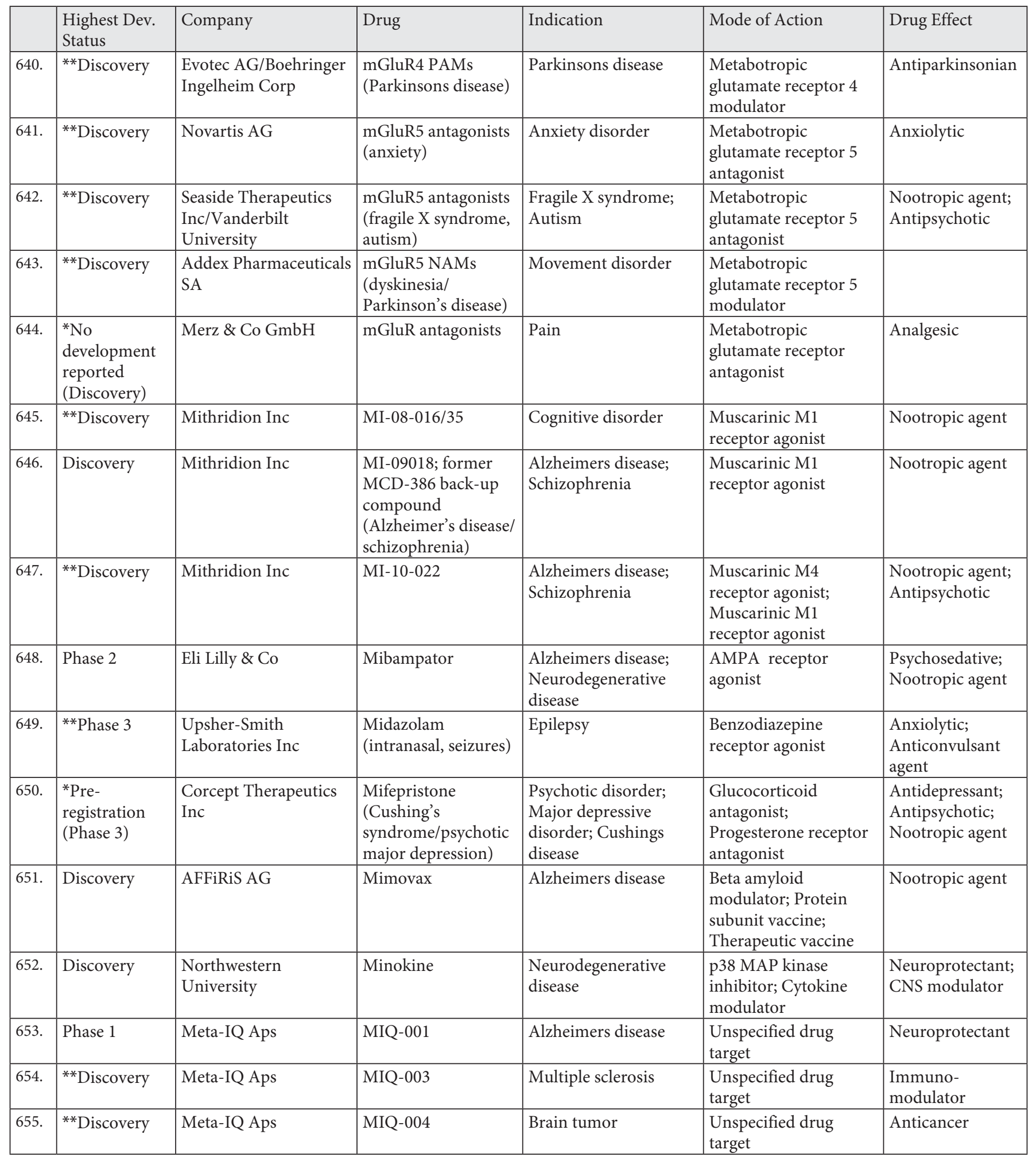




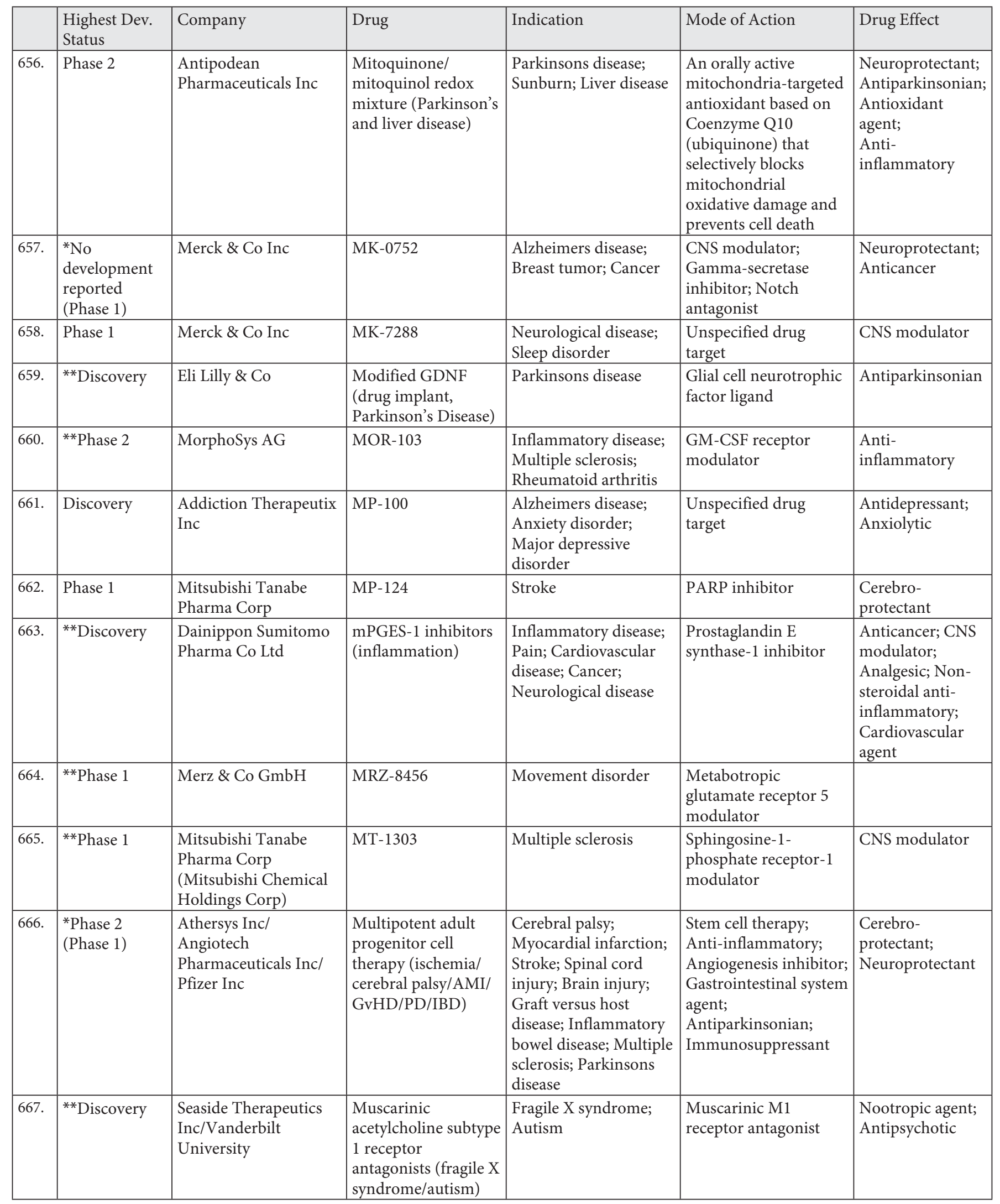




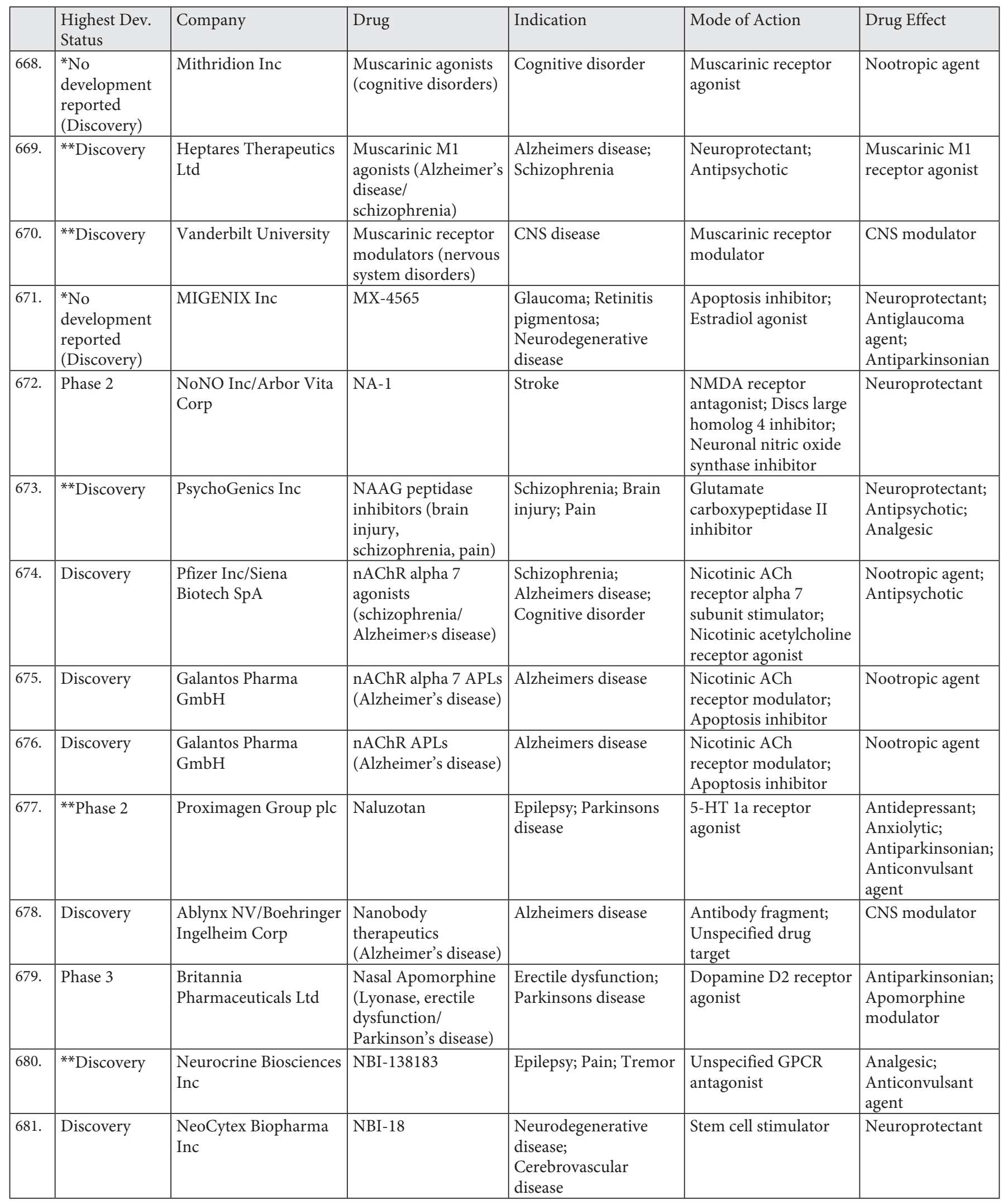




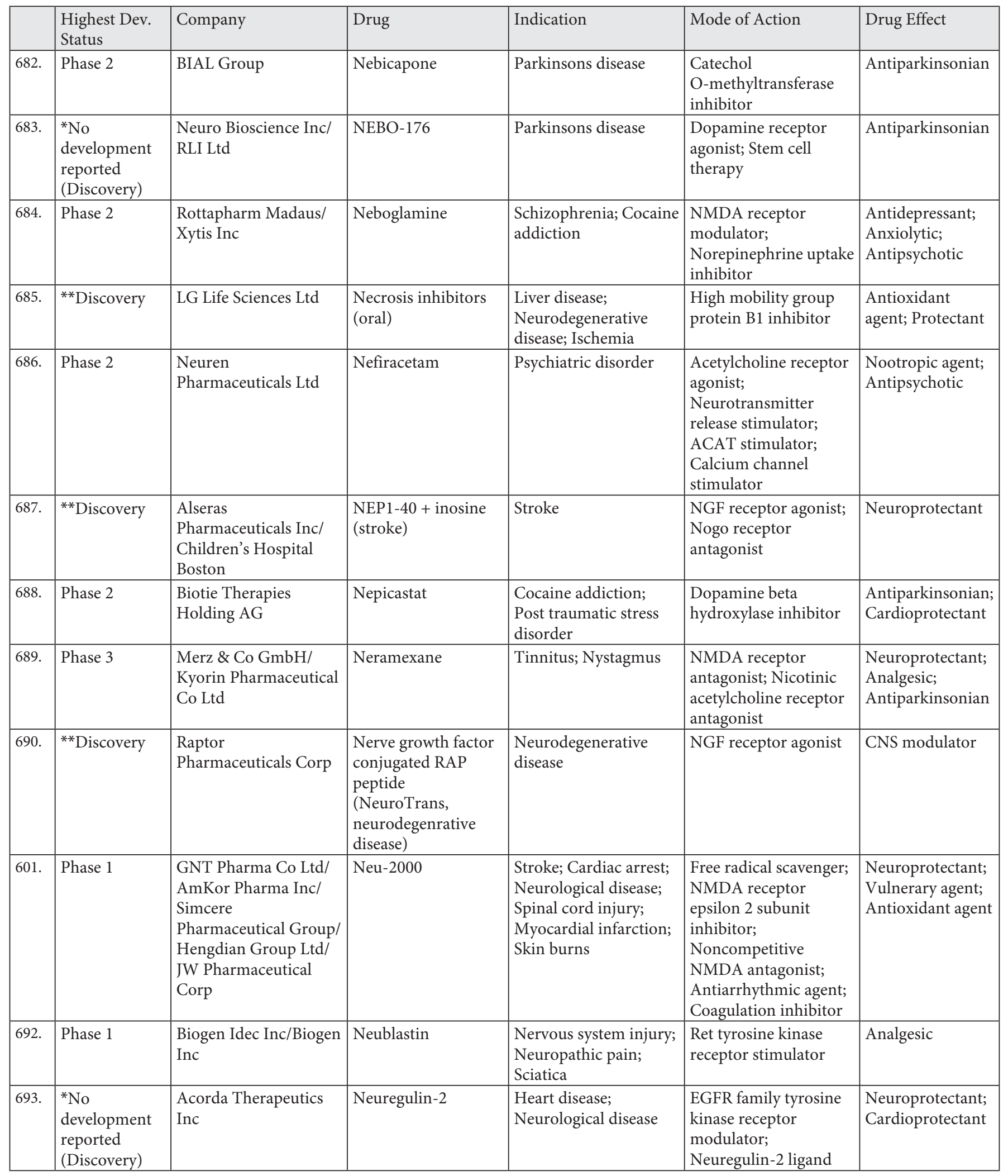




\begin{tabular}{|c|c|c|c|c|c|c|}
\hline & $\begin{array}{l}\text { Highest Dev. } \\
\text { Status }\end{array}$ & Company & Drug & Indication & Mode of Action & Drug Effect \\
\hline 694. & Discovery & $\begin{array}{l}\text { University of } \\
\text { Minnesota }\end{array}$ & $\begin{array}{l}\text { Neuroimmunophilin } \\
\text { ligands (alopecia) }\end{array}$ & Alopecia & $\begin{array}{l}\text { FK506 binding } \\
\text { protein-12 inhibitor }\end{array}$ & $\begin{array}{l}\text { Chemoprotectant; } \\
\text { Neuroprotectant; } \\
\text { Antiparkinsonian; } \\
\text { Dermatological } \\
\text { agent }\end{array}$ \\
\hline 695. & Discovery & Abbott Laboratories & $\begin{array}{l}\text { Neurological } \\
\text { therapeutics }\end{array}$ & Neurological disease & $\begin{array}{l}\text { CNS modulator; } \\
\text { Unspecified drug } \\
\text { target }\end{array}$ & \\
\hline 696. & Discovery & Abbott Laboratories & $\begin{array}{l}\text { Neuronal nAChR } \\
\text { modulators }\end{array}$ & $\begin{array}{l}\text { Alzheimers disease; } \\
\text { Neurodegenerative } \\
\text { disease; Pain; } \\
\text { Nicotine dependence; } \\
\text { Anxiety disorder; } \\
\text { Schizophrenia; } \\
\text { Major depressive } \\
\text { disorder }\end{array}$ & $\begin{array}{l}\text { Nicotinic ACh } \\
\text { receptor alpha } 4 \\
\text { subunit modulator; } \\
\text { Nicotinic ACh } \\
\text { receptor alpha } 7 \\
\text { subunit stimulator; } \\
\text { Nicotinic ACh } \\
\text { receptor beta } 2 \text { subunit } \\
\text { modulator; Nicotinic } \\
\text { ACh receptor agonist }\end{array}$ & $\begin{array}{l}\text { Anxiolytic; } \\
\text { Antipsychotic; } \\
\text { Analgesic; } \\
\text { Nootropic agent; } \\
\text { Antidepressant; } \\
\text { Neuroprotectant }\end{array}$ \\
\hline 697. & **Discovery & GlaxoSmithKline plc & $\begin{array}{l}\text { Neuropeptide S } \\
\text { antagonist } \\
\text { (neurological } \\
\text { diseases) } \\
\end{array}$ & Neurological disease & $\begin{array}{l}\text { Neuropeptide receptor } \\
\text { S antagonist }\end{array}$ & \\
\hline 698. & **Discovery & $\begin{array}{l}\text { TauRx Therapeutics } \\
\text { Pte Ltd }\end{array}$ & Neuroprotectants & $\begin{array}{l}\text { Neurodegenerative } \\
\text { disease }\end{array}$ & & Neuroprotectant \\
\hline 699. & Discovery & Trophos SA & $\begin{array}{l}\text { Neuroprotectants } \\
\text { (Huntington's } \\
\text { disease) } \\
\end{array}$ & Huntingtons chorea & $\begin{array}{l}\text { Unspecified drug } \\
\text { target }\end{array}$ & Neuroprotectant \\
\hline 700. & **Phase 1 & Acino Holding AG & $\begin{array}{l}\text { Neuroprotectant } \\
\text { (transdermal } \\
\text { therapeutic system, } \\
\text { Alzheimers disease) } \\
\end{array}$ & Alzheimers disease & $\begin{array}{l}\text { Unspecified drug } \\
\text { target }\end{array}$ & Neuroprotectant \\
\hline 703. & Phase 2 & NeuroGeneration Inc & NGN-9076 & Parkinsons disease & Cell line & Antiparkinsonian \\
\hline 704. & ${ }^{* *}$ Discovery & NeuroGeneration Inc & NGN-9078 & Stroke & & Neuroprotectant \\
\hline 705. & ${ }^{* *}$ Discovery & NeuroGeneration Inc & NGN-9079 & Alzheimers disease & & $\begin{array}{l}\text { Neuroprotectant; } \\
\text { Nootropic agent }\end{array}$ \\
\hline 706. & **Discovery & NeuroGeneration Inc & NGN-9080 & Spinal cord injury & $\begin{array}{l}\text { Bone synthesis } \\
\text { modulator }\end{array}$ & \\
\hline 707. & $\begin{array}{l}\text { *No } \\
\text { development } \\
\text { reported } \\
\text { (Phase 1) }\end{array}$ & $\begin{array}{l}\text { Raptor } \\
\text { Pharmaceuticals Corp }\end{array}$ & NGX-426 & $\begin{array}{l}\text { Neuropathic pain; } \\
\text { Migraine }\end{array}$ & $\begin{array}{l}\text { Kainate receptor } \\
\text { antagonist; AMPA } \\
\text { receptor antagonist; } \\
\text { Glutamate receptor } \\
\text { antagonist }\end{array}$ & Analgesic \\
\hline 708. & $\begin{array}{l}\text { *Phase } 1 \\
\text { (Discovery) }\end{array}$ & $\begin{array}{l}\text { Neurimmune } \\
\text { Therapeutics AG/ } \\
\text { Biogen Idec Inc }\end{array}$ & $\begin{array}{l}\text { NI-101; former } \\
\text { Monoclonal } \\
\text { antibodies } \\
\text { (Alzheimer's disease) }\end{array}$ & Alzheimers disease & $\begin{array}{l}\text { Beta amyloid } \\
\text { antagonist }\end{array}$ & Neuroprotectant \\
\hline 709. & ${ }^{* *}$ Discovery & $\begin{array}{l}\text { Novartis Institutes for } \\
\text { BioMedical Research } \\
\text { Inc (Novartis AG) }\end{array}$ & NIBR-785 & Multiple sclerosis & $\begin{array}{l}\text { Sphingosine-1- } \\
\text { phosphate receptor-1 } \\
\text { agonist }\end{array}$ & $\begin{array}{l}\text { Immuno- } \\
\text { suppressant }\end{array}$ \\
\hline
\end{tabular}




\begin{tabular}{|c|c|c|c|c|c|c|}
\hline & $\begin{array}{l}\text { Highest Dev. } \\
\text { Status }\end{array}$ & Company & Drug & Indication & Mode of Action & Drug Effect \\
\hline 710. & **Discovery & Targacept Inc & \begin{tabular}{|l|} 
Nicotinic $\mathrm{ACh}$ \\
agonists (Parkinsons \\
disease)
\end{tabular} & Parkinsons disease & $\begin{array}{l}\text { Nicotinic ACh } \\
\text { receptor alpha } 4 \\
\text { subunit stimulator; } \\
\text { Nicotinic ACh } \\
\text { receptor alpha } 6 \\
\text { subunit inhibitor; } \\
\text { Nicotinic ACh } \\
\text { receptor alpha } 7 \\
\text { subunit stimulator; } \\
\text { Nicotinic ACh } \\
\text { receptor beta } 2 \text { subunit } \\
\text { stimulator; Nicotinic } \\
\text { acetylcholine receptor } \\
\text { agonist }\end{array}$ & $\begin{array}{l}\text { Neuroprotectant; } \\
\text { Antiparkinsonian }\end{array}$ \\
\hline 712. & Phase 1 & $\begin{array}{l}\text { Archer } \\
\text { Pharmaceuticals }\end{array}$ & \begin{tabular}{|l|} 
Nilvadipine \\
derivative \\
(Alzheimer's disease)
\end{tabular} & Alzheimers disease & $\begin{array}{l}\text { Amyloid protein } \\
\text { deposition inhibitor }\end{array}$ & Neuroprotectant \\
\hline 713. & ${ }^{* *}$ Phase 1 & $\begin{array}{l}\text { Archer } \\
\text { Pharmaceuticals }\end{array}$ & \begin{tabular}{|l|} 
Nivaldipine \\
derivative (sustained \\
release, Alzheimer's \\
disease) \\
\end{tabular} & Alzheimers disease & $\begin{array}{l}\text { Amyloid protein } \\
\text { deposition inhibitor }\end{array}$ & Neuroprotectant \\
\hline 716. & ${ }^{* *}$ Phase 2 & Neurologix Inc & NLX-P101 & Parkinsons disease & $\begin{array}{l}\text { Adeno-associated virus } \\
\text { based gene therapy; } \\
\text { Glutamate } \\
\text { decarboxylase } \\
\text { stimulator }\end{array}$ & Antiparkinsonian \\
\hline 717. & Discovery & $\begin{array}{l}\text { Merck Sharp \& Dohme } \\
\text { Research Laboratories }\end{array}$ & $\begin{array}{l}\text { NMDA receptor } \\
\text { antagonists (NR2B } \\
\text { subtype-selective) }\end{array}$ & $\begin{array}{l}\text { Neuropathic pain; } \\
\text { Parkinsons disease; } \\
\text { Stroke; Epilepsy }\end{array}$ & $\begin{array}{l}\text { NMDA receptor } \\
\text { epsilon } 2 \text { subunit } \\
\text { inhibitor }\end{array}$ & $\begin{array}{l}\text { Neuroprotectant; } \\
\text { Analgesic; } \\
\text { Antiparkinsonian; } \\
\text { Anticonvulsant } \\
\text { agent }\end{array}$ \\
\hline 718. & Discovery & Neuronascent Inc & $\begin{array}{l}\text { NNI-AD; former } \\
\text { NNI-362 }\end{array}$ & Alzheimers disease & $\begin{array}{l}\text { Neuron formation } \\
\text { stimulant }\end{array}$ & $\begin{array}{l}\text { Nootropic agent; } \\
\text { Neuroprotectant }\end{array}$ \\
\hline 719 & Phase 2 & $\begin{array}{l}\text { Neuren } \\
\text { Pharmaceuticals Ltd }\end{array}$ & $\begin{array}{l}\text { NNZ-2566 } \\
\text { (intravenous, brain } \\
\text { injury/stroke) }\end{array}$ & $\begin{array}{l}\text { Neurological disease; } \\
\text { Brain injury }\end{array}$ & $\begin{array}{l}\text { Apoptosis inhibitor; } \\
\text { Anti-inflammatory; } \\
\text { Cytokine receptor } \\
\text { antagonist }\end{array}$ & Neuroprotectant \\
\hline 720. & Discovery & $\begin{array}{l}\text { Neuren } \\
\text { Pharmaceuticals Ltd }\end{array}$ & $\begin{array}{l}\text { NNZ-2566 (oral, } \\
\text { neurodegeneration/ } \\
\text { injury) }\end{array}$ & $\begin{array}{l}\text { Neurodegenerative } \\
\text { disease; Brain injury; } \\
\text { Rett syndrome }\end{array}$ & $\begin{array}{l}\text { Unspecified drug } \\
\text { target }\end{array}$ & Neuroprotectant \\
\hline
\end{tabular}




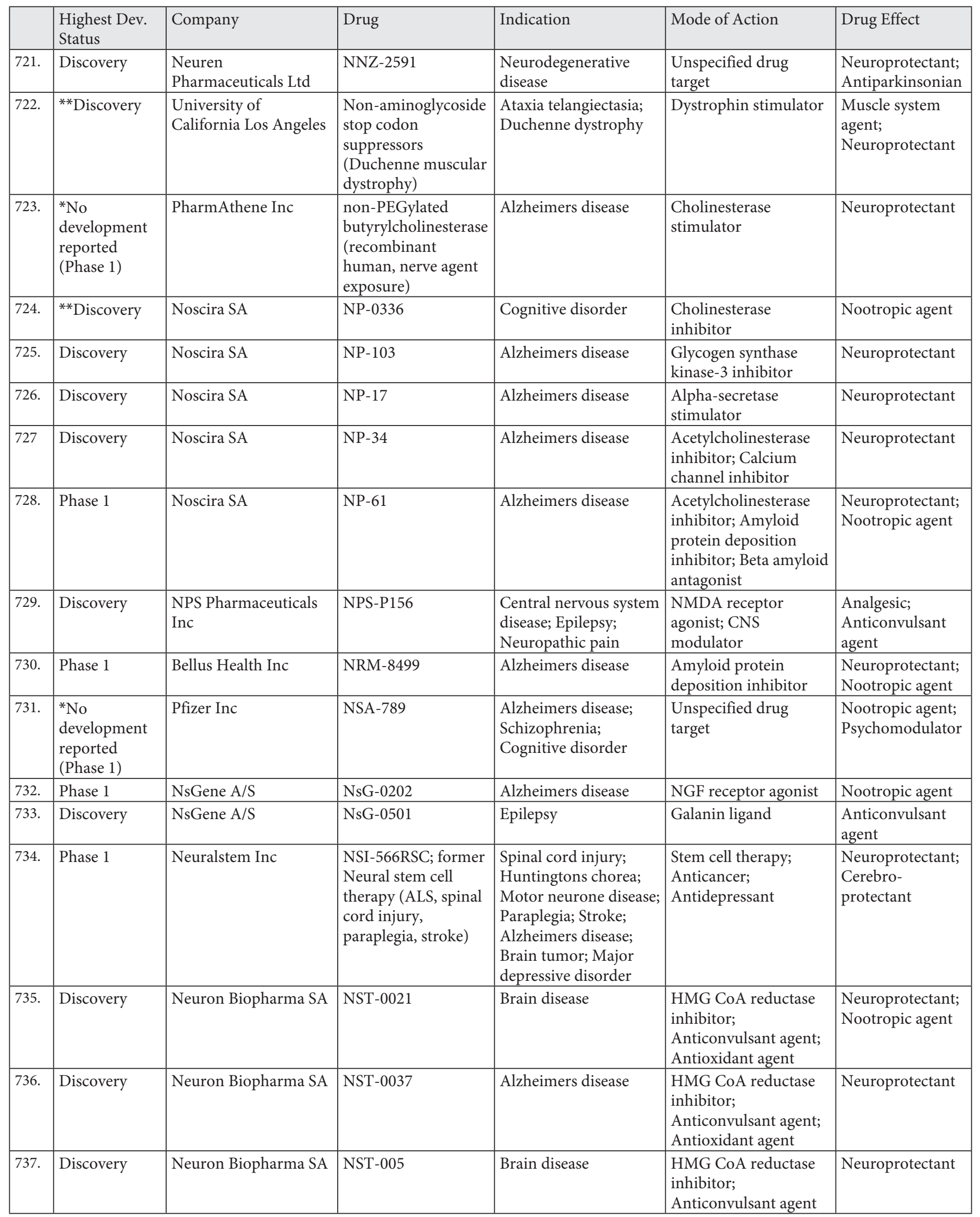




\begin{tabular}{|c|c|c|c|c|c|c|}
\hline & $\begin{array}{l}\text { Highest Dev. } \\
\text { Status }\end{array}$ & Company & Drug & Indication & Mode of Action & Drug Effect \\
\hline 738. & **Discovery & Neurotez Inc & NT-1 & Alzheimers disease & $\begin{array}{l}\text { Presenilin modulator; } \\
\text { Beta amyloid synthesis } \\
\text { inhibitor; CAP Gly } \\
\text { domain linker protein } \\
1 \text { modulator }\end{array}$ & Neuroprotectant \\
\hline 739. & **Discovery & Neurotez Inc & NT-2 & Alzheimers disease & $\begin{array}{l}\text { Presenilin modulator; } \\
\text { Beta amyloid synthesis } \\
\text { inhibitor; CAP Gly } \\
\text { domain linker protein } \\
1 \text { modulator } \\
\end{array}$ & Neuroprotectant \\
\hline 740. & Discovery & Mayo Foundation & NT-69-L & $\begin{array}{l}\text { Alzheimers disease; } \\
\text { Pain; Parkinsons } \\
\text { disease; Nicotine } \\
\text { dependence; } \\
\text { Schizophrenia; } \\
\text { Cognitive disorder; } \\
\text { Alcoholism }\end{array}$ & $\begin{array}{l}\text { Neurotensin receptor } \\
\text { agonist }\end{array}$ & $\begin{array}{l}\text { Antipsychotic; } \\
\text { Analgesic; } \\
\text { Antiparkinsonian; } \\
\text { Nootropic agent }\end{array}$ \\
\hline 741. & ${ }^{* *}$ Phase 2 & $\begin{array}{l}\text { Stem Cell Therapeutics } \\
\text { Corp }\end{array}$ & NTx-488 & Multiple sclerosis & Prolactin ligand & Neuroprotectant \\
\hline 742. & Discovery & $\begin{array}{l}\text { Neuromed } \\
\text { Pharmaceuticals Inc/ } \\
\text { Zalicus Inc }\end{array}$ & $\begin{array}{l}\text { N-type calcium } \\
\text { channel blockers } \\
\text { (pain) }\end{array}$ & Pain & $\begin{array}{l}\text { Calcium channel } \\
\text { inhibitor N-type }\end{array}$ & Analgesic \\
\hline 743. & ${ }^{* *}$ Discovery & $\begin{array}{l}\text { NeuroVive } \\
\text { Pharmaceutical AB/to- } \\
\text { BBB technologies BV }\end{array}$ & NVP-014 & $\begin{array}{l}\text { Stroke; Neurological } \\
\text { disease }\end{array}$ & $\begin{array}{l}\text { Peptidyl-prolyl cis- } \\
\text { trans isomerase D } \\
\text { inhibitor }\end{array}$ & Neuroprotectant \\
\hline 744. & **Discovery & $\begin{array}{l}\text { NeuroVive } \\
\text { Pharmaceutical AB }\end{array}$ & NVP-015 & $\begin{array}{l}\text { Obesity; Mitochondrial } \\
\text { disease; Cardiovascular } \\
\text { disease; Neurological } \\
\text { disease }\end{array}$ & $\begin{array}{l}\text { Peptidylprolyl } \\
\text { isomerase inhibitor }\end{array}$ & Neuroprotectant \\
\hline 748. & Phase 1 & $\begin{array}{l}\text { Garnet } \\
\text { BioTherapeutics Inc }\end{array}$ & NX-CP105 & $\begin{array}{l}\text { Myocardial infarction; } \\
\text { Stroke }\end{array}$ & $\begin{array}{l}\text { Cytokine synthesis } \\
\text { stimulator; Unspecified } \\
\text { growth factor receptor } \\
\text { modulator }\end{array}$ & Cardioprotectant \\
\hline 749. & Discovery & $\begin{array}{l}\text { Nymox Pharmaceutical } \\
\text { Corp }\end{array}$ & NXD-9062 & Alzheimers disease & $\begin{array}{l}\text { Unspecified drug } \\
\text { target }\end{array}$ & Neuroprotectant \\
\hline 750. & **Phase 3 & $\begin{array}{l}\text { Genentech Inc/Roche } \\
\text { Holding AG }\end{array}$ & Ocrelizumab & Multiple sclerosis & $\begin{array}{l}\text { B-lymphocyte antigen } \\
\text { CD20 inhibitor; } \\
\text { Anticancer } \\
\text { monoclonal antibody }\end{array}$ & $\begin{array}{l}\text { Anticancer; Anti- } \\
\text { inflammatory }\end{array}$ \\
\hline 751. & $\begin{array}{l}\text { *No } \\
\text { development } \\
\text { reported } \\
(\text { Phase 2) }\end{array}$ & ThromboGenics NV & $\begin{array}{l}\text { Ocriplasmin } \\
\text { (injected, stroke) }\end{array}$ & Stroke & $\begin{array}{l}\text { Fibrinolysis stimulator; } \\
\text { Plasmin stimulator; } \\
\text { Alpha-2 antiplasmin } \\
\text { inhibitor }\end{array}$ & Neuroprotectant \\
\hline 752. & Phase 3 & Trophos SA & Olesoxime & $\begin{array}{l}\text { Motor neurone disease; } \\
\text { Parkinsons disease; } \\
\text { Spinal muscular } \\
\text { atrophy; Multiple } \\
\text { sclerosis; Peripheral } \\
\text { neuropathy }\end{array}$ & Apoptosis inhibitor & $\begin{array}{l}\text { Neuroprotectant; } \\
\text { Analgesic; } \\
\text { Antiparkinsonian }\end{array}$ \\
\hline
\end{tabular}




\begin{tabular}{|c|c|c|c|c|c|c|}
\hline & $\begin{array}{l}\text { Highest Dev. } \\
\text { Status }\end{array}$ & Company & Drug & Indication & Mode of Action & Drug Effect \\
\hline 753. & **Discovery & Noscira SA & $\begin{array}{l}\text { Olfactory } \\
\text { ensheathing glia cell } \\
\text { therapy (spinal cord } \\
\text { injury) } \\
\end{array}$ & Spinal cord injury & & Neuroprotectant \\
\hline 754. & $\begin{array}{l}\text { *Phase } 1 \\
\text { (Discovery) }\end{array}$ & $\begin{array}{l}\text { Santhera } \\
\text { Pharmaceuticals AG }\end{array}$ & Omigapil & Muscular dystrophy & $\begin{array}{l}\text { Apoptosis inhibitor; } \\
\text { Triosephosphate } \\
\text { dehydrogenase } \\
\text { modulator }\end{array}$ & $\begin{array}{l}\text { Neuroprotectant; } \\
\text { Nootropic agent; } \\
\text { Antiparkinsonian }\end{array}$ \\
\hline 755. & ${ }^{* *}$ Phase 2 & $\begin{array}{l}\text { Ono Pharmaceutical } \\
\text { Co Ltd/Merck KGaA }\end{array}$ & ONO-4641 & Multiple sclerosis & $\begin{array}{l}\text { Sphingosine-1- } \\
\text { phosphate receptor-1 } \\
\text { agonist }\end{array}$ & $\begin{array}{l}\text { Immuno- } \\
\text { modulator }\end{array}$ \\
\hline 756. & ***Phase 3 & Portela \& Ca SA & Opicapone & Parkinsons disease & $\begin{array}{l}\text { Catechol } \\
\text { O-methyltransferase } \\
\text { inhibitor } \\
\end{array}$ & Antiparkinsonian \\
\hline 758. & ${ }^{* *}$ Phase 2 & $\begin{array}{l}\text { Osmotica } \\
\text { Pharmaceutical Corp }\end{array}$ & OS-320 & Parkinsons disease & $\begin{array}{l}\text { Unspecified drug } \\
\text { target }\end{array}$ & CNS modulator \\
\hline 759. & **Discovery & $\begin{array}{l}\text { Osmotica } \\
\text { Pharmaceutical Corp }\end{array}$ & OS-440 & Muscle hypertonia & $\begin{array}{l}\text { Unspecified drug } \\
\text { target }\end{array}$ & CNS modulator \\
\hline 760. & **Discovery & $\begin{array}{l}\text { Intellect Neurosciences } \\
\text { Inc }\end{array}$ & OX-2 & $\begin{array}{l}\text { Neurodegenerative } \\
\text { disease }\end{array}$ & & Neuroprotectant \\
\hline 761. & $\begin{array}{l}{ }^{*} \text { Discontinued } \\
(\text { Phase } 1)\end{array}$ & $\begin{array}{l}\text { Intellect Neurosciences } \\
\text { Inc/New York } \\
\text { University }\end{array}$ & $\begin{array}{l}\text { OX1; former } \\
\text { OXIGON }\end{array}$ & $\begin{array}{l}\text { Alzheimers disease; } \\
\text { Huntingtons chorea; } \\
\text { Parkinsons disease }\end{array}$ & $\begin{array}{l}\text { Beta amyloid } \\
\text { antagonist; } \\
\text { Antioxidant agent; } \\
\text { Cooper metabolism } \\
\text { modulator }\end{array}$ & $\begin{array}{l}\text { Neuroprotectant; } \\
\text { Nootropic agent; } \\
\text { Antiparkinsonian }\end{array}$ \\
\hline 764. & Discovery & Afraxis Inc & $\begin{array}{l}\text { p21-activated kinase } \\
\text { inhibitor (central } \\
\text { nervous system } \\
\text { disorders/cancer) } \\
\end{array}$ & $\begin{array}{l}\text { Central nervous system } \\
\text { disease; Cancer }\end{array}$ & $\begin{array}{l}\text { PAK protein kinase } \\
\text { inhibitor; Anticancer } \\
\text { protein kinase } \\
\text { inhibitor }\end{array}$ & $\begin{array}{l}\text { Neuroprotectant; } \\
\text { Nootropic agent }\end{array}$ \\
\hline 765. & **Discovery & $\begin{array}{l}\text { Nexgenix } \\
\text { Pharmaceuticals Inc }\end{array}$ & $\begin{array}{l}\text { p21 activated kinase } \\
\text { inhibitors (type } 2 \\
\text { neurofibromatosis, } \\
\text { fragile X syndrome/ } \\
\text { autism) } \\
\end{array}$ & $\begin{array}{l}\text { Fragile X syndrome; } \\
\text { Neurofibromatosis; } \\
\text { Autism }\end{array}$ & $\begin{array}{l}\text { PAK protein kinase } \\
\text { inhibitor; Anticancer } \\
\text { protein kinase } \\
\text { inhibitor }\end{array}$ & Neuroprotectant \\
\hline 766. & ${ }^{* *}$ Discovery & $\begin{array}{l}\text { Affectis } \\
\text { Pharmaceuticals AG/ } \\
\text { Merck Serono SA }\end{array}$ & $\begin{array}{l}\text { P2X7 antagonists } \\
\text { (oral, } \\
\text { neuroinflammation) }\end{array}$ & $\begin{array}{l}\text { Nervous system } \\
\text { inflammation }\end{array}$ & $\begin{array}{l}\text { Cytokine release } \\
\text { inhibitor; Anti- } \\
\text { inflammatory; P2X7 } \\
\text { purinoceptor } \\
\text { antagonist } \\
\end{array}$ & CNS modulator \\
\hline
\end{tabular}




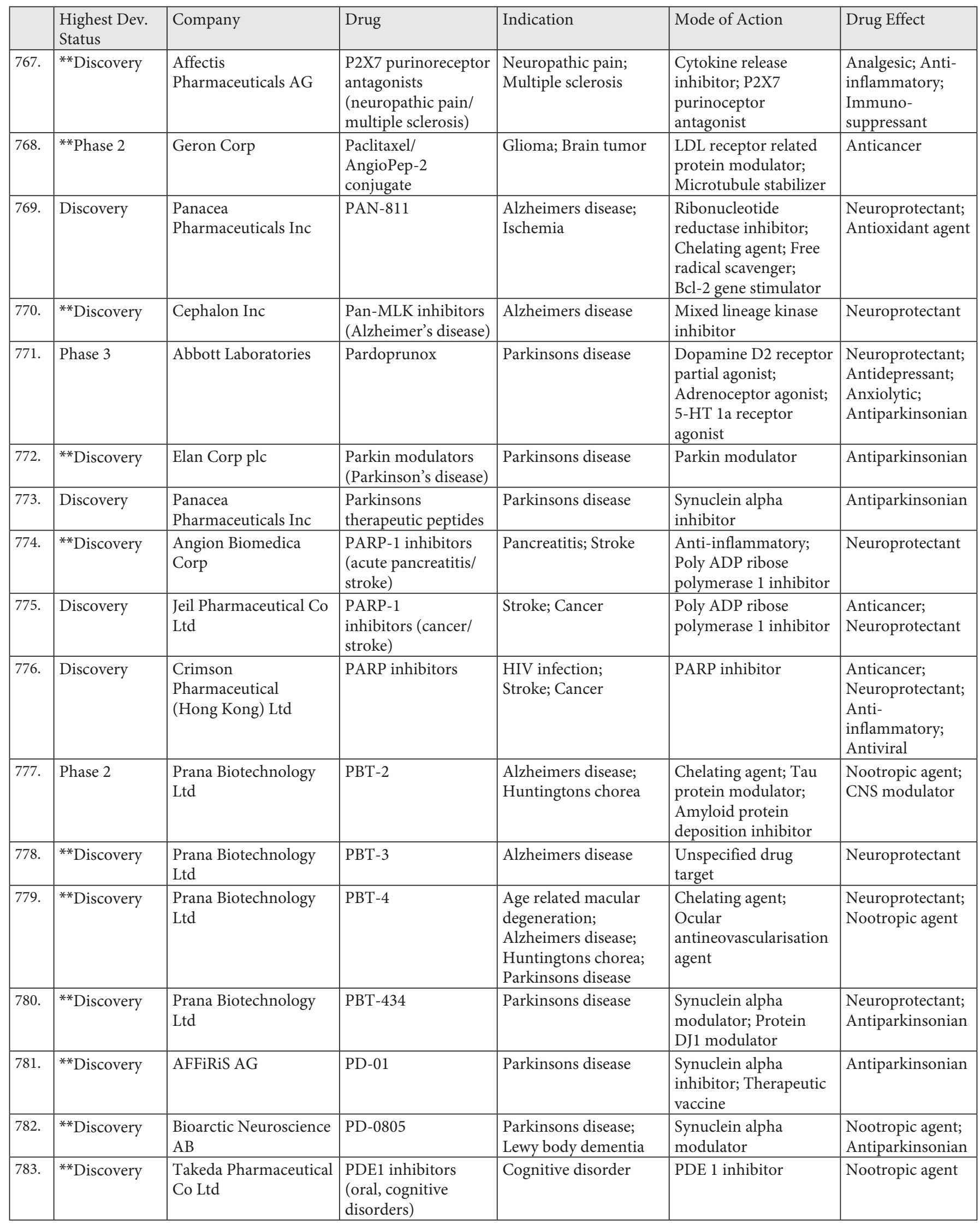




\begin{tabular}{|c|c|c|c|c|c|c|}
\hline & $\begin{array}{l}\text { Highest Dev. } \\
\text { Status }\end{array}$ & Company & Drug & Indication & Mode of Action & Drug Effect \\
\hline 784. & $\begin{array}{l}{ }^{*} \text { Discontinued } \\
\text { (Discovery) }\end{array}$ & Pfizer Inc & $\begin{array}{l}\text { PDE10A inhibitors } \\
\text { (psychosis) }\end{array}$ & $\begin{array}{l}\text { Psychiatric disorder; } \\
\text { Neurodegenerative } \\
\text { disease }\end{array}$ & PDE 10 inhibitor & $\begin{array}{l}\text { Antipsychotic; } \\
\text { Neuroprotectant }\end{array}$ \\
\hline 785. & ${ }^{* *}$ Discovery & Biocrea GmbH & $\begin{array}{l}\text { PDE } 10 \text { inhibitors } \\
\text { (CNS disorders) }\end{array}$ & $\begin{array}{l}\text { Schizophrenia; Central } \\
\text { nervous system disease }\end{array}$ & PDE 10 inhibitor & Antipsychotic \\
\hline 786. & ***Discovery & Biocrea GmbH & $\begin{array}{l}\text { PDE } 2 \text { inhibitors } \\
\text { (mild cognitive } \\
\text { impairment) } \\
\end{array}$ & $\begin{array}{l}\text { Mild cognitive } \\
\text { impairment }\end{array}$ & PDE 2 inhibitor & Neuroprotectant \\
\hline 787. & Phase 1 & $\begin{array}{l}\text { University of } \\
\text { Auckland/Cornell } \\
\text { University } \\
\end{array}$ & PD gene therapy & Parkinson disease & $\begin{array}{l}\text { Adenovirus based gene } \\
\text { therapy; Unspecified } \\
\text { drug target }\end{array}$ & Antiparkinsonian \\
\hline 788. & $\begin{array}{l}{ }^{*} \text { Phase } 2 \\
\text { (Phase } 1)\end{array}$ & $\begin{array}{l}\text { Halozyme } \\
\text { Therapeutics Inc }\end{array}$ & \begin{tabular}{|l|} 
PEGylated \\
hyaluronidase \\
(human \\
recombinant) \\
(intravenous, stroke/ \\
cancer) \\
\end{tabular} & $\begin{array}{l}\text { Pancreas tumor; } \\
\text { Stroke; Solid tumor }\end{array}$ & $\begin{array}{l}\text { Hyaluronidase } \\
\text { stimulator }\end{array}$ & Anticancer \\
\hline 789. & **Phase 3 & Biogen Idec Inc & $\begin{array}{l}\text { PEGylated IFN beta } \\
\text { 1-a (multiple } \\
\text { sclerosis) } \\
\end{array}$ & Multiple sclerosis & Interferon beta ligand & $\begin{array}{l}\text { Immuno- } \\
\text { modulator }\end{array}$ \\
\hline 790. & Discovery & $\begin{array}{l}\text { CoDa Therapeutics } \\
\text { (NZ) Ltd } \\
\end{array}$ & Peptagon & Stroke & $\begin{array}{l}\text { Gap junction pathway } \\
\text { modulator }\end{array}$ & Neuroprotectant \\
\hline 791. & ${ }^{* *}$ Discovery & ProteoTech Inc & Pepticlere & Alzheimers disease & $\begin{array}{l}\text { Amyloid protein } \\
\text { deposition inhibitor; } \\
\text { Laminin modulator } \\
\end{array}$ & Neuroprotectant \\
\hline 792. & $\begin{array}{l}{ }^{*} \text { Pre- } \\
\text { registration } \\
\text { (Phase 3) }\end{array}$ & Eisai Co Ltd & Perampanel & $\begin{array}{l}\text { Epilepsy; Multiple } \\
\text { sclerosis; Migraine; } \\
\text { Diabetic neuropathy; } \\
\text { Neuropathic pain; } \\
\text { Postherpetic neuralgia }\end{array}$ & $\begin{array}{l}\text { AMPA receptor } \\
\text { antagonist }\end{array}$ & $\begin{array}{l}\text { Neuroprotectant; } \\
\text { Anticonvulsant } \\
\text { agent; Analgesic; } \\
\text { Antiparkinsonian }\end{array}$ \\
\hline 795. & **Discovery & AC Immune SA & $\begin{array}{l}\text { PET imaging agent } \\
\text { (Alzheimer's disease) }\end{array}$ & Alzheimers disease & PET contrast agent & $\begin{array}{l}\text { Radiodiagnostic; } \\
\text { CNS diagnostic } \\
\text { agent }\end{array}$ \\
\hline 796. & **Phase 1 & $\begin{array}{l}\text { Janssen Alzheimer } \\
\text { Immunotherapy/Pfizer } \\
\text { Inc }\end{array}$ & PF-05236812 & Alzheimers disease & $\begin{array}{l}\text { Beta amyloid } \\
\text { modulator }\end{array}$ & Neuroprotectant \\
\hline 797. & $\begin{array}{l}{ }^{*} \text { Phase } 2 \\
(\text { Phase } 1)\end{array}$ & \begin{tabular}{|l|} 
Pfizer Inc/EnVivo \\
Pharmaceuticals Inc
\end{tabular} & PF-2545920 & \begin{tabular}{|l|} 
Schizophrenia; \\
Huntingtons chorea
\end{tabular} & PDE 10 inhibitor & $\begin{array}{l}\text { Antipsychotic; } \\
\text { Nootropic agent }\end{array}$ \\
\hline 798. & $\begin{array}{l}{ }^{*} \text { Discontinued } \\
(\text { Phase } 2)\end{array}$ & Pfizer Inc & PF-3654746 & $\begin{array}{l}\text { Alzheimers disease; } \\
\text { Schizophrenia; } \\
\text { Cognitive disorder; } \\
\text { Narcolepsy }\end{array}$ & $\begin{array}{l}\text { Histamine } \mathrm{H} 3 \text { receptor } \\
\text { antagonist; } \\
\text { Anti-inflammatory }\end{array}$ & $\begin{array}{l}\text { Nootropic agent; } \\
\text { Psychomodulator; } \\
\text { CNS modulator }\end{array}$ \\
\hline 799. & Discovery & Pfizer Inc & PF-4181366 & Cognitive disorder & PDE 9a inhibitor & Nootropic agent \\
\hline 800. & $\begin{array}{l}{ }^{*} \text { Discontinued } \\
(\text { Phase } 2)\end{array}$ & Pfizer Inc & PF-4447943 & $\begin{array}{l}\text { Alzheimers disease; } \\
\text { Cognitive disorder }\end{array}$ & PDE 9a inhibitor & Nootropic agent \\
\hline
\end{tabular}




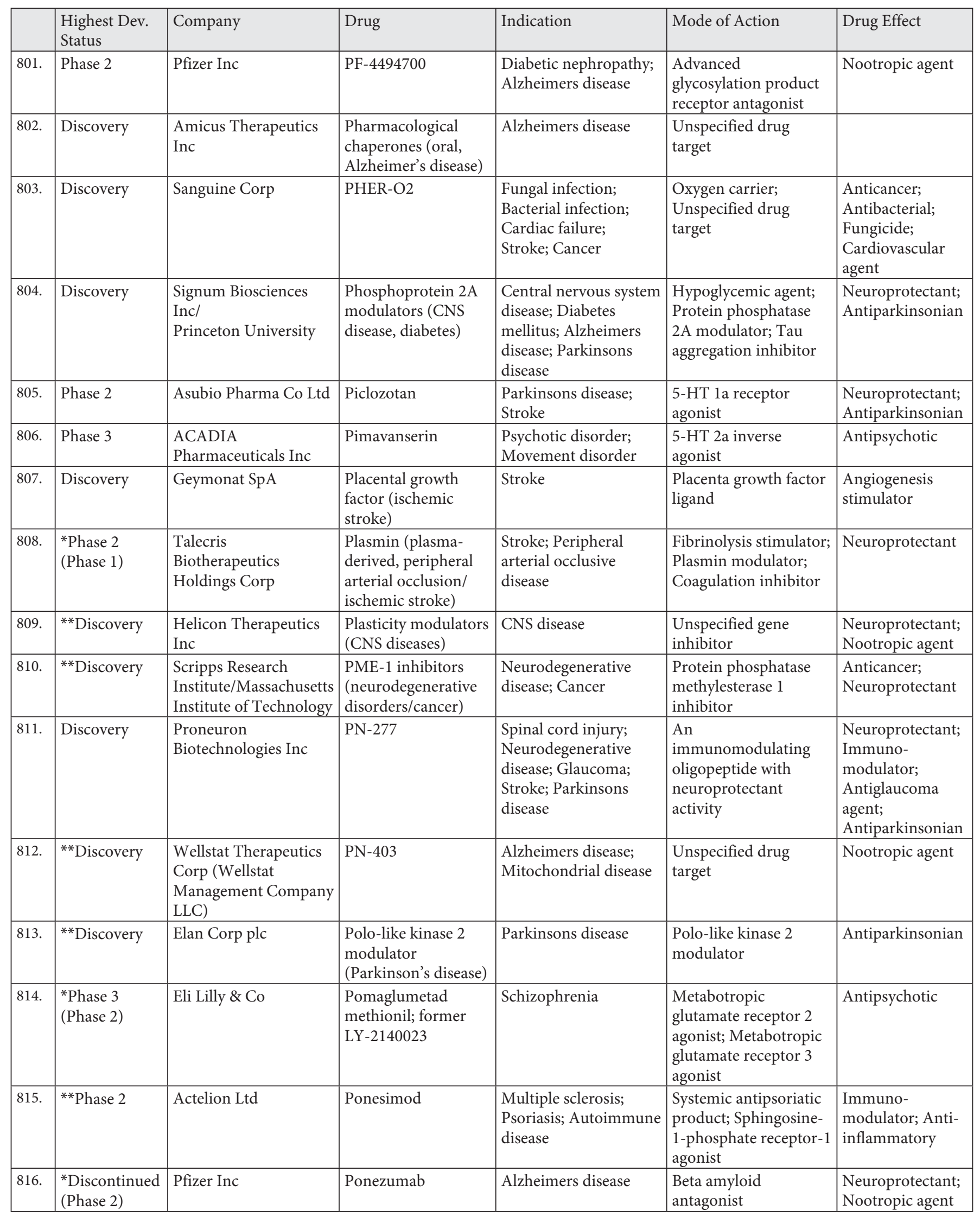




\begin{tabular}{|c|c|c|c|c|c|c|}
\hline & $\begin{array}{l}\text { Highest Dev. } \\
\text { Status }\end{array}$ & Company & Drug & Indication & Mode of Action & Drug Effect \\
\hline 817. & Discovery & $\begin{array}{l}\text { University of Kuopio/ } \\
\text { Finncovery Oy }\end{array}$ & $\begin{array}{l}\text { POP inhibitor } \\
\text { (Alzheimers) }\end{array}$ & Alzheimers disease & $\begin{array}{l}\text { Prolylendopeptidase } \\
\text { inhibitor }\end{array}$ & Neuroprotectant \\
\hline 819. & ${ }^{* *}$ Discovery & Vanderbilt University & $\begin{array}{l}\text { Positive allosteric } \\
\text { mGluR4 modulators } \\
\text { (Parkinson's disease) }\end{array}$ & Parkinsons disease & $\begin{array}{l}\text { Metabotropic } \\
\text { glutamate receptor } 4 \\
\text { modulator }\end{array}$ & Antiparkinsonian \\
\hline 820. & Phase 2 & Abbott Laboratories & Pozanicline & $\begin{array}{l}\text { Attention deficit } \\
\text { hyperactivity disorder; } \\
\text { Nicotine dependence }\end{array}$ & $\begin{array}{l}\text { Nicotinic ACh receptor } \\
\text { alpha } 4 \text { subunit } \\
\text { stimulator; Nicotinic } \\
\text { ACh receptor beta } 2 \\
\text { subunit stimulator; } \\
\text { Nicotinic ACh receptor } \\
\text { partial agonist }\end{array}$ & $\begin{array}{l}\text { Antipsychotic; } \\
\text { Nootropic agent }\end{array}$ \\
\hline 821. & **Discovery & GlaxoSmithKline plc & $\begin{array}{l}\text { PPAR gamma } \\
\text { agonists }\end{array}$ & $\begin{array}{l}\text { Multiple sclerosis; } \\
\text { Atherosclerosis; Non- } \\
\text { insulin dependent } \\
\text { diabetes } \\
\end{array}$ & $\begin{array}{l}\text { Insulin sensitizer; } \\
\text { PPAR gamma agonist }\end{array}$ & $\begin{array}{l}\text { Hypoglycemic } \\
\text { agent }\end{array}$ \\
\hline 822. & ${ }^{* *}$ Phase 1 & Probiodrug AG & PQ-912 & Alzheimers disease & $\begin{array}{l}\text { Glutaminyl peptide } \\
\text { cyclotransferase } \\
\text { inhibitor; Amyloid } \\
\text { protein deposition } \\
\text { inhibitor }\end{array}$ & Neuroprotectant \\
\hline 823. & Phase 1 & $\begin{array}{l}\text { NeuroScience } \\
\text { Pharmaceuticals Inc }\end{array}$ & $\begin{array}{l}\text { Pregnenolone } \\
\text { (schizophrenia) }\end{array}$ & Schizophrenia & $\begin{array}{l}\text { Steroid hormone } \\
\text { antagonist }\end{array}$ & Antipsychotic \\
\hline 827. & Discovery & $\begin{array}{l}\text { Endogenous Stem Cells } \\
\text { Activators Inc }\end{array}$ & Propentofylline & Alzheimers disease & $\begin{array}{l}\text { PDE inhibitor; Stem } \\
\text { cell modulator }\end{array}$ & $\begin{array}{l}\text { Antiarterio- } \\
\text { sclerotic }\end{array}$ \\
\hline 828. & $\begin{array}{l}{ }^{*} \text { Discontinued } \\
\text { (Discovery) }\end{array}$ & Vyrex Corp & Propofol phosphate & $\begin{array}{l}\text { Anesthesia; } \\
\text { Neurological disease }\end{array}$ & $\begin{array}{l}\text { A water-soluble } \\
\text { prodrug of the } \\
\text { anesthetic propofol } \\
\text { that has demonstrated } \\
\text { antioxidant and anti- } \\
\text { inflammatory } \\
\text { properties }\end{array}$ & $\begin{array}{l}\text { Anesthetic; } \\
\text { Anxiolytic; } \\
\text { Hypnotic; Anti- } \\
\text { inflammatory; } \\
\text { Antioxidant agent }\end{array}$ \\
\hline 829. & ${ }^{* *}$ Phase 2 & Oxford BioMedica plc & ProSavin & Parkinsons disease & $\begin{array}{l}\text { Dopamine synthesis } \\
\text { stimulant; Retrovirus } \\
\text { based gene therapy; } \\
\text { GTP cyclohydrolase-I } \\
\text { stimulator; Tyrosine } \\
\text { hydroxylase stimulator; } \\
\text { Dopa decarboxylase } \\
\text { stimulator }\end{array}$ & Antiparkinsonian \\
\hline
\end{tabular}




\begin{tabular}{|c|c|c|c|c|c|c|}
\hline & $\begin{array}{l}\text { Highest Dev. } \\
\text { Status }\end{array}$ & Company & Drug & Indication & Mode of Action & Drug Effect \\
\hline 830. & Discovery & $\begin{array}{l}\text { Cambria } \\
\text { Pharmaceuticals Inc }\end{array}$ & $\begin{array}{l}\text { Protein misfolding } \\
\text { therapies (ALS) }\end{array}$ & Motor neurone disease & $\begin{array}{l}\text { Unspecified drug } \\
\text { target }\end{array}$ & Neuroprotectant \\
\hline 832. & $\begin{array}{l}{ }^{*} \text { No } \\
\text { development } \\
\text { reported } \\
\text { (Phase 1) }\end{array}$ & PharmAthene Inc & \begin{tabular}{|l|} 
Protexia; former \\
PEGylated \\
butyrylcholinesterase \\
(recombinant \\
human, nerve agent \\
exposure)
\end{tabular} & $\begin{array}{l}\text { Alzheimers disease; } \\
\text { Toxicity }\end{array}$ & $\begin{array}{l}\text { Cholinesterase } \\
\text { stimulator }\end{array}$ & $\begin{array}{l}\text { Neuroprotectant; } \\
\text { Antidote }\end{array}$ \\
\hline 833. & Discovery & $\begin{array}{l}\text { Upsher-Smith } \\
\text { Laboratories Inc }\end{array}$ & PRX-1 & Parkinsons disease & $\begin{array}{l}\text { Dopamine receptor } \\
\text { agonist }\end{array}$ & Antiparkinsonian \\
\hline 835. & $\begin{array}{l}{ }^{*} \text { No } \\
\text { development } \\
\text { reported } \\
\text { (Discovery) } \\
\end{array}$ & Proximagen Group plc & $\begin{array}{l}\text { PRX-5 program } \\
\text { (cognitive decline/ } \\
\text { parkinsons disease) }\end{array}$ & $\begin{array}{l}\text { Cognitive disorder; } \\
\text { Parkinsons disease }\end{array}$ & $\begin{array}{l}\text { Dopamine D1 receptor } \\
\text { agonist }\end{array}$ & $\begin{array}{l}\text { Nootropic agent; } \\
\text { Antiparkinsonian }\end{array}$ \\
\hline 836. & ${ }^{* *}$ Discovery & Proximagen Group plc & $\begin{array}{l}\text { PRX-6 gene therapy } \\
\text { (Parkinson's disease) }\end{array}$ & Parkinsons disease & $\begin{array}{l}\text { Apoptosis inhibitor; } \\
\text { Gene therapy; } \\
\text { Unspecified drug } \\
\text { target }\end{array}$ & $\begin{array}{l}\text { Neuroprotectant; } \\
\text { Antiparkinsonian }\end{array}$ \\
\hline 837. & Discovery & $\begin{array}{l}\text { Protagenic } \\
\text { Therapeutics Inc }\end{array}$ & PT-00114 & $\begin{array}{l}\text { Anxiety disorder; } \\
\text { Neurological disease; } \\
\text { Injury; Major } \\
\text { depressive disorder } \\
\end{array}$ & Neuropeptide agonist & $\begin{array}{l}\text { Neuroprotectant; } \\
\text { Antidepressant; } \\
\text { Anxiolytic }\end{array}$ \\
\hline 840. & $\begin{array}{l}\text { *Phase } 1 \\
\text { (Discovery) }\end{array}$ & $\begin{array}{l}\text { Memorial Sloan- } \\
\text { Kettering Cancer } \\
\text { Center }\end{array}$ & $\begin{array}{l}\text { PU-H71; former } \\
\text { Hsp90 inhibitors }\end{array}$ & $\begin{array}{l}\text { Alzheimers disease; } \\
\text { Cancer; Multiple } \\
\text { sclerosis }\end{array}$ & Hsp 90 inhibitor & $\begin{array}{l}\text { Anticancer; } \\
\text { Neuroprotectant; } \\
\text { Anti- } \\
\text { inflammatory } \\
\end{array}$ \\
\hline 841. & Phase 1 & Phytopharm plc & PYM-50018 & $\begin{array}{l}\text { Motor neurone disease; } \\
\text { Neuromuscular } \\
\text { disease; Glaucoma }\end{array}$ & Adrenergic modulator & $\begin{array}{l}\text { Neuroprotectant; } \\
\text { Cardioprotectant }\end{array}$ \\
\hline 842. & Phase 2 & Phytopharm plc & PYM-50028 & $\begin{array}{l}\text { Alzheimers disease; } \\
\text { Parkinsons disease; } \\
\text { Motor neurone disease; } \\
\text { Glaucoma }\end{array}$ & $\begin{array}{l}\text { Dopamine modulator; } \\
\text { Neuronal growth } \\
\text { factor receptor agonist; } \\
\text { Muscarinic M1 } \\
\text { receptor modulator; } \\
\text { Glial cell neurotrophic } \\
\text { factor ligand } \\
\text { modulator; Brain } \\
\text { derived neurotrophic } \\
\text { factor ligand } \\
\text { modulator }\end{array}$ & $\begin{array}{l}\text { Neuroprotectant; } \\
\text { Nootropic agent; } \\
\text { Antiparkinsonian }\end{array}$ \\
\hline 843. & Phase 2 & Quigley Pharma Inc & QR-333 & Diabetic neuropathy & $\begin{array}{l}\text { Aldose reductase } \\
\text { inhibitor }\end{array}$ & $\begin{array}{l}\text { Neuroprotectant; } \\
\text { Antioxidant agent }\end{array}$ \\
\hline
\end{tabular}




\begin{tabular}{|c|c|c|c|c|c|c|}
\hline & $\begin{array}{l}\text { Highest Dev. } \\
\text { Status }\end{array}$ & Company & Drug & Indication & Mode of Action & Drug Effect \\
\hline 844. & $\begin{array}{l}{ }^{*} \text { No } \\
\text { development } \\
\text { reported } \\
\text { (Phase 2) }\end{array}$ & $\begin{array}{l}\text { Gedeon Richter Ltd/ } \\
\text { Forest Laboratories Inc }\end{array}$ & Radiprodil & Neuropathic pain; Pain & $\begin{array}{l}\text { NMDA receptor } \\
\text { antagonist }\end{array}$ & Analgesic \\
\hline 845. & Phase 3 & $\begin{array}{l}\text { Newron } \\
\text { Pharmaceuticals SpA }\end{array}$ & Ralfinamide & $\begin{array}{l}\text { Neuropathic Pain; } \\
\text { Pain; Psychiatric } \\
\text { disorder }\end{array}$ & $\begin{array}{l}\text { Sodium channel } \\
\text { inhibitor; Calcium } \\
\text { channel inhibitor } \\
\text { N-type; NMDA } \\
\text { receptor antagonist } \\
\end{array}$ & $\begin{array}{l}\text { Analgesic; } \\
\text { Antipsychotic }\end{array}$ \\
\hline 846. & ${ }^{* *}$ Discovery & Syntaxin Ltd/Ipsen & $\begin{array}{l}\text { Recombinant } \\
\text { botulinum toxin } \\
\text { targeted secretion } \\
\text { inhibitors } \\
\text { (neurological } \\
\text { disorder) }\end{array}$ & Neurological disease & $\begin{array}{l}\text { Acetylcholine receptor } \\
\text { antagonist; } \\
\text { Neuromuscular } \\
\text { blocking agent }\end{array}$ & \\
\hline 848. & $\begin{array}{l}\text { *Phase } 1 \\
\text { (Discovery) }\end{array}$ & Reneuron Group plc & ReN-001 & Stroke & Stem cell modulator & Neuroprotectant \\
\hline 849. & Discovery & Reneuron Group plc & ReN-004 & $\begin{array}{l}\text { Alzheimers disease; } \\
\text { Parkinsons disease }\end{array}$ & Stem cell therapy & $\begin{array}{l}\text { Neuroprotectant; } \\
\text { Nootropic agent; } \\
\text { Antiparkinsonian }\end{array}$ \\
\hline 850. & Discovery & ReNeuron Group plc & ReN-005 & Huntingtons chorea & Stem cell therapy & Neuroprotectant \\
\hline 851. & ${ }^{* *}$ Discovery & Biovista Inc & $\begin{array}{l}\text { Repositioned } \\
\text { compounds } \\
\text { (neurological } \\
\text { diseases/depression) }\end{array}$ & $\begin{array}{l}\text { Neurological disease; } \\
\text { Major depressive } \\
\text { disorder }\end{array}$ & $\begin{array}{l}\text { Unspecified drug } \\
\text { target }\end{array}$ & $\begin{array}{l}\text { Nootropic agent; } \\
\text { Antidepressant; } \\
\text { Antiparkinsonian; } \\
\text { Anticonvulsant } \\
\text { agent }\end{array}$ \\
\hline 854. & $\begin{array}{l}{ }^{*} \text { Launched } \\
\text { (Phase 3) }\end{array}$ & $\begin{array}{l}\text { Valeant } \\
\text { Pharmaceuticals } \\
\text { International/ } \\
\text { GlaxoSmithKline plc }\end{array}$ & Retigabine & $\begin{array}{l}\text { Postherpetic neuralgia; } \\
\text { Epilepsy }\end{array}$ & $\begin{array}{l}\text { GABA A agonist; } \\
\text { Potassium channel } \\
\text { activator }\end{array}$ & $\begin{array}{l}\text { Anticonvulsant } \\
\text { agent; Vasodilator }\end{array}$ \\
\hline 855. & Phase 1 & $\begin{array}{l}\text { Valeant } \\
\text { Pharmaceuticals } \\
\text { International/ } \\
\text { GlaxoSmithKline plc } \\
\end{array}$ & $\begin{array}{l}\text { Retigabine (sustained } \\
\text { release) }\end{array}$ & Epilepsy & $\begin{array}{l}\text { GABA A agonist; } \\
\text { Potassium channel } \\
\text { stimulator }\end{array}$ & $\begin{array}{l}\text { Anticonvulsant } \\
\text { agent; Vasodilator }\end{array}$ \\
\hline 856. & Phase 1 & $\begin{array}{l}\text { Trigen GmbH/ } \\
\text { Corimmun GmbH }\end{array}$ & $\begin{array}{l}\text { Revacept; former } \\
\text { PR-15 }\end{array}$ & $\begin{array}{l}\text { Coronary thrombosis; } \\
\text { Atherosclerosis; } \\
\text { Stroke }\end{array}$ & $\begin{array}{l}\text { Platelet aggregation } \\
\text { inhibitor; Unspecified } \\
\text { drug target }\end{array}$ & $\begin{array}{l}\text { Coagulation } \\
\text { inhibitor }\end{array}$ \\
\hline 857. & ***Phase 2 & $\begin{array}{l}\text { Glenmark } \\
\text { Pharmaceuticals Ltd }\end{array}$ & Revamilast & $\begin{array}{l}\text { Inflammatory disease; } \\
\text { Multiple sclerosis; } \\
\text { Rheumatoid arthritis; } \\
\text { Asthma }\end{array}$ & PDE 4 inhibitor & $\begin{array}{l}\text { Anti- } \\
\text { inflammatory }\end{array}$ \\
\hline
\end{tabular}




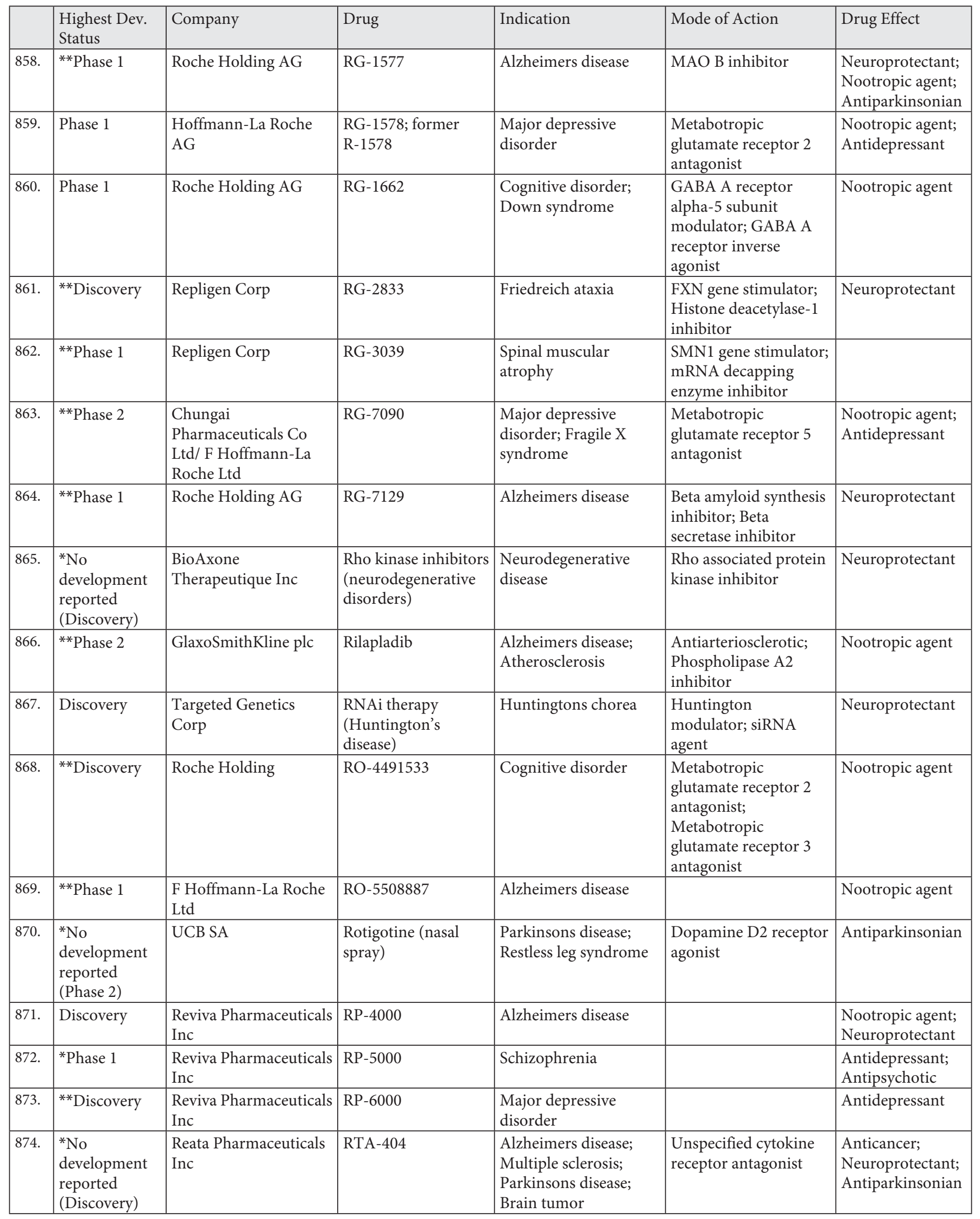




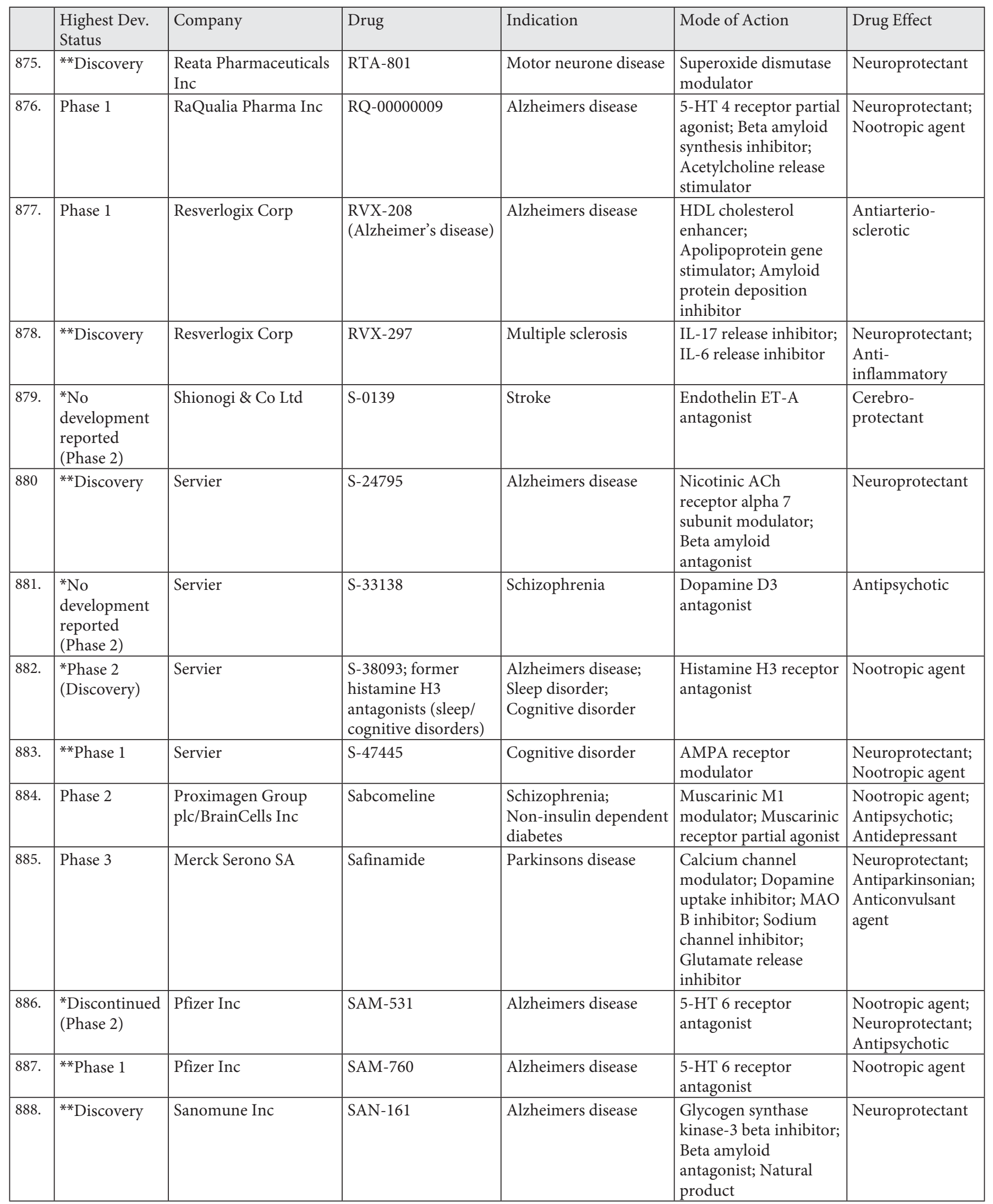




\begin{tabular}{|c|c|c|c|c|c|c|}
\hline & $\begin{array}{l}\text { Highest Dev. } \\
\text { Status }\end{array}$ & Company & Drug & Indication & Mode of Action & Drug Effect \\
\hline 889. & ${ }^{* *}$ Phase 1 & Sanofi & SAR-104772 & Stroke & $\begin{array}{l}\text { Thrombin-active } \\
\text { fibrinolysis inhibitor } \\
\text { inhibitor }\end{array}$ & $\begin{array}{l}\text { Coagulation } \\
\text { inhibitor }\end{array}$ \\
\hline 890. & $\begin{array}{l}\text { *Phase } 2 \\
\text { (Phase 1) }\end{array}$ & Sanofi & SAR-110894 & $\begin{array}{l}\text { Alzheimers disease; } \\
\text { Cognitive disorder }\end{array}$ & $\begin{array}{l}\text { Histamine } \mathrm{H} 3 \text { receptor } \\
\text { antagonist }\end{array}$ & Nootropic agent \\
\hline 891. & ${ }^{* *}$ Phase 1 & Sanofi & SAR-126119 & Stroke & $\begin{array}{l}\text { Thrombin-active } \\
\text { fibrinolysis inhibitor } \\
\text { inhibitor }\end{array}$ & $\begin{array}{l}\text { Coagulation } \\
\text { inhibitor }\end{array}$ \\
\hline 892. & ${ }^{* *}$ Phase 1 & $\begin{array}{l}\text { Glenmark } \\
\text { Pharmaceuticals Ltd/ } \\
\text { Sanofi }\end{array}$ & SAR-339658 & $\begin{array}{l}\text { Inflammatory bowel } \\
\text { disease; Multiple } \\
\text { sclerosis; Crohns } \\
\text { disease } \\
\end{array}$ & $\begin{array}{l}\text { Integrin antagonist; } \\
\text { CD49b antagonist }\end{array}$ & $\begin{array}{l}\text { Anti- } \\
\text { inflammatory }\end{array}$ \\
\hline 893. & \begin{tabular}{|l|} 
*Discontinued \\
$($ Discovery $)$
\end{tabular} & GlaxoSmithKline plc & SB-277011 & Drug dependence & \begin{tabular}{|l}
$\begin{array}{l}\text { Dopamine D3 } \\
\text { antagonist }\end{array}$ \\
\end{tabular} & Antipsychotic \\
\hline 895. & Phase 2 & GlaxoSmithKline plc & SB-742457 & Alzheimers disease & $\begin{array}{l}\text { 5-HT } 6 \text { antagonist; } \\
\text { 5-HT 2a receptor } \\
\text { antagonist }\end{array}$ & $\begin{array}{l}\text { Antipsychotic; } \\
\text { Nootropic agent }\end{array}$ \\
\hline 896. & ${ }^{* *}$ Discovery & Icogenex Corp & $\begin{array}{l}\text { SBIM therapeutics } \\
\text { (Huntington's } \\
\text { disease) }\end{array}$ & Huntingtons chorea & Huntingtin inhibitor & Neuroprotectant \\
\hline 897. & $\begin{array}{l}{ }^{*} \text { No } \\
\text { development } \\
\text { reported } \\
(\text { Phase 2) } \\
\end{array}$ & Merck \& Co Inc & SCH-900435 & $\begin{array}{l}\text { Alcoholism; Panic } \\
\text { disorder; } \\
\text { Schizophrenia }\end{array}$ & $\begin{array}{l}\text { Glycine transporter-1 } \\
\text { inhibitor }\end{array}$ & Antipsychotic \\
\hline 900. & Discovery & $\begin{array}{l}\text { Taisho Pharmaceutical } \\
\text { Co Ltd }\end{array}$ & SEA-0400 & Stroke & $\begin{array}{l}\mathrm{Na}+\mathrm{Ca} 2+\text { ion } \\
\text { exchange inhibitor }\end{array}$ & Neuroprotectant \\
\hline 901. & ${ }^{* *}$ Discovery & $\begin{array}{l}\text { Kareus Therapeutics } \\
\text { SA }\end{array}$ & \begin{tabular}{|l|} 
Second generation \\
DMAD project \\
(Alzheimer's disease) \\
\end{tabular} & Alzheimers disease & $\begin{array}{l}\text { Unspecified drug } \\
\text { target }\end{array}$ & Neuroprotectant \\
\hline 902. & Discovery & ALSP Inc & $\begin{array}{l}\text { Secretase inhibitors } \\
\text { (Alzheimers disease) }\end{array}$ & Alzheimers disease & $\begin{array}{l}\text { Cathepsin B inhibitor; } \\
\text { Secretase inhibitor }\end{array}$ & \\
\hline 903. & **Phase 3 & Novartis AG & Secukinumab & $\begin{array}{l}\text { Psoriatic arthritis; } \\
\text { Multiple myeloma; } \\
\text { Multiple sclerosis; } \\
\text { Psoriasis; Polymyalgia } \\
\text { rheumatica; } \\
\text { Rheumatoid arthritis; } \\
\text { Xerophthalmia; } \\
\text { Uveitis; Ankylosing } \\
\text { spondylitis; Crohns } \\
\text { disease }\end{array}$ & IL-17 antagonist & $\begin{array}{l}\text { Systemic } \\
\text { antipsoriatic } \\
\text { product; } \\
\text { Anticancer; Anti- } \\
\text { inflammatory }\end{array}$ \\
\hline 904. & **Discovery & \begin{tabular}{|l|} 
Selvita Life Sciences \\
Solutions/Orion Corp
\end{tabular} & SEL-103 & Alzheimers disease & $\begin{array}{l}\begin{array}{l}\text { Unspecified drug } \\
\text { target }\end{array} \\
\end{array}$ & Nootropic agent \\
\hline
\end{tabular}




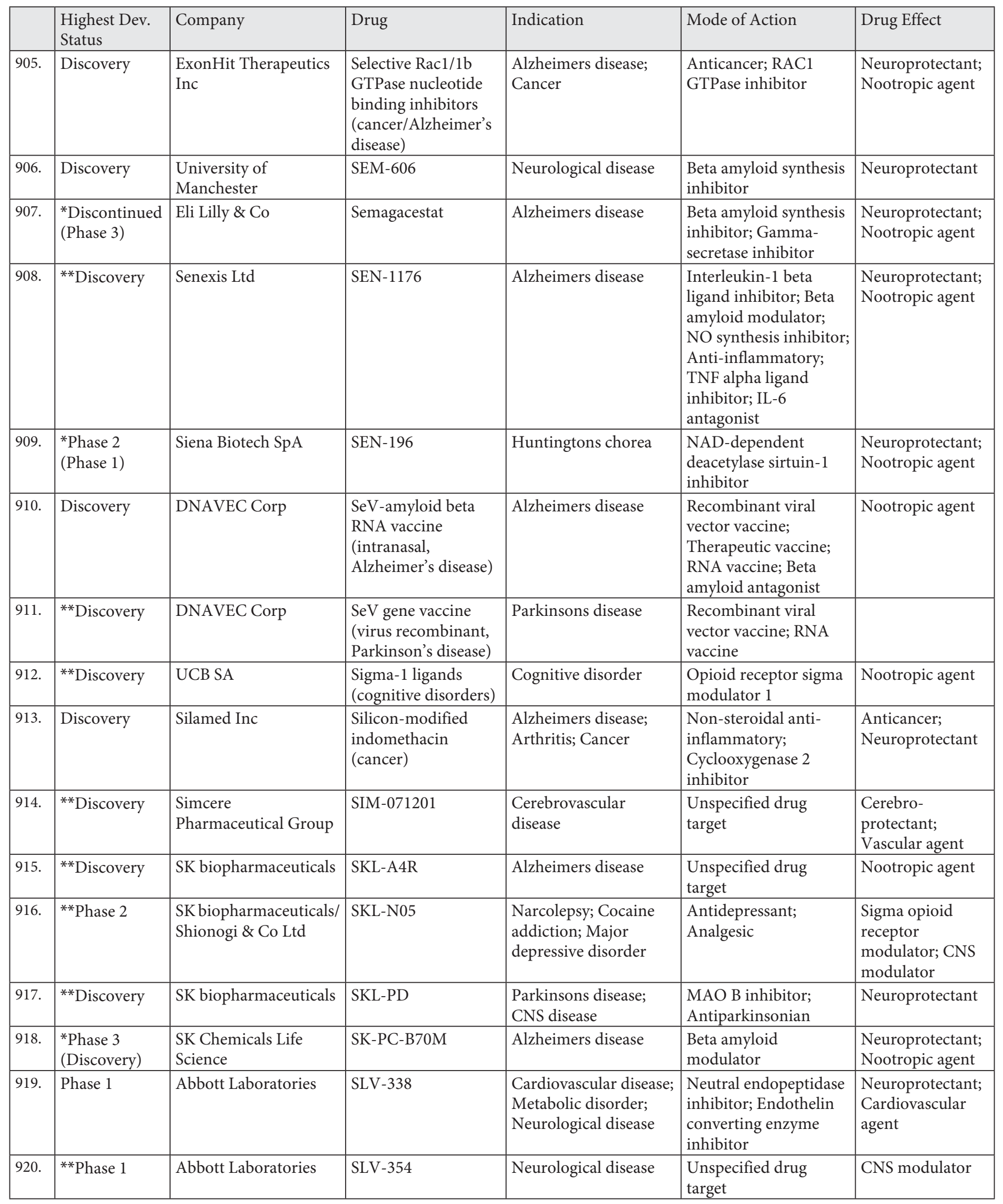




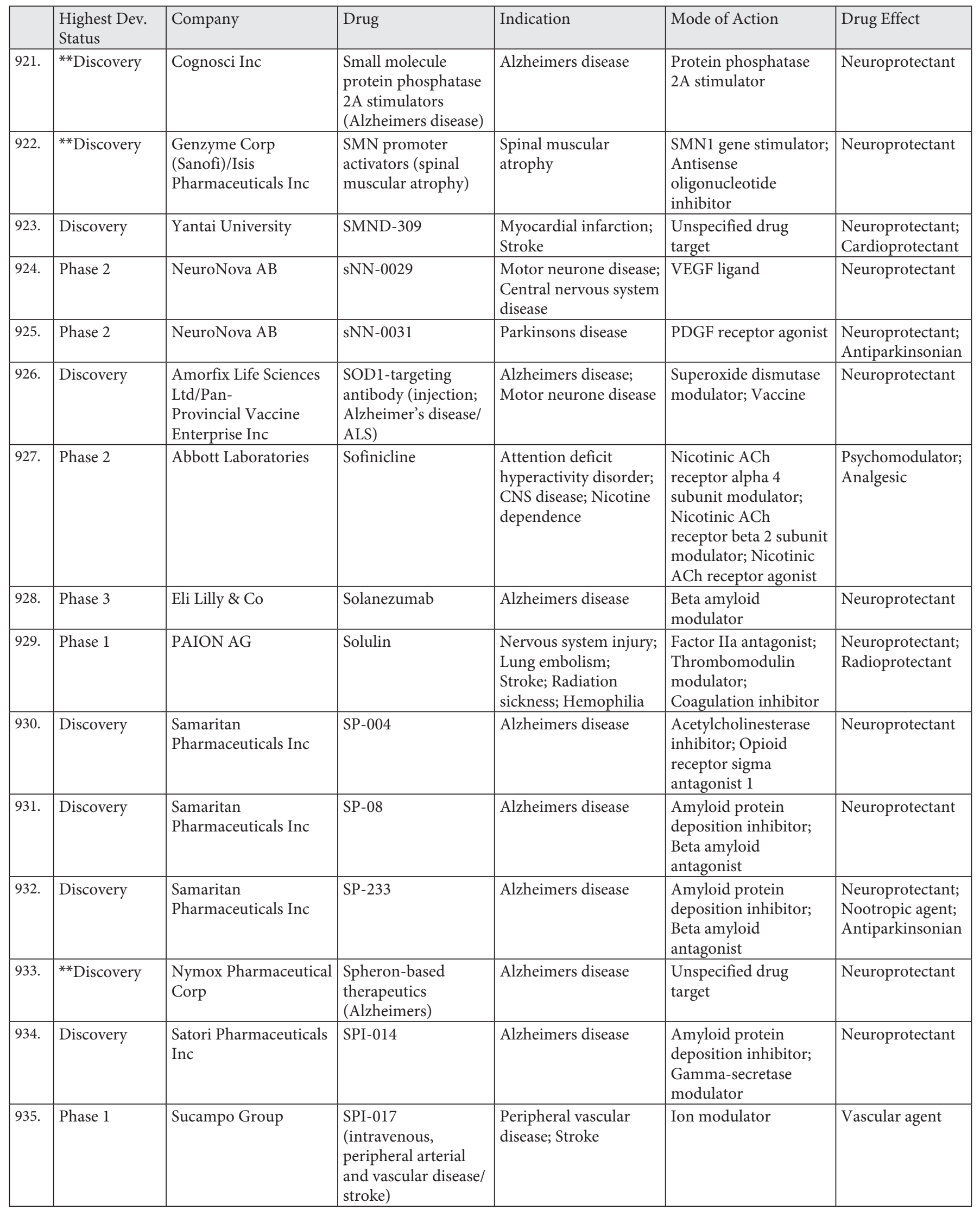




\begin{tabular}{|c|c|c|c|c|c|c|}
\hline & $\begin{array}{l}\text { Highest Dev. } \\
\text { Status }\end{array}$ & Company & Drug & Indication & Mode of Action & Drug Effect \\
\hline 936. & Discovery & Sucampo Group & $\begin{array}{l}\text { SPI-017 (oral, } \\
\text { Alzheimer's disease) }\end{array}$ & Alzheimers disease & Ion modulator & \\
\hline 938. & **Discovery & $\begin{array}{l}\text { Sucampo } \\
\text { Pharmaceuticals Inc } \\
\text { (Sucampo Group) }\end{array}$ & SPI-3608 & Spinal stenosis & $\begin{array}{l}\text { Unspecified ion } \\
\text { channel modulator }\end{array}$ & \\
\hline 939. & Discovery & AstraZeneca plc & $\begin{array}{l}\text { Spirofuropyridine } \\
\text { alpha-7 neuronal } \\
\text { nicotinic receptor } \\
\text { agonists (cognitive } \\
\text { disorder) } \\
\end{array}$ & Cognitive disorder & $\begin{array}{l}\text { Nicotinic Ach receptor } \\
\text { alpha } 7 \text { subunit } \\
\text { modulator }\end{array}$ & Nootropic agent \\
\hline 941. & Phase 2 & $\begin{array}{l}\text { Sonexa Therapeutics/ } \\
\text { Zenyaku Kogyo Co Ltd }\end{array}$ & $\begin{array}{l}\text { ST-101; former } \\
\text { ZSET-1446 }\end{array}$ & $\begin{array}{l}\text { Cognitive disorder; } \\
\text { Major depressive } \\
\text { disorder; Alzheimers } \\
\text { disease; Tremor }\end{array}$ & $\begin{array}{l}\text { Acetylcholine release } \\
\text { stimulator; CAM } \\
\text { kinase kinase beta } \\
\text { stimulator }\end{array}$ & $\begin{array}{l}\text { Neuroprotectant; } \\
\text { Nootropic agent; } \\
\text { Antidepressant }\end{array}$ \\
\hline 942. & **Discovery & $\begin{array}{l}\text { University of } \\
\text { California San Diego } \\
\text { (University of } \\
\text { California)/Life } \\
\text { Technologies Corp/ } \\
\text { The Salk Institute for } \\
\text { Biological Studies }\end{array}$ & $\begin{array}{l}\text { Stem cell-derived } \\
\text { astrocytes (ALS) }\end{array}$ & Motor neurone disease & Astrocyte modulator & Neuroprotectant \\
\hline 944. & ${ }^{* *}$ Discovery & $\begin{array}{l}\text { Medipost Co Ltd/ } \\
\text { Genexine Co Ltd }\end{array}$ & $\begin{array}{l}\text { Stem cell therapy } \\
\text { (spinal cord injury) }\end{array}$ & Spinal cord injury & BDNF gene stimulator & $\begin{array}{l}\text { Gene therapy; } \\
\text { Stem cell } \\
\text { stimulator }\end{array}$ \\
\hline 945. & ${ }^{* *}$ Clinical & $\begin{array}{l}\text { Stemedica Cell } \\
\text { Technologies Inc }\end{array}$ & $\begin{array}{l}\text { Stem cell therapy } \\
\text { (vascular dementia/ } \\
\text { Alzheimer's disease) }\end{array}$ & $\begin{array}{l}\text { Alzheimers disease; } \\
\text { Vascular dementia }\end{array}$ & & Nootropic agent \\
\hline 946. & $\begin{array}{l}{ }^{*} \mathrm{No} \\
\text { development } \\
\text { reported } \\
\text { (Discovery) } \\
\end{array}$ & University of Miami & Stilbazulenyl nitrone & $\begin{array}{l}\text { Stroke; Brain injury; } \\
\text { Ischemic heart disease }\end{array}$ & $\begin{array}{l}\text { Azulenyl nitrone-based } \\
\text { antioxidant }\end{array}$ & $\begin{array}{l}\text { Neuroprotectant; } \\
\text { Antioxidant } \\
\text { agent; } \\
\text { Cardioprotectant }\end{array}$ \\
\hline 947. & Discovery & \begin{tabular}{|l} 
Dong Wha \\
Pharmaceutical \\
Industry Co Ltd \\
\end{tabular} & Stroke program & Stroke & $\begin{array}{l}\text { Unspecified drug } \\
\text { target }\end{array}$ & Neuroprotectant \\
\hline 948. & ** Discovery & NuvOx Pharma LLC & Stroke program & Stroke & & $\begin{array}{l}\text { Cerebro- } \\
\text { protectant }\end{array}$ \\
\hline 949. & Phase 1 & $\begin{array}{l}\text { Seaside Therapeutics } \\
\text { LLC }\end{array}$ & STX-107 & $\begin{array}{l}\text { Fragile X syndrome; } \\
\text { Autism }\end{array}$ & $\begin{array}{l}\text { Metabotropic } \\
\text { glutamate receptor } 5 \\
\text { antagonist }\end{array}$ & $\begin{array}{l}\text { Nootropic agent; } \\
\text { Antipsychotic }\end{array}$ \\
\hline
\end{tabular}




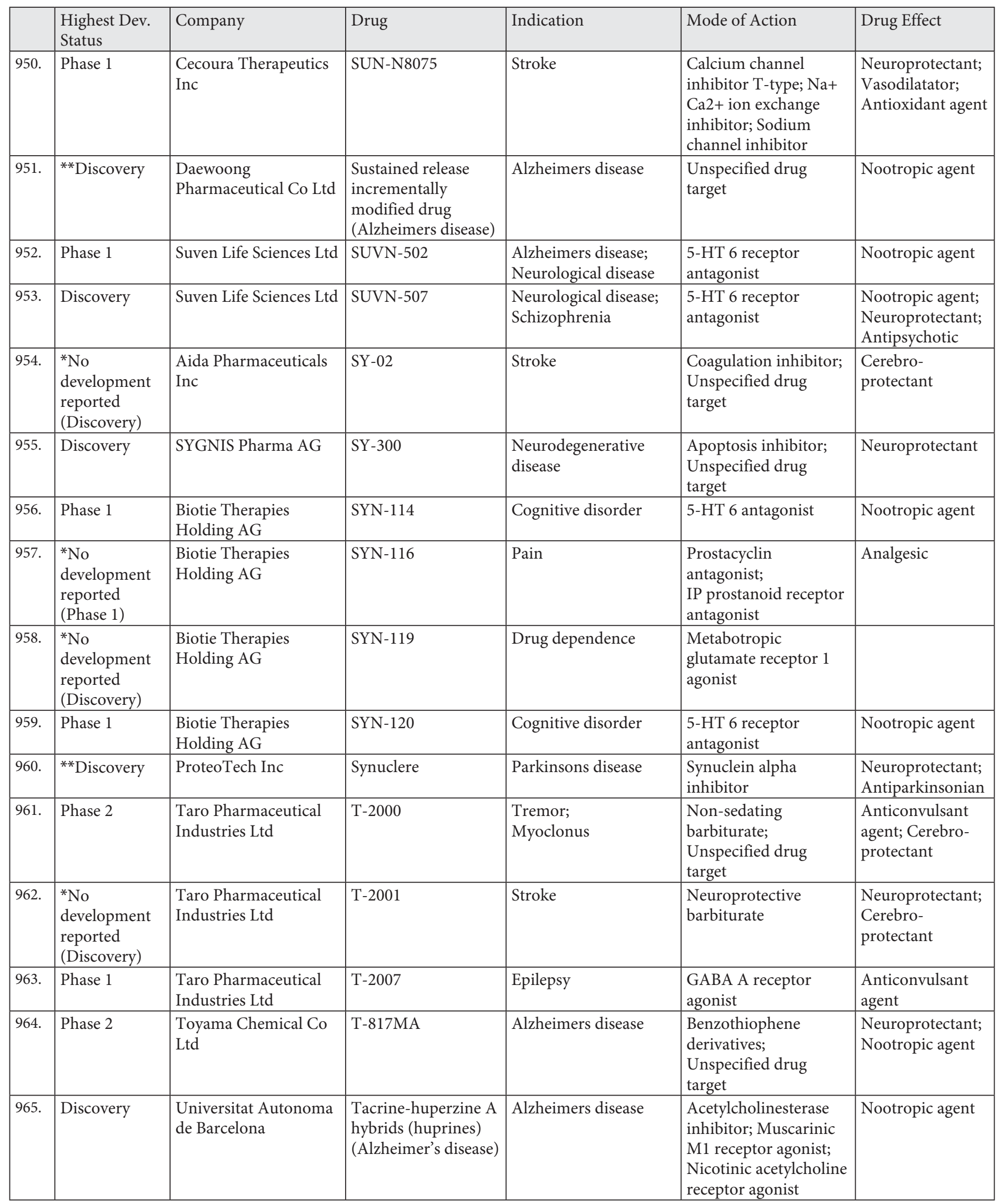




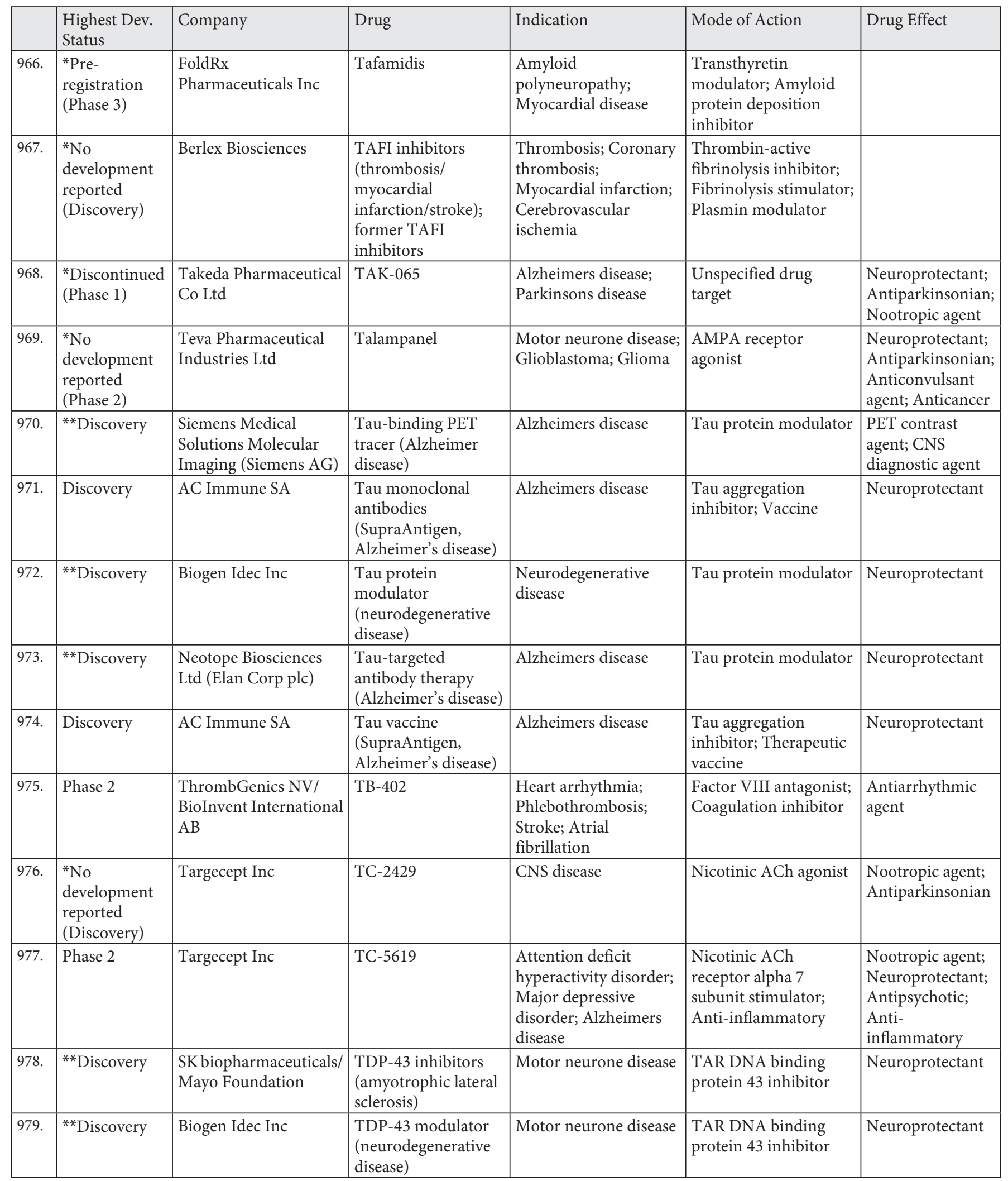




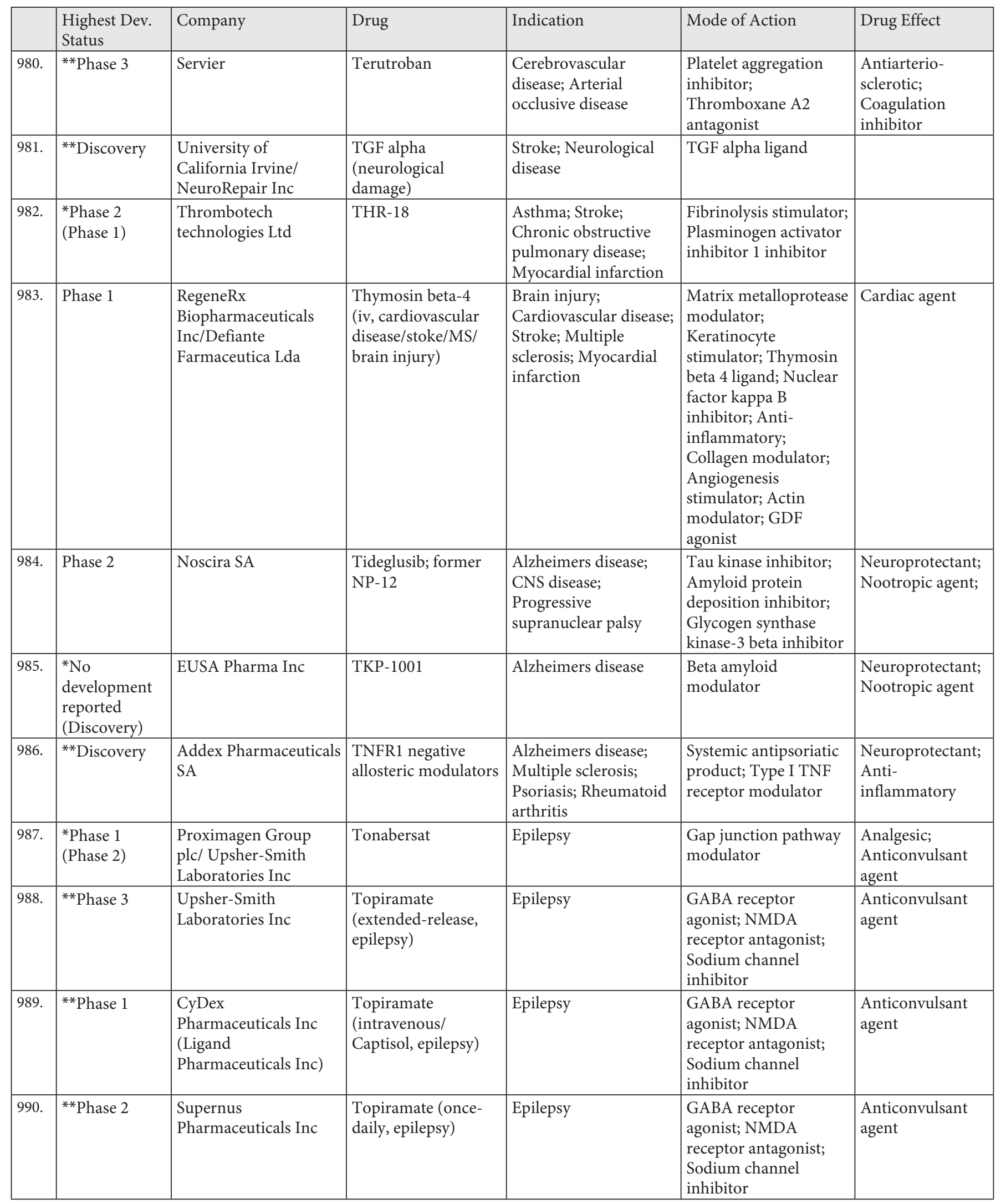




\begin{tabular}{|c|c|c|c|c|c|c|}
\hline & $\begin{array}{l}\text { Highest Dev. } \\
\text { Status }\end{array}$ & Company & Drug & Indication & Mode of Action & Drug Effect \\
\hline 991. & Phase 2 & $\begin{array}{l}\text { Biotie Therapies } \\
\text { Holding AG }\end{array}$ & $\begin{array}{l}\text { Tozadenant; former } \\
\text { SYN-115 }\end{array}$ & Parkinsons disease & $\begin{array}{l}\text { Adenosine A2a } \\
\text { receptor antagonist }\end{array}$ & $\begin{array}{l}\text { Antiparkinsonian; } \\
\text { Anxiolytic; } \\
\text { Nootropic agent }\end{array}$ \\
\hline 992. & ${ }^{* *}$ Discovery & $\begin{array}{l}\text { CHDI Foundation Inc } \\
\text { (CHDI Inc)/Evotec AG }\end{array}$ & $\begin{array}{l}\text { Transglutaminase } 2 \\
\text { inhibitors } \\
\text { (Huntington's } \\
\text { disease) } \\
\end{array}$ & Huntingtons chorea & $\begin{array}{l}\text { Tissue } \\
\text { transglutaminase } \\
\text { inhibitor }\end{array}$ & Nootropic agent \\
\hline 993. & **Discovery & $\begin{array}{l}\text { Digna Biotech SL/ } \\
\text { Flamel Technologies } \\
\text { SA }\end{array}$ & \begin{tabular}{|l} 
Transmethylator \\
inhibitor (oral \\
controlled release/ \\
Micropump, \\
multiple sclerosis)
\end{tabular} & Multiple sclerosis & $\begin{array}{l}\text { Methyltransferase } \\
\text { inhibitor }\end{array}$ & $\begin{array}{l}\text { Anti- } \\
\text { inflammatory }\end{array}$ \\
\hline 994. & **Discovery & Digna Biotech SL & $\begin{array}{l}\text { Transmethylator } \\
\text { inhibitor (oral, MS/ } \\
\text { transplant rejection) }\end{array}$ & $\begin{array}{l}\text { Multiple sclerosis; } \\
\text { Transplant rejection }\end{array}$ & $\begin{array}{l}\text { Methyltransferase } \\
\text { inhibitor }\end{array}$ & $\begin{array}{l}\text { Anti- } \\
\text { inflammatory }\end{array}$ \\
\hline 996. & ${ }^{* *}$ Discovery & $\begin{array}{l}\text { Bristol-Myers Squibb } \\
\text { Co/Albany Molecular } \\
\text { Research Inc }\end{array}$ & $\begin{array}{l}\text { Triple reuptake } \\
\text { inhibitors } \\
\text { (depression/CNS } \\
\text { disease) }\end{array}$ & CNS disease & $\begin{array}{l}\text { Dopamine uptake } \\
\text { inhibitor; Monoamine } \\
\text { uptake inhibitor; } \\
\text { Norepinephrine uptake } \\
\text { inhibitor; 5-HT uptake } \\
\text { inhibitor } \\
\end{array}$ & Antidepressant \\
\hline 997. & **Discovery & $\begin{array}{l}\text { Addex Pharmaceuticals } \\
\text { SA }\end{array}$ & \begin{tabular}{|l|} 
TrkB negative \\
allosteric modulators \\
(neurodegenerative \\
diseases) \\
\end{tabular} & $\begin{array}{l}\text { Neurodegenerative } \\
\text { disease }\end{array}$ & $\begin{array}{l}\text { TrkB receptor } \\
\text { modulator }\end{array}$ & Neuroprotectant \\
\hline 1001. & Phase 1 & $\begin{array}{l}\text { Taisho Pharmaceutical } \\
\text { Co Ltd }\end{array}$ & TS-011 & Cerebral infarction & $\begin{array}{l}\text { Arachidonic acid } \\
\text { metabolism inhibitor }\end{array}$ & $\begin{array}{l}\text { Cerebro- } \\
\text { protectant; Anti- } \\
\text { inflammatory }\end{array}$ \\
\hline 1002. & $\begin{array}{l}\text { *Phase } 1 \\
\text { (Discovery) }\end{array}$ & $\begin{array}{l}\text { Transition } \\
\text { Therapeutics Inc }\end{array}$ & $\begin{array}{l}\text { TT-301; former anti- } \\
\text { neuroinflammatories } \\
\text { (Alzheimer's disease) }\end{array}$ & CNS disease; Arthritis & $\begin{array}{l}\text { Interleukin-1 beta } \\
\text { ligand inhibitor; } \\
\text { Monocyte chemotactic } \\
\text { protein } 1 \text { ligand } \\
\text { inhibitor; TNF alpha } \\
\text { synthesis inhibitor; } \\
\text { IL-6 antagonist; } \\
\text { RANTES ligand } \\
\text { inhibitor; Cytokine } \\
\text { synthesis inhibitor } \\
\end{array}$ & $\begin{array}{l}\text { Neuroprotectant; } \\
\text { Anti- } \\
\text { inflammatory; } \\
\text { CNS modulator }\end{array}$ \\
\hline 1003. & Discovery & $\begin{array}{l}\text { Transition } \\
\text { Therapeutics Inc }\end{array}$ & $\begin{array}{l}\text { TT-302; former } \\
\text { MW01-5-188WH }\end{array}$ & CNS disease; Arthritis & $\begin{array}{l}\text { Monocyte chemotactic } \\
\text { protein } 1 \text { ligand } \\
\text { inhibitor; TNF alpha } \\
\text { ligand inhibitor; IL-6 } \\
\text { antagonist; RANTES } \\
\text { ligand inhibitor; } \\
\text { Cytokine synthesis } \\
\text { inhibitor }\end{array}$ & $\begin{array}{l}\text { Neuroprotectant; } \\
\text { CNS modulator; } \\
\text { Anti- } \\
\text { inflammatory }\end{array}$ \\
\hline
\end{tabular}




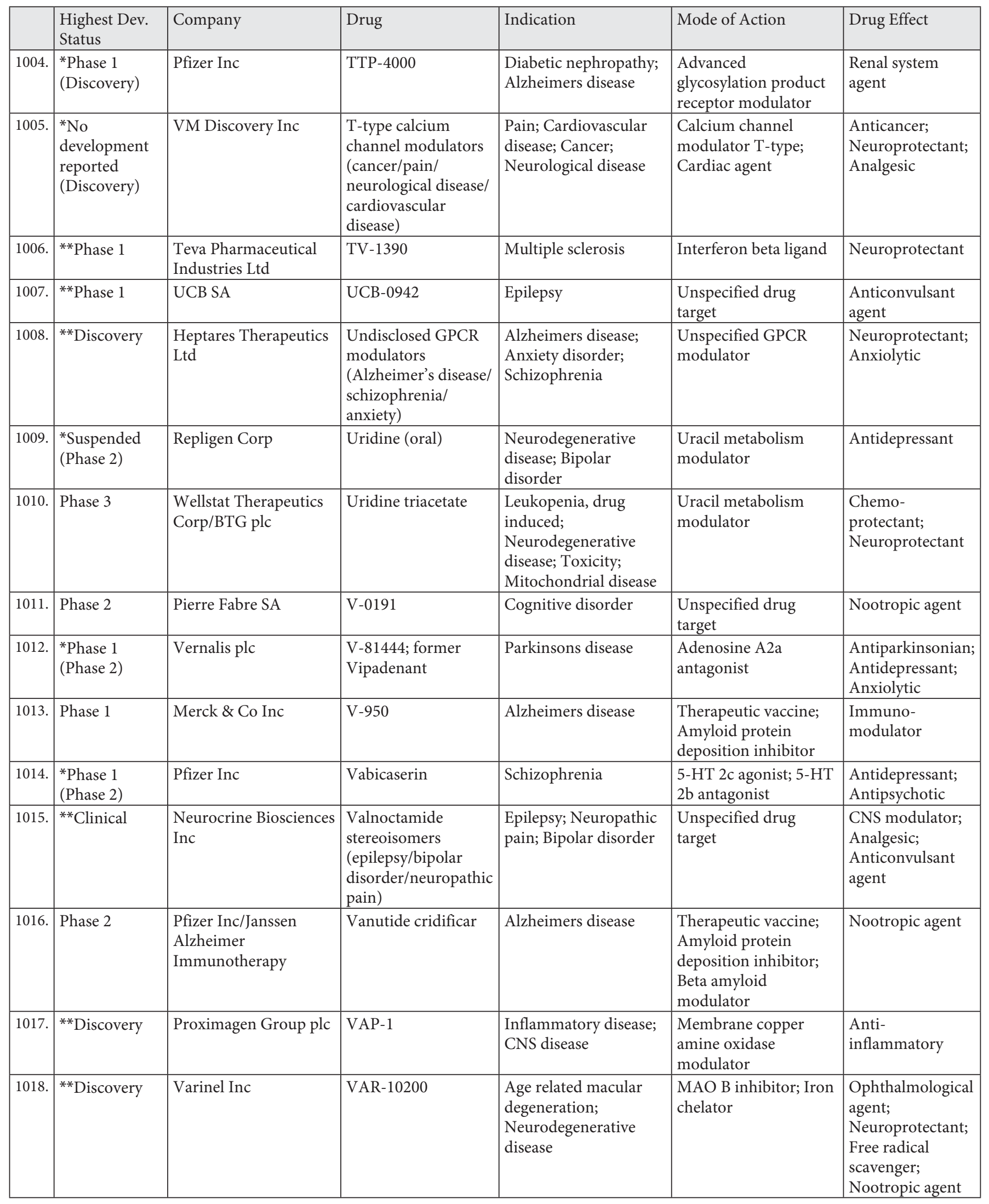




\begin{tabular}{|c|c|c|c|c|c|c|}
\hline & $\begin{array}{l}\text { Highest Dev. } \\
\text { Status }\end{array}$ & Company & Drug & Indication & Mode of Action & Drug Effect \\
\hline 1019. & Discovery & $\begin{array}{l}\text { Technion Research \& } \\
\text { Development } \\
\text { Foundation Ltd/ } \\
\text { Weizmann Institute of } \\
\text { Science/Varinel Inc }\end{array}$ & VAR-10300 & $\begin{array}{l}\text { Neurodegenerative } \\
\text { disease }\end{array}$ & $\begin{array}{l}\text { Iron chelator; MAO } \\
\text { inhibitor; Apoptosis } \\
\text { inhibitor }\end{array}$ & $\begin{array}{l}\text { Nootropic agent; } \\
\text { Antiparkinsonian; } \\
\text { Antioxidant agent }\end{array}$ \\
\hline 1020. & **Discovery & $\begin{array}{l}\text { Critical Outcome } \\
\text { Technologies Inc }\end{array}$ & $\begin{array}{l}\text { VEGFR/PDGFR } \\
\text { kinase inhibitors } \\
\text { (multiple sclerosis) }\end{array}$ & Multiple sclerosis & $\begin{array}{l}\text { VEGF receptor } \\
\text { antagonist; PDGF } \\
\text { receptor antagonist }\end{array}$ & \\
\hline 1021. & Discovery & Oxford BioMedica plc & $\begin{array}{l}\text { VEGF-targeting gene } \\
\text { therapy (ALS, } \\
\text { LentiVector) }\end{array}$ & Motor neuron disease & $\begin{array}{l}\text { VEGF receptor } \\
\text { agonist; Retrovirus } \\
\text { based gene therapy }\end{array}$ & Neuroprotectant \\
\hline 1022. & Phase 2 & Theravance Inc & Velusetrag & $\begin{array}{l}\text { Alzheimers disease; } \\
\text { Functional bowel } \\
\text { disorder }\end{array}$ & $\begin{array}{l}\text { 5-HT } 4 \text { receptor } \\
\text { agonist }\end{array}$ & $\begin{array}{l}\text { Neuroprotectant; } \\
\text { Laxative; } \\
\text { Nootropic agent }\end{array}$ \\
\hline 1024. & **Discovery & Vanderbilt University & VU-0364770 & Parkinsons disease & $\begin{array}{l}\text { Metabotropic } \\
\text { glutamate receptor } 4 \\
\text { modulator }\end{array}$ & Antiparkinsonian \\
\hline 1025. & Phase 2 & $\begin{array}{l}\text { Vertex Pharmaceuticals } \\
\text { Inc }\end{array}$ & VX-765 & Epilepsy & $\begin{array}{l}\text { Systemic antipsoriatic } \\
\text { product; Anti- } \\
\text { inflammatory; } \\
\text { Anticonvulsant agent; } \\
\text { Interleukin-1 } \\
\text { converting enzyme } \\
\text { inhibitor }\end{array}$ & $\begin{array}{l}\text { Neuroprotectant; } \\
\text { Cardioprotectant }\end{array}$ \\
\hline 1028. & Phase 2 & $\begin{array}{l}\text { Auris Medical AG/ } \\
\text { Xigen SA }\end{array}$ & XG-102 & $\begin{array}{l}\text { Inner ear disease; } \\
\text { Alzheimers disease; } \\
\text { Myocardial infarction; } \\
\text { Stroke; Hearing } \\
\text { disorder; Inflammatory } \\
\text { disease }\end{array}$ & $\begin{array}{l}\text { Apoptosis inhibitor; } \\
\text { Beta amyloid synthesis } \\
\text { inhibitor; Jun N } \\
\text { terminal kinase } \\
\text { inhibitor }\end{array}$ & $\begin{array}{l}\text { Neuroprotectant; } \\
\text { Cardioprotectant; } \\
\text { Anti- } \\
\text { inflammatory }\end{array}$ \\
\hline 1029. & ${ }^{* *}$ Discovery & Neurologix Inc & $\begin{array}{l}\text { XIAP gene therapy } \\
\text { (AAV vector, } \\
\text { Huntington's } \\
\text { disease) }\end{array}$ & Huntingtons chorea & $\begin{array}{l}\text { X-linked inhibitor of } \\
\text { apoptosis protein } \\
\text { stimulator; Apoptosis } \\
\text { inhibitor; Adeno- } \\
\text { associated virus based } \\
\text { gene therapy } \\
\end{array}$ & Neuroprotectant \\
\hline 1030. & ***Phase 2 & XenoPort Inc & XP-21279 & Parkinsons disease & $\begin{array}{l}\text { Dopamine receptor } \\
\text { agonist }\end{array}$ & Antiparkinsonian \\
\hline 1031. & ${ }^{* *}$ Discovery & XenoPort Inc & XP-23829 & Multiple sclerosis & Anti-inflammatory & Neuroprotectant \\
\hline
\end{tabular}




\begin{tabular}{|c|c|c|c|c|c|c|}
\hline & $\begin{array}{l}\text { Highest Dev. } \\
\text { Status }\end{array}$ & Company & Drug & Indication & Mode of Action & Drug Effect \\
\hline 1032. & ${ }^{* *}$ Discovery & \begin{tabular}{|l|} 
Korea Research \\
Institute of Chemical \\
Technology/Yungjin \\
Pharmaceutical Co Ltd \\
\end{tabular} & YJP-60107 & $\begin{array}{l}\text { Neurodegenerative } \\
\text { disease }\end{array}$ & Caspase inhibitor & Neuroprotectant \\
\hline 1033. & ${ }^{* *}$ Phase 1 & SK biopharmaceuticals & YKP-10461 & CNS disease & & Neuroprotectant \\
\hline 1034. & ***Phase 2 & SK biopharmaceuticals & YKP-3089 & $\begin{array}{l}\text { Epilepsy; Neuropathic } \\
\text { pain; Anxiety disorder }\end{array}$ & $\begin{array}{l}\text { Unspecified drug } \\
\text { target }\end{array}$ & $\begin{array}{l}\text { Anxiolytic; } \\
\text { Analgesic; } \\
\text { Anticonvulsant } \\
\text { agent }\end{array}$ \\
\hline 1035. & Discovery & Zalicus Inc & $\begin{array}{l}\text { Z-944; former T-type } \\
\text { calcium channel } \\
\text { blockers (pain/ } \\
\text { hypertension/ } \\
\text { epilepsy) }\end{array}$ & $\begin{array}{l}\text { Pain; Hypertension; } \\
\text { Epilepsy }\end{array}$ & $\begin{array}{l}\text { Calcium channel } \\
\text { inhibitor T-type; Class } \\
\text { IV antiarrhythmic } \\
\text { agent }\end{array}$ & $\begin{array}{l}\text { Antihypertensive; } \\
\text { Analgesic; } \\
\text { Hypoglycemic } \\
\text { agent; } \\
\text { Anticonvulsant } \\
\text { agent }\end{array}$ \\
\hline 1037. & **Discovery & $\begin{array}{l}\text { Sangamo BioSciences } \\
\text { Inc/CHDI Foundation } \\
\text { Inc }\end{array}$ & $\begin{array}{l}\text { ZFP TFs } \\
\text { (Huntington's } \\
\text { disease) }\end{array}$ & Huntingtons chorea & $\begin{array}{l}\text { Huntingtin inhibitor; } \\
\text { Gene therapy; Zinc } \\
\text { finger protein } \\
\text { transcription factor } \\
\text { agonist }\end{array}$ & Neuroprotectant \\
\hline
\end{tabular}


No Development Reported: No evidence of continuing development has been reported for the past 18 months.

Discontinued: Confirmation from the company source that in-house development has been terminated.

Discovery: Late research stage, preparation for human testing: adaptation of research chemical synthesis (mg) to larger scale $(\mathrm{kg})$, selection of salt form, selection of galenical form, design of clinical proof of concept studies, definition of endpoints, selection of biomarkers for clinical testing, additional safety testing, IND (investigational new drug) filing, clinical ethical review boards.

Phase 1: Clinical testing: tolerance in humans, repeated dosing, some escalation; proof of therapeutic concept or mechanism using scientific evaluation methods in a limited number of volunteers or patients.

Phase 2: Dose-finding studies, statistics, double blind studies.

Phase 3: Proof of efficacy, comparison to standard therapy, statistics, double blind studies with up to thousands of patients; final phase of testing before registration and license to market.
'Investigational Drugs database, Copyright 2011 Thomson Reuters, http://partnering.thomson-pharma.com/.'

This source was amended whenever the author found more accurate information on the websites of the companies.

\section{Disclaimer}

The author does not warrant or assume any legal liability or responsibility for the accuracy, completeness, or usefulness of the information in the article. It is not the intention of the author to provide medical advice or to promote or endorse any medical practice, test or program, but rather to provide readers with information to better understand neurodegenerative diseases. The author is not responsible for errors in or omissions of information contained in the article or any actions resulting from the use of such information. Readers are encouraged to confirm the information in the article with other reliable sources. 